UNIVERSIDADE DE SÃO PAULO

FFCLRP - DEPARTAMENTO DE PSICOLOGIA

PROGRAMA DE PÓS-GRADUAÇÃO EM PSICOLOGIA

\title{
Depressão materna, recursos, adversidades do ambiente familiar e o comportamento de escolares, avaliado por mães e professoras
}

Ana Karina Braguim Martineli

Dissertação apresentada à Faculdade de Filosofia, Ciências e Letras de Ribeirão Preto da USP, como parte das exigências para a obtenção do título de Mestre em Ciências, Área: Psicologia em Saúde e Desenvolvimento.

RIBEIRÃO PRETO - SP 

Depressão materna, recursos, adversidades do ambiente familiar e o comportamento de escolares, avaliado por mães e professoras

Dissertação apresentada à Faculdade de Filosofia, Ciências e Letras de Ribeirão Preto da USP, como parte das exigências para a obtenção do título de Mestre em Ciências.

Área de Concentração: Psicologia em Saúde e Desenvolvimento.

Orientadora: Prof. ${ }^{\text {a }}$ Dr. ${ }^{\text {a }}$ Sonia Regina Loureiro 
Autorizo a reprodução e divulgação total ou parcial deste trabalho, por qualquer meio convencional ou eletrônico, para fins de estudo e pesquisa, desde que citada a fonte.

Catalogação na publicação

Serviço de Biblioteca e Documentação

Instituto de Psicologia da Universidade de São Paulo

Martineli, Ana Karina Braguim.

Depressão materna, recursos, adversidades do ambiente familiar e o comportamento de escolares, avaliado por mães e professoras / Ana Karina Braguim Martineli; orientadora Sônia Regina Loureiro. -- Ribeirão Preto, 2017.

$168 \mathrm{f}$.

Dissertação (Mestrado) - Faculdade de Filosofia Ciências e Letras de Ribeirão Preto da Universidade de São Paulo. Programa de Pós-Graduação em Psicologia. Área de Concentração: Psicologia em Saúde e Desenvolvimento.

1. Comportamento infantil. 2. Depressão materna.

3. Vulnerabilidade social. 4. Escolares. 5. Professores. 
Nome: Ana Karina Braguim Martineli

Título: Depressão materna, recursos, adversidades do ambiente familiar e o comportamento de escolares, avaliado por mães e professoras.

Dissertação apresentada ao Programa de PósGraduação em Psicologia da Faculdade de Filosofia, Ciências e Letras de Ribeirão Preto da Universidade de São Paulo, para a obtenção do título de Mestre em Ciências.

Aprovado em:

Banca Examinadora

Prof. Dr. :

Instituição: Assinatura:

Julgamento:

Prof. Dr. :

Instituição: Assinatura:

Julgamento:

Prof. Dr. :

Instituição: Assinatura:

Julgamento: 

Dedico este trabalho à minha tia, Mariângela Braguim Antônio, psicóloga, por sempre me incentivar a trilhar o caminho da área acadêmica, sobretudo, a atividade científica. 



\section{AGRADECIMENTOS}

À minha orientadora Prof. ${ }^{a}$ Dr. ${ }^{a}$ Sonia Regina Loureiro, pela oportunidade do trabalho, pela paciência e riqueza nos ensinamentos, e especialmente, pela impecável condução deste estudo, oferecendo-me novas oportunidades de conhecimento e crescimento.

À psicóloga Dr. a Fernanda Aguiar Pizeta, colaboradora desta pesquisa, por ter compartilhado suas experiências com total dedicação e carinho, facilitando o meu caminhar durante essa jornada.

À professora Dr. ${ }^{a}$ Sonia Regina Pasian, que me apresentou à Prof. ${ }^{a}$ Dr. ${ }^{a}$ Sonia Regina Loureiro, proporcionando o início dessa jornada.

Aos funcionários da Escola Estadual Adolfo Alfeu Ferrero, pela disponibilidade e suporte, essenciais para a realização deste trabalho.

Às mães e crianças que participaram deste estudo, por disponibilizarem seu tempo e contribuírem com suas histórias, favorecendo o aprendizado acadêmico e pessoal.

Às colegas do grupo de pesquisa, psicólogas Paola Passareli Carrazzoni, Thaysa Brinck Silva, Karina Pereira Lima, Ana Paula Casagrande Silva, Flávia Farnochi Marucci e Marina Delduca Cilino, por compartilharem seus conhecimentos, contribuindo para o meu crescimento profissional.

À minha amiga, psicóloga, Aline Politi, pelo caminhar conjunto durante a pósgraduação, especialmente nos momentos de desânimo e conquistas mútuas.

Aos familiares e amigos, que direta ou indiretamente, me incentivaram e torceram para a realização e conclusão deste trabalho.

Ao meu querido esposo Matheus, pelo apoio a todos os meus sonhos, pelo carinho e acolhimento nos momentos de dificuldades e pela paciência com os distanciamentos necessários para a elaboração deste trabalho.

Ao meu amado filho Lucas, pela oportunidade que me deu em exercer o papel da maternidade, contribuindo para o meu crescimento pessoal e para uma melhor compreensão da complexidade da relação mãe-filho.

E aos meus amados pais, Vanda e Toninho, pelo amor, carinho, dedicação, educação, acolhimento e confiança, disponibilizados em todas as etapas do meu desenvolvimento, base para o meu amadurecimento emocional. 



\section{RESUMO}

Martineli, A. K. B. (2017). Depressão materna, recursos, adversidades do ambiente familiar $e$ o comportamento de escolares, avaliado por mães e professoras. (Dissertação de Mestrado). Programa de Pós-Graduação em Psicologia, Faculdade de Filosofia, Ciências e Letras de Ribeirão Preto, Universidade de São Paulo, Ribeirão Preto.

A depressão materna é reconhecida como uma adversidade que incide sobre o ambiente familiar, mostrando-se associada a problemas comportamentais em escolares. Verifica-se a demanda por estudos que abordem condições de risco e proteção do ambiente familiar e que avaliem as crianças por múltiplos informantes. Objetivou-se: (a) comparar e correlacionar os recursos e eventos estressores do ambiente familiar de crianças que convivem com a depressão materna e que apresentam problemas de comportamento, com os apresentados por crianças que convivem com mães sem depressão e que não apresentam problemas comportamentais; e (b) comparar e correlacionar os comportamentos das crianças, segundo a avaliação das suas mães e professoras. Adotou-se um delineamento transversal e avaliou-se uma amostra de conveniência composta por 85 díades mães-crianças, distribuídas em: G1 = 26 mães com indicadores de depressão e crianças com problemas comportamentais; G2 $=29$ mães sem indicadores de depressão e crianças com problemas comportamentais e G3 = 30 mães sem indicadores de depressão e crianças sem problemas comportamentais. Foram incluídas crianças de ambos os sexos, de sete a 10 anos. Procedeu-se à avaliação primeiramente com as mães, seguida das crianças e professoras. Foram aplicados com as mães, em sessão única, face a face, os instrumentos: Questionário Geral, Questionário sobre a Saúde do Paciente, Inventário de Recursos do Ambiente Familiar, Escala de Eventos Adversos, Escala de Adversidade Crônica e Questionário de Capacidades e Dificuldades (SDQ). As crianças foram avaliadas quanto ao nível intelectual pelo teste Matrizes Progressivas Coloridas de Raven - Escala Especial. As professoras responderam ao SDQ - professores, precedido de informações sobre o desempenho escolar das crianças. Os dados obtidos foram codificados de acordo com as proposições técnicas e procedeu-se a análise dos mesmos por procedimentos estatísticos, adotando-se o nível de significância de 5\% (p \),05). Quando das comparações entre os grupos verificou-se com diferenças significativas, que: as famílias que convivem com a depressão materna apresentaram mais indicadores de adversidades crônicas; e as crianças com problemas comportamentais, menos recursos e mais adversidades crônicas. As mães identificaram, com significância estatística, mais problemas de comportamento das crianças $(\bar{x}=$ $17,51 ; \sigma=6,98)$ em relação às professoras $(\bar{x}=9,33 ; \sigma=7,25)$; e ainda verificou-se associações entre a depressão materna e os problemas de comportamento dos escolares, na avaliação de mães ( $r$ $=0,490)$ e professoras $(r=0,294)$ e dos problemas comportamentais com o baixo desempenho escolar. Constatou-se que: (a) as crianças que convivem com a depressão materna apresentaram indicadores de múltiplas condições de risco em seu ambiente familiar, o que pode estar favorecendo os problemas comportamentais, os quais também se associaram a menos recursos; e (b) as mães e professoras divergiram quando das avaliações dos problemas de comportamento das crianças, evidenciando a utilização de diferentes parâmetros de avaliação nos contextos familiar e escolar. Considera-se que tais dados podem instrumentar programas de prevenção no contexto escolar e de intervenção no contexto familiar, com possíveis benefícios para o comportamento das crianças.

Palavras-chave: Comportamento infantil. Depressão materna. Vulnerabilidade social. Escolares. Professores. 



\begin{abstract}
Martineli, A. K. B. (2017). Maternal depression, resources and adversity in the family environment, and schoolchildren's behavior assessed by mothers and teachers. (Master's Dissertation). Graduate Program in Psychology, Faculty of Philosophy, Sciences and Letter at Ribeirão Preto, University of São Paulo, Ribeirão Preto.

Maternal depression is known to be an adversity that affects the family environment and is associated with behavioral problems among schoolchildren. There is a need for studies addressing risk and protective conditions of the family environment assessing children through multiple informants. The objectives were (a) to compare and correlate resources and stressors in the family environment of children who live with maternal depression and present behavioral problems with the resources and the stressors of children whose mothers do not present depression and who do not present behavioral problems; and (b) to compare and correlate the behaviors of children from the perspective of their mothers and teachers. A cross-sectional design was used to assess a convenience sample composed of 85 mother-child pairs distributed between: G1 $=26$ mothers with indicators of depression and children with behavioral problems; G2 $=29$ mothers without indicators of depression and children with behavioral problems; and G3 $=30$ mothers without indicators of depression and children without behavioral problems. Children aged from seven to 10 years old, of both sexes, were included. Assessment was initiated with the mothers, followed by the children and teachers. The following instruments were applied face-to-face to the mothers in a single session: General Questionnaire, Patient Health Questionnaire, Family Environment Resource Inventory, Adverse Events Scale, Chronic Adversity Scale, and The Strengths and Difficulties Questionnaire (SDQ). The children's intellectual level was assessed using Raven's Progressive Matrices - Special Scale. The teachers responded to the SDQ - teachers, preceded by information on the children's school performance. Data were coded according to technical propositions and statistically analyzed adopting a significance level of 5\% (p $₫ 0.05$ ). Comparisons among groups showed the following significant differences: the families facing maternal depression presented more indicators of chronic adversities; and the children with behavioral problems presented fewer resources and more chronic adversities. The mothers identified more behavioral problems in children $(\bar{x}=17.51 ; \sigma=6,98)$ than teachers $(\bar{x}=9.33$; $\sigma=7,25)$. The mothers' $(r=0.490)$ and teachers' $(r=0.294)$ assessments showed associations between maternal depression and children's behavioral problems and between behavioral problems and poor school performance. We verified that: (a) children living with maternal depression presented multiple risk indicators in their family environment, which may have favored behavioral problems, which were also associated with having fewer resources; and (b) mothers and teachers diverged in regard to their assessments concerning the children's behavioral problems, showing that different parameters were used in the family and school contexts. These data may support the development of preventive programs in the school context and also interventions for the family context, which may benefit children's behaviors.
\end{abstract}

Key words: Child behavior. Maternal depression. Social vulnerability. Schoolchildren. Teachers. 



\section{LISTA DE FIGURAS}

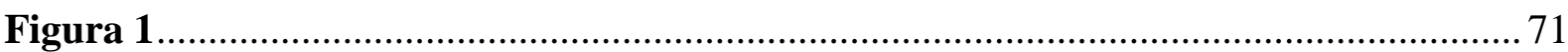

Percurso amostral dos grupos G1, G2 e G3 



\section{LISTA DE TABELAS}

Tabela 1

Comparações entre os grupos (G1, G2 e G3) quanto as variáveis sociodemográficas das mães e das famílias $(\mathrm{n}=85)$.

Tabela 2 87

Comparações entre os grupos (G1, G2 e G3) quanto às variáveis sociodemográficas das crianças $(n=85)$.

Tabela 3 88

Comparações entre os grupos (G1, G2 e G3) quanto ao comportamento das crianças (SDQ), segundo a avaliação das mães e professoras $(n=85)$.

Tabela 4 90

Comparações entre os grupos (G1, G2 e G3) quanto ao comportamento das crianças, tendo por referência as classificações dos escores em Sem dificuldade ou Com dificuldade (SDQ), tendo como informantes mães e professoras $(\mathrm{n}=85)$.

Tabela 5

Comparações entre as avaliações relativas ao comportamento das crianças (SDQ), tendo por referência mães e professoras como respondentes $(n=85)$.

Tabela 6

Comparações entre os grupos (G1, G2, G3) referente ao desempenho escolar das crianças em português e matemática $(n=85)$.

Tabela 7

Comparações entre os grupos (G1, G2 e G3) quanto aos recursos (RAF), eventos estressores (EEA) e às adversidades crônicas $($ EAC) do ambiente familiar $(n=85)$.

Tabela 8

Comparações quanto aos recursos (RAF), eventos adversos (EEA) e às adversidades crônicas (EAC) do ambiente familiar de crianças que convivem com mães Com depressão $(\mathrm{n}=26)$ e Sem depressão $(\mathrm{n}=59)$.

Tabela 9

Comparações quanto aos recursos (RAF), eventos adversos (EEA) e às adversidades crônicas (EAC) do ambiente familiar de crianças Com dificuldades comportamentais $(n=55)$ e Sem dificuldades comportamentais $(n=30)$, tendo por referência as avaliações das mães.

Tabela 10

Comparações quanto aos recursos (RAF), eventos adversos (EEA) e adversidades crônicas (EAC) do ambiente familiar de crianças Com dificuldades comportamentais $(n=20)$ e Sem dificuldades comportamentais $(n=65)$, tendo por referência as avaliações das professoras. 
Tabela 11.

Comparações quanto aos recursos (RAF), eventos estressores (EEA) e às adversidades crônicas (EAC) do ambiente familiar de crianças Sem dificuldades comportamentais, segundo a avaliação de mães e professoras $(\mathrm{n}=28)$, Com dificuldades comportamentais, segundo a avaliação de mães ou professoras $(\mathrm{n}=39)$ e Com dificuldades comportamentais, segundo a avaliação de mães e professoras $(n=18)$.

Tabela 12 .

Correlações significativas entre os indicadores comportamentais das crianças, segundo a avaliação de mães e professoras no SDQ e as variáveis sociodemográficas.

Tabela 13 .

Correlações significativas entre a presença de indicadores de depressão materna e as variáveis sociodemográficas.

Tabela 14

Correlações significativas entre os indicadores comportamentais das crianças no SDQ, segundo a avaliação de mães e professoras e a presença de indicadores de depressão materna.

Tabela 15 .

Correlações significativas entre indicadores comportamentais das crianças no SDQ, segundo a avaliação de mães e professoras e o desempenho escolar em português e matemática.

Tabela 16 .

Correlações significativas entre os problemas comportamentais das crianças no SDQ e desempenho escolar nas disciplinas português e matemática, considerando as avaliações das mães, das professoras e mães/professoras em conjunto.

Tabela 17.

Correlações significativas entre os indicadores comportamentais das crianças no SDQ e os recursos (RAF) e adversidades crônicas (EAC) do ambiente familiar.

Tabela 18

Correlações significativas entre os eventos estressores (EEA) e adversidades crônicas (EAC) do ambiente familiar e os indicadores de depressão materna. 


\section{LISTA DE ABREVIATURAS E SIGLAS}

\section{ABEP}

Associação Brasileira de Empresas e Pesquisas

APA

American Psychological Association

\section{CBCL}

Child behavior checklist

CEP

Comitê de Ética em Pesquisa

$\mathrm{CNPq}$

Conselho Nacional de Desenvolvimento Científico e Tecnológico

\section{DAWBA}

Development and Well-Being Assessment for Children and Adolescents

DP

Desvio Padrão

$\mathbf{E}$

Especificidade

EAC

Escala de Adversidade Crônica

EEA

Escala de Eventos Adversos

FFCLRP

Faculdade de Filosofia Ciências e Letras de Ribeirão Preto

G1

Grupo de díades mães-crianças, cujas mães apresentavam indicadores de depressão e as crianças apresentavam problemas comportamentais

G2

Grupo de díades mães-crianças, cujas mães apresentavam ausência de indicadores de depressão e as crianças apresentavam problemas comportamentais

G3

Grupo de díades mães-crianças, cujas mães apresentavam ausência de indicadores de depressão e as crianças ausência de problemas comportamentais 


\section{HTPC}

Hora de Trabalho Pedagógico Coletivo

\section{IBGE}

Instituto Brasileiro de Geografia e Estatística

\section{IDEB}

Índice de Desenvolvimento da Educação Básica

\section{IDH}

Índice de Desenvolvimento Humano

\section{OMS}

Organização Mundial de Saúde

\section{PHQ-9}

Questionário sobre a Saúde do Paciente-9

\section{PRIME-MD}

Primary Care Evaluation of Mental Disorders

\section{QI}

Quociente Intelectual

\section{RAF}

Inventário de Recursos do Ambiente Familiar

$\mathbf{S}$

Sensibilidade

SDQ

Questionário de Capacidades e Dificuldades

\section{SPSS}

Statistical Package for Social Sciences

\section{TCLE}

Termo de Consentimento Livre e Esclarecido

USP

Universidade de São Paulo 


\section{LISTA DE APÊNDICES}

APÊNDICE A .

Solicitação de autorização para a coleta de dados

APÊNDICE B...

Termo de Consentimento Livre e Esclarecido (Mães)

APÊNDICE C

Termo de Consentimento Livre e Esclarecido (Crianças)

APÊNDICE D.

Termo de Consentimento Livre e Esclarecido (Professoras)

APÊNDICE E.

Questionário Geral (Mães) 



\section{LISTA DE ANEXOS}

Anexo A

Carta de Aprovação do Comitê de Ética em Pesquisa da FFCLRP-USP

ANEXO B

Questionário sobre a Saúde do Paciente (PHQ-9)

Anexo C.

Inventário de Recursos do Ambiente Familiar

ANEXO D.

Escala de Evento Adversos

ANEXo E

Escala de Adversidade Crônica

ANEXo F

Questionário de Capacidades e Dificuldades (SDQ) - versão mães

ANEXo G.

Questionário de Capacidades e Dificuldades (SDQ) - versão professores

ANEXO H. 168

Itens do Critério de Classificação Econômica Brasil desenvolvido pela Associação Brasileira de Empresas de Pesquisas - ABEP 



\section{SUMÁRIO}

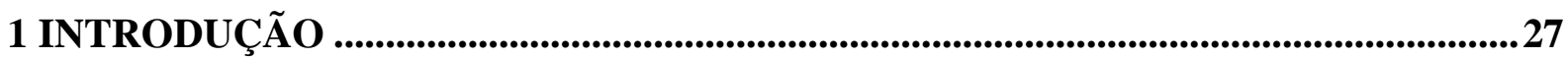

1.1 Abordagem teórica da psicopatologia do desenvolvimento ...........................................29

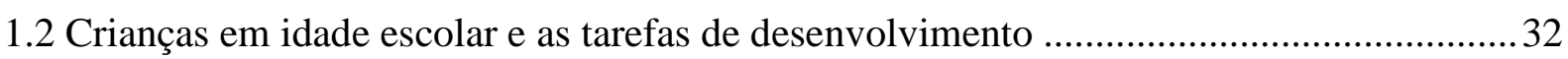

$1.3 \mathrm{O}$ ambiente escolar como contexto de desenvolvimento dos escolares ...............................37

$1.4 \mathrm{O}$ ambiente familiar como contexto de desenvolvimento dos escolares ...........................42

1.5 A convivência com a Depressão Materna: implicações para as crianças em idade

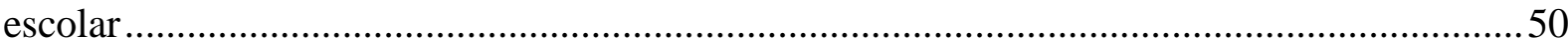

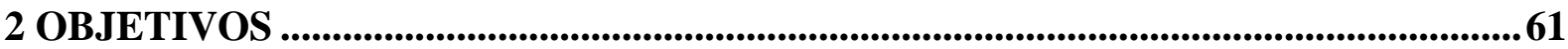

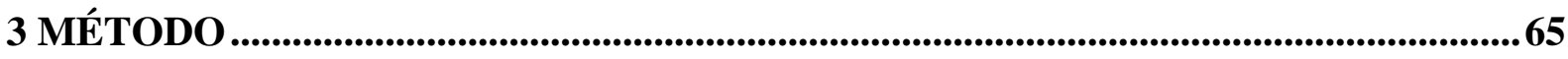

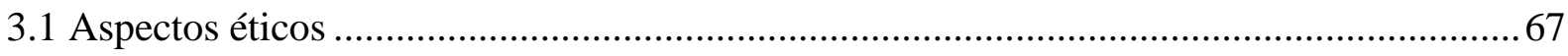

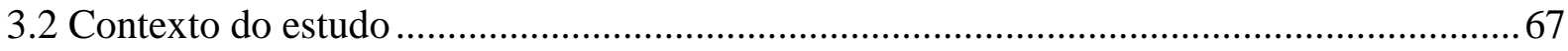

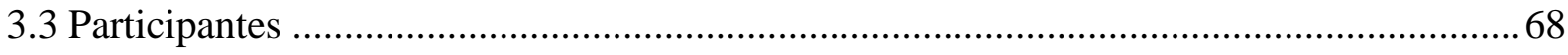

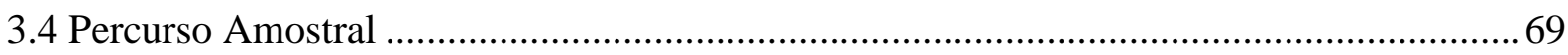

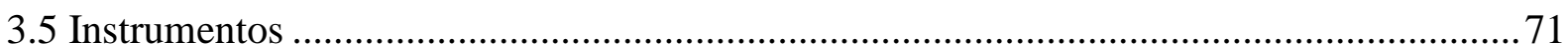

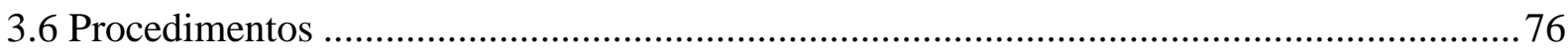

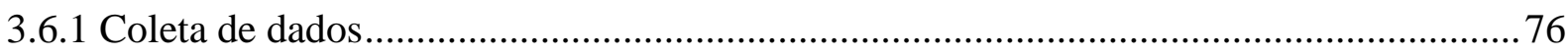

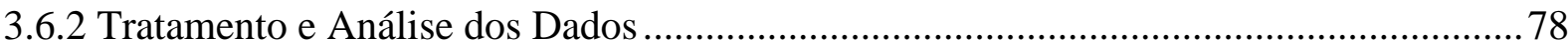

4 RESULTADOS

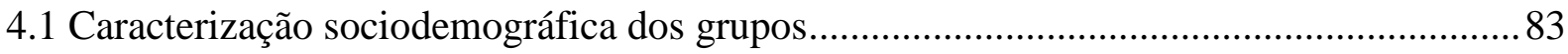

4.2 Caracterização e comparações entre os grupos quanto ao comportamento das crianças ... 88

4.3 Comparações entre as avaliações de mães e professoras quanto ao comportamento das

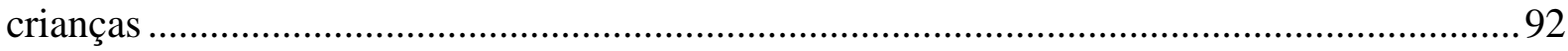

4.4 Comparações entre os grupos quanto ao desempenho escolar das crianças.......................93

4.5 Comparações entre os grupos quanto aos recursos e eventos estressores do ambiente

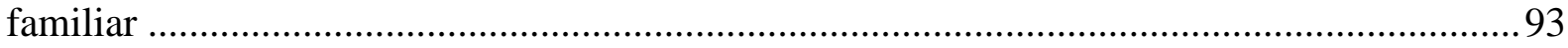

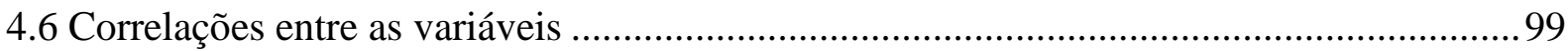

5 DISCUSSÃ

5.1 Características sociodemográficas da amostra e peculiaridades relativas à depressão .... 107 
5.2 Depressão materna, recursos e estressores do ambiente familiar: implicações para o

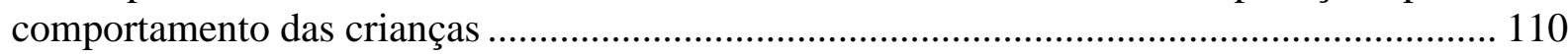

5.3 Indicadores comportamentais das crianças: avaliações de mães e professoras ............... 114

5.3.1 Indicadores comportamentais das crianças e influência da depressão materna............ 115

5.3.2 Indicadores comportamentais das crianças e aspectos contextuais ............................. 117

5.3.3 Indicadores comportamentais das crianças e comparações de avaliadores .................. 118

5.4 Desempenho escolar e indicadores comportamentais de crianças: avaliações de mães e

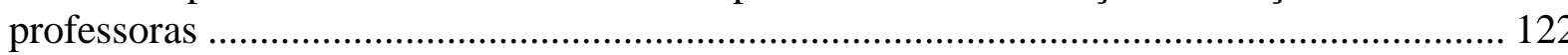

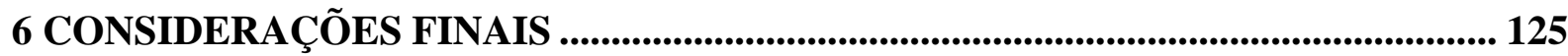

REFERTENCIAS

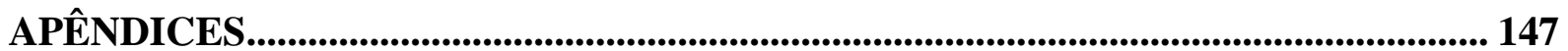

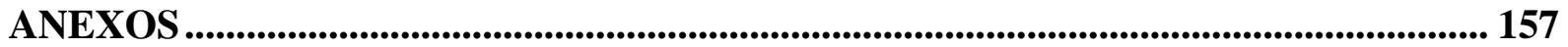


1 INTRODUÇÃO 



\subsection{Abordagem teórica da psicopatologia do desenvolvimento}

O presente estudo tem como abordagem teórica a psicopatologia do desenvolvimento, uma vez que esse campo se configura como uma importante perspectiva para o estudo da doença e da saúde mental (Sameroff, 2000). De acordo com Toth e Cicchetti (2010) tal abordagem se pauta pelo interesse na compreensão das múltiplas condições que favorecem a competência e/ou a disfunção ao longo do ciclo vital, com destaques para os aspectos biológicos, psicológicos, sociais e culturais que influenciam desfechos diversos de desenvolvimento, favorecendo a resiliência ou desadaptação.

Estudos voltados para a compreensão de condições que favorecem tanto o desenvolvimento de competências quanto as dificuldades apresentadas pelas pessoas, começaram a surgir a partir da década de 1980 (Yunes, 2003), tendo como base conceitos, tais como: adversidades, fatores de risco, eventos estressores, vulnerabilidade, enfrentamento, resiliência e fatores de proteção. A seguir, apresentar-se-á de forma breve os principais conceitos norteadores da Psicopatologia do Desenvolvimento.

$\mathrm{O}$ indivíduo, ao longo de sua trajetória de vida, pode se deparar com algumas adversidades, que influenciam o seu desenvolvimento saudável. Deste modo, a adversidade é reconhecida por envolver múltiplos estressores (Masten \& Gewirtz, 2006), destacando-se como tal, os fatores de risco e os eventos estressores.

Yunes, Garcia e Albuquerque (2007), definem fatores de risco como eventos negativos que aumentam a probabilidade de o indivíduo vir a apresentar problemas físicos, sociais ou emocionais quando a eles submetidos, em algum momento de sua trajetória de desenvolvimento. De acordo com Rutter (1987), o risco deve ser pensado como um processo e não como uma variável isolada, uma vez que varia conforme as circunstâncias de vida de cada indivíduo, resultando em diferentes consequências. Desta forma, considera-se que os fatores de risco envolvem uma rede complexa de acontecimentos anteriores e posteriores a um determinado evento negativo. Alguns fatores de risco são reconhecidos na literatura pelo seu impacto negativo, tais como, as condições de pobreza extrema, as rupturas familiares, a exposição à violência, experiências de doenças graves ou persistentes do próprio indivíduo ou de sua família, perdas dos pais, dentre outros (Pesce, Assis, Santos, \& Oliveira, 2004).

Quanto aos eventos estressores, Masten e Gewirtz (2006) os definem como episódios ou experiências de vida traumáticas e incomuns que geralmente promovem resultados desfavoráveis na trajetória do indivíduo. Em outras palavras, essas ocorrências de vida 
alteram o ambiente do indivíduo promovendo uma tensão, que interfere diretamente nas suas respostas. Yunes e Szymanski (2001), acrescentam que tais respostas ocorrem na vida da pessoa, devido à sobrecarga de seus recursos adaptativos, frente aos acontecimentos temporários ou transitórios presentes ou pregressos. Para essas autoras, as experiências de vida negativas são inevitáveis, entretanto, a visão subjetiva do indivíduo frente à determinadas situações, tais como, a sua percepção, a sua interpretação e o sentido atribuído a um dado evento estressor é o que o caracteriza ou não como uma condição de estresse.

Sobre essa questão, Silberg, Rutter, Neale e Eaves (2001), consideram que os eventos estressores se diferenciam em dependentes e independentes. Os dependentes estão ligados diretamente aos sujeitos e envolvem a sua participação, dependendo prioritariamente da forma como o indivíduo se coloca nas relações interpessoais e de como se relaciona com o meio, ou seja, da forma como o seu comportamento provoca situações desfavoráveis para si mesmo. Em contrapartida, os eventos estressores independentes não envolvem a participação do indivíduo, uma vez que são inevitáveis, estando relacionados a eventos que são considerados parte do ciclo vital de desenvolvimento, tais como por exemplo, a morte de um familiar ou a saída de um filho de casa.

Considerando as variedades de respostas emitidas pelo indivíduo frente aos estressores ou riscos, Yunes e Szymanski (2001) ressaltam que tais respostas se relacionam a vulnerabilidade e aos recursos de enfrentamento, os quais operam somente na presença de estresse e/ou risco, não tendo efeito quando tais condições estão ausentes.

De acordo com Pesce et al. (2004), por vulnerabilidade, entende-se a predisposição individual para desenvolver variadas formas de psicopatologias ou comportamentos não eficazes, ou a susceptibilidade para um resultado negativo no desenvolvimento. Na mesma direção, Masten e Gewirtz (2006) salientam que ao se pensar em vulnerabilidade é preciso levar em conta às disposições psicológicas individuais que podem potencializar os efeitos dos agentes estressores, dificultando a resposta positiva do indivíduo e aumentando a predisposição para um desenvolvimento não-adaptado frente a essas experiências negativas.

Em contrapartida, os recursos de enfrentamento são considerados por Yunes e Szymanski (2001) como estratégias utilizadas frente às adversidades, uma vez que amenizam os aspectos negativos das situações de estresse ou risco, favorecendo as respostas de adaptação do indivíduo ao seu ambiente. Nesse sentido, para tal adaptação, o indivíduo conta com recursos caracterizados como fatores de proteção e resiliência.

Os fatores de proteção são considerados pontos chaves para a compreensão da resiliência. De acordo com Pesce et al. (2004), os mecanismos de proteção de um indivíduo 
são de fundamental importância para o restabelecimento do equilíbrio perdido. Entretanto, Yunes e Szymanski (2001) esclarecem que os fatores de proteção não são sinônimos de experiências positivas, mas sim se referem a qualidades ou condições do indivíduo ou do ambiente que podem modificar as respostas frente às situações adversas. Acrescentam ainda que, tais fatores não tem a função simplesmente de favorecer o desenvolvimento normal, mas sim de modificar a resposta do indivíduo em situações adversas. Pinheiro (2004) considera como fatores de proteção do indivíduo os seus atributos disposicionais, a coesão familiar e a rede de apoio social bem definida, uma vez que favorecem tanto a sua competência, quanto a sua adaptação. Em situações de adversidade os fatores de proteção podem favorecer a resiliência.

Segundo Regalla (2007), a resiliência é um conceito que tem sido explorado e aplicado nas mais diversas áreas que envolvem o ser humano e o seu ambiente de relacionamento. Nesse sentido, Bee (2003) considera que a resiliência não depende somente de aspectos individuais, como as habilidades cognitivas e sociais, uma vez que são observadas fortes influências dos fatores ambientais.

De acordo com a definição clássica de Rutter (1987), entende-se por resiliência um conjunto de processos sociais e intrapsíquicos que possibilitam o desenvolvimento de uma vida saudável, mesmo na presença de um ambiente pouco favorável. Deste modo, não se deve considerar resiliência como um atributo fixo do indivíduo, uma vez que esse processo resulta da combinação entre os atributos da criança ou jovem e de seu ambiente familiar.

A aplicação e a própria definição de resiliência vêm se modificando com a ampliação de novas compreensões e estudos sobre a temática. Walsh (2005), define resiliência como a capacidade de renascer da adversidade fortalecido e com mais recursos, relacionando o conceito a um processo ativo de resistência, reestruturação e crescimento, em resposta à crises e desafios. Acrescenta que o termo se refere a experiências simultâneas de sofrimento e de coragem do indivíduo, que resultam em superação e adaptação, consideradas maneiras eficientes de enfrentamento das dificuldades.

A referida autora, considera ainda relevante, estudos que abordem a resiliência em famílias enquanto uma possibilidade de adaptação dos membros familiares, uma vez que os processos interacionais dessa rede de relacionamentos e experiências, no decorrer do ciclo vital, podem oferecer estratégias diversas de enfrentamento frente às adversidades. Dessa forma, entende que quando a família se expõe a situações de crise ou estresse permanente, surgem os processos de resiliência familiar, permitindo que as mesmas superem as crises fortalecidas, independente das fontes de estresse serem internas ou externas à família. 
Considerando essa breve definição dos conceitos relevantes para a compreensão do enfoque teórico da Psicopatologia do Desenvolvimento, ressalta-se que tal abordagem busca identificar o que interfere ou ameaça na realização adequada das tarefas de desenvolvimento, próprias de cada período de vida, favorecendo a adaptação e a competência, ou as dificuldades, tendo por referência as condições pessoais e do ambiente de convivência das pessoas (Pizeta, 2014).

A seguir, sob tal enfoque, abordar-se-á as características das crianças em idade escolar e as suas tarefas típicas de desenvolvimento, por ser essa faixa etária o foco da presente pesquisa.

\subsection{Crianças em idade escolar e as tarefas de desenvolvimento}

O indivíduo ao longo de sua vida passa por vários estágios de desenvolvimento, entretanto, para atender as demandas de cada estágio, utiliza-se de recursos internos e externos, afim de instrumentar as novas conquistas. Com relação ao desenvolvimento infantil, considera-se que em cada estágio alcançado, as crianças abordam as tarefas de modo diferente, percebendo o mundo de forma diferente e preocupando-se com questões diferentes, uma vez que se verifica uma reorganização de estratégias ou o uso de habilidades inteiramente novas (Bee, 2003).

Dessen e Polonia (2007) definem estágios de desenvolvimento como um conjunto de padrões comportamentais e de habilidades típicas de uma determinada idade ou fase de desenvolvimento. Com sentido semelhante, Marturano e Loureiro (2003) consideram que cada estágio de desenvolvimento se relaciona com o período em que a pessoa se encontra em sua trajetória de vida, incluindo as vivências dos períodos anteriores e as novas demandas e tarefas do ambiente, específicas de cada período. Wright e Masten (2006) destacam que a adaptação em cada período pode ser pautada por indicadores relativos à ausência de patologias, a competência para realização de tarefas próprias do período do ciclo vital e ainda ao bem-estar subjetivo, enquanto que a desadaptação, segundo Price e Zwolinski (2010), pode ser considerada como um desvio das normas específicas de cada etapa do desenvolvimento.

Referente aos aspectos de desenvolvimento para as crianças em idade escolar, Marturano, Trivellato-Ferreira e Gardinal (2009) consideram que os indicadores de adequação das crianças às demandas de aprendizagem e de relacionamento esperados pela sociedade 
relacionam-se à competência cognitiva para o aprendizado escolar formal, à competência comportamental de auto-regulação e à adaptação ao meio social mais amplo. Ainda descrevem algumas mudanças relevantes no contexto de desenvolvimento das crianças em idade escolar, especificamente no período de passagem para o ensino fundamental, tais como, lidar com um novo ambiente, relacionar-se com adultos ainda desconhecidos, conquistar a aceitação em um novo grupo de iguais, além de enfrentar demandas acadêmicas mais desafiadoras. Ressaltam que nesse período, as mudanças cognitivas são fundamentais para a preparação das crianças para as exigências da adolescência e da vida adulta.

De acordo com Marturano e Loureiro (2003), os indicadores comportamentais e de desempenho acadêmico destacam-se pela importância que assumem no período escolar, uma vez que neste, as principais tarefas típicas de desenvolvimento envolvem a socialização e o desempenho acadêmico. Entretanto, considerando a importância do comportamento como um indicador de adaptação das crianças em idade escolar, faz-se necessário uma breve apresentação sobre os problemas comportamentais mais frequentes apresentados pelos escolares.

Nos contextos escolares e familiares são frequentes as indicações de dificuldades adaptativas referidas como problemas comportamentais das crianças. Tais problemas são considerados por Bolsoni-Silva (2003), déficits ou excessos comportamentais que prejudicam a interação das crianças com os seus pares e com adultos de sua convivência. Segundo Bee (2003) faz-se necessário caracterizar os problemas comportamentais, uma vez que estes podem se manifestar por meio dos comportamentos externalizantes e internalizantes.

De acordo com Achenbach e Edelbrock (1979) os comportamentos internalizantes são caracterizados por retraimento, ansiedade, preocupação exagerada, tristeza, insegurança, timidez, medos, manifestações psicossomáticas, recusa escolar, dentre outros. Bee (2003) acrescenta que os problemas internalizantes se relacionam à ansiedade e depressão, destacando maior ocorrência nas crianças que convivem com pais depressivos.

Em contrapartida, Achenbach (1991) considera que os comportamentos externalizantes, são marcados pela impulsividade, explosividade, agressividade, agitação, características desafiadoras e antissociais, como mentiras, furtos, falta às aulas, desrespeito à limites, brigas e hostilidades nos relacionamentos. Bee (2003) ao referir aos problemas externalizantes, relaciona-os aos transtornos de conduta, que incluem os comportamentos de agressividade, propensão à discussões e brigas, desobediência, irritabilidade e ameaças. Ressalta que as crianças com tais comportamentos, provavelmente foram expostas desde o início de suas vidas às diversas situações de vulnerabilidade, dentre elas, o apego inseguro, o 
temperamento difícil e a inteligência limitada dos pais. Contudo, ressalta que os problemas externalizantes podem se transformar em transtorno de conduta ou em desenvolvimento adaptativo, dependendo da configuração do ambiente familiar e do manejo dos pais para com o controle de seus filhos, nos períodos iniciais de suas vidas.

Bolsoni-Silva, Marturano, Pereira e Manfrinato (2006) consideram que tanto os problemas externalizantes como os internalizantes prejudicam o desenvolvimento das crianças, uma vez que os externalizantes podem gerar conflitos e provocar rejeições por parte de pais, professores e colegas, enquanto que os internalizantes podem privar as crianças de interagir com o ambiente, dificultando a sua interação com seus pares ou com os adultos.

Considerando a diferenciação dos problemas de comportamento pelo sexo das crianças, Borsa, Souza e Bandeira (2011), realizaram um estudo com o objetivo de investigar a prevalência de problemas de comportamento, em uma amostra de crianças escolares residentes no interior do Rio Grande do Sul. Participaram 140 pais, mães ou cuidadores de meninos e meninas, matriculados entre o terceiro e o quinto ano do ensino fundamental, de escolas públicas e privadas. Os resultados apontaram para a prevalência de mais problemas de comportamento em meninos, sobretudo os externalizantes, enquanto que as meninas, no geral, apresentaram menos problemas de comportamento, sendo as queixas mais frequentes referentes aos comportamentos internalizantes.

De modo semelhante, Bolsoni-Silva, Mariano, Loureiro e Bonaccorsi (2013), com base em um estudo sobre a comparação de práticas educativas de professores do ensino regular e do especial com os comportamentos infantis em grupos diferenciados por problemas de comportamento e pelo sexo das crianças na faixa etária de seis a nove anos, constataram a presença de mais meninos com indicadores de problemas de comportamento em comparação às meninas, uma vez que estas apresentaram baixa frequência de comportamentos considerados problemáticos.

No contexto escolar, segundo Ferriolli, Marturano e Puntel (2007), os comportamentos externalizantes são identificados com maior facilidade, possivelmente por apresentarem maior visibilidade e consequentemente interferirem na dinâmica da sala de aula. Consideram que o papel dos professores é fundamental ao aluno, uma vez que conseguem identificar as dificuldades dos escolares e desenvolvem atividades que proporcionam o desenvolvimento de suas habilidades sociais e relacionais. Em concordância com tais autoras, Lyra, Assis, Njaine, Oliveira e Pires (2009) consideram que os professores em sala de aula, identificam os problemas comportamentais das crianças com facilidade, uma vez que o longo tempo de 
convivência com os escolares facilita as suas observações, sobretudo quanto às comparações das avaliações das crianças de uma mesma faixa etária.

Por outro lado, verifica-se que pais e professores, nem sempre têm uma avaliação concordante quanto a presença de problemas comportamentais das crianças. Leis, Heron, Stuart e Mendelson (2014) apontaram que as divergências entre os relatos de mães e professores, podem ser explicadas pelas diferenças dos contextos nos quais os comportamentos são observados e uma possível influência da saúde mental materna.

Um estudo realizado por Bolsoni-Silva et al. (2006) buscou um maior entendimento a respeito da concordância entre mães e professoras, na avaliação do comportamento de crianças. Os achados das comparações por gênero mostraram que as mães foram mais atentas às manifestações internalizantes de suas filhas, enquanto que as professoras ressaltaram mais as manifestações externalizantes dos alunos de sexo masculino. Baseado nesses achados, as autoras apontaram que os professores consideraram como desadaptadas aquelas crianças com comportamentos que não se enquadravam estritamente no padrão modal esperado, e em contrapartida, no contexto familiar, dada a convivência continuada e próxima com seus filhos, as mães relataram nuances que escaparam aos professores, como, por exemplo, certas manifestações internalizantes mais sutis.

O uso de múltiplos informantes foi abordado também por Kovess et al. (2015) em um amplo projeto sobre saúde mental das crianças em idade escolar. O estudo foi desenvolvido na Europa, especificamente em sete países, incluindo a Itália, Holanda, Alemanha, Romênia, Bulgária, Lituânia e Turquia, visando identificar o conjunto de indicadores de fatores de risco para a saúde mental das crianças com idade de seis a nove anos. Participaram do estudo 9084 crianças de escolas primárias, que completaram o questionário Dominic Interactive em sua própria língua, 6563 professores e 6031 pais que responderam o Questionário de Capacidades e Dificuldades (SDQ). Dentre os vários achados, verificaram que os professores avaliaram as crianças com mais problemas externalizantes e menos problemas internalizantes em comparação à avaliação dos pais. Também identificaram que as crianças relataram mais problemas internalizantes do que os pais e os professores.

Berg-Nielsen, Solheim, Belsky e Wichstrom (2012) exploraram a concordância entre avaliações de pais e professores considerando as relações dos sintomas depressivos maternos a uma maior percepção dos problemas de comportamento das crianças, em comparação com as avaliações realizadas por outros informantes. Verificaram que os professores relataram menos problemas de comportamento das crianças do que os pais, ressaltando a relevancia das avaliações feitas pelos professores, pois esses tomam como parâmetro a convivência diária 
com diferentes crianças em situações mais estruturadas que as vivenciadas no contexto familiar.

Com o objetivo de verificar características comportamentais de crianças com desenvolvimento típico de leitura, Stivanin, Scheuer e Assumpção Jr (2008) realizaram um estudo utilizando o SDQ. Participaram pais e professores de 74 crianças leitoras, de ambos os gêneros, que cursavam a $2^{\mathrm{a}}, 3^{\mathrm{a}}$ ou $4^{\mathrm{a}}$ séries do Ensino Fundamental de uma escola pública municipal. No que diz respeito à comparação das avaliações realizadas pelos pais e professores referentes às características comportamentais das crianças, os resultados indicaram que as respostas dos pais preencheram mais critérios para a categoria "desenvolvimento anormal" do que as respostas dos professores, em todas as subescalas do SDQ.

Cury e Golfeto (2003) realizaram um estudo transversal em uma escola pública da cidade Ribeirão Preto-SP, com o objetivo de rastrear possíveis transtornos psiquiátricos de crianças por meio da aplicação do SDQ. Participaram da pesquisa mães e professores de 112 crianças com idade entre seis a 11 anos que cursavam as quatro primeiras séries do ensino fundamental. Identificaram uma taxa de prevalência de 18,7\% para problemas de comportamento na avaliação realizada pelos pais e de $8,3 \%$, na avaliação feita pelos professores. A diferença na pontuação das escalas entre os pais e professores, demonstrou a falta de concordância entre os vários informantes sobre a presença de sintomas comportamentais.

Para a avaliação da prevalência de problemas de saúde mental infantil no Brasil, Goodman et al. (2005) compararam dois lugares do país, com características distintas, sendo um no nordeste, e o outro, no sudeste do país. Utilizaram os instrumentos SDQ e Development and Well-Being Assessment for Children and Adolescents (DAWBA) para a avaliação de 519 crianças e adolescentes, de cinco a 14 anos, tendo os pais, professores e os próprios adolescentes como informantes. Verificaram que as crianças da região nordeste apresentaram mais problemas internalizantes e externalizantes e indicadores de hiperatividade, em comparação às crianças do sudeste, embora o impacto dos sintomas tenham sido maiores para essas últimas. Quanto aos sintomas, considerando conjuntamente as duas regiões, observaram que os meninos apresentaram níveis mais elevados de problemas de hiperatividade e conduta (problemas externalizantes), tendo como referência o relato do professor; e as meninas apresentaram maiores taxas de sintomas emocionais (problemas internalizantes), tanto no que se refere ao relato dos pais quanto ao autorrelato. 
Verifica-se na literatura como recomendável o uso de múltiplos informantes, inclusive do auto relato, no que diz respeito às avaliações dos problemas comportamentais de crianças e adolescentes. Considera-se que ao se coletar informações de várias fontes, tem-se um quadro mais detalhado sobre o comportamento do avaliado, além evidenciar as distintas manifestações em diferentes contextos (Achenbach, 1991). Em concordância com o referido autor, Stivanin, Scheuer e Assumpção (2008) consideram que as divergências referentes as informações obtidas por pais e professores ocorrem, devido aos diferentes olhares, conhecimentos e formas de falar ou se expressar a respeito dos sujeitos por eles avaliados, entretanto, é necessário cuidado e atenção quanto aos dados fornecidos.

Deste modo, considera-se que os problemas comportamentais das crianças se destacam como relevantes tanto no contexto familiar como escolar, por representarem as dificuldades mais frequentes apresentadas pelos escolares (Achenbach et al., 2008). Nesse sentido, considera-se importante ressaltar que alguns instrumentos de avaliação são reconhecidos por permitirem avaliar de forma sistemática o comportamento das crianças, como é o caso do SDQ, reconhecido e validado em muitos países, permitindo avaliações realizadas tanto por pais como por professores (Saur \& Loureiro, 2012).

A adaptação ou desadaptação das crianças em idade escolar se expressam nos contextos familiares e escolares onde se interpõem as maiores ocorrências dos eventos estressores (Poletto, Koller, \& Dell'Aglio, 2009). Dada a importância de tais contextos para o desenvolvimento dos escolares, serão abordados nos próximos tópicos o papel da escola e o papel da família, assim como os desafios encontrados pelas crianças em tais contextos.

\subsection{O ambiente escolar como contexto de desenvolvimento dos escolares}

A escola assume um importante papel para as crianças, uma vez que as experiências vivenciadas em tal contexto refletem em todos os aspectos de seu desenvolvimento. De acordo com Erikson (1976), em cada período do desenvolvimento algumas experiências são consideradas sensíveis por terem mais influência sobre as demandas típicas do período. Nesse sentido, para as crianças de seis a 12 anos, a demanda típica se expressa pela crise evolutiva decorrente do desafio da produtividade, sendo o reconhecimento social por meio de sua capacidade de suma importância. 
Marturano (2013) considera que no período escolar, especificamente na entrada para o ensino fundamental, as crianças se deparam com novas demandas, destacando dentre elas, o envolvimento com um novo ambiente, o relacionamento com adultos ainda desconhecidos, a aceitação em um novo grupo de iguais e o enfrentamento de demandas acadêmicas mais desafiadoras. Refere que as mudanças frente ao contexto social são visíveis, uma vez os adultos tornam-se mais exigentes e apresentam menos tolerância com a dependência das crianças. Quanto as relações interpessoais, descreve que as negociações realizadas com as crianças da mesma idade e mais velhas, tornam-se a base das interações, enquanto que no plano acadêmico, as crianças se deparam com novas habilidades e conhecimentos a serem desenvolvidos e dominados. Deste modo, o escolar enfrenta um enorme desafio à sua capacidade adaptativa, uma vez que várias mudanças simultâneas requerem adaptações extremamente elaboradas (Marturano \& Elias, 2006).

Ao longo do desenvolvimento as demandas são diversas, dado o objetivo do presente estudo, atentar-se-á exclusivamente ao desempenho acadêmico e a socialização como demandas que influenciam diretamente o comportamento dos escolares. A seguir apresentarse-á alguns estudos que enfocaram tais aspectos.

No contexto acadêmico, segundo Marturano e Loureiro (2003), as dificuldades escolares podem acentuar as vivências de menos valia, condições estas favorecedoras de outras dificuldades comportamentais e emocionais. Inversamente, quando a criança apresenta desempenho escolar satisfatório, os sentimentos de auto-estima e auto-eficácia são favorecidos, contribuindo para a motivação e persistência em relação as atividades acadêmicas (Antunes \& Fontaine, 2005). Segundo D’abreu e Marturano (2010), crianças identificadas com a queixa escolar, tornam-se mais vulneráveis aos problemas emocionais e comportamentais. Masten e Reed (2002) consideram a queixa escolar uma adversidade crônica que interfere diretamente na realização acadêmica, favorecendo o risco de desadaptação social. O baixo desempenho escolar, de acordo com Bernard, Ellis e Terjesen (2006) resulta de uma discrepância entre a aptidão acadêmica e o desempenho da criança, considerando desempenho, seja em notas ou tarefas, abaixo de um nível esperado para a idade, habilidade e potencial de um indivíduo. Destaca-se em diversos estudos a associação de problemas acadêmicos e comportamentais.

Cia e Barham (2009) realizaram um estudo com o objetivo de relacionar o desempenho acadêmico e o desenvolvimento socioemocional das crianças, caracterizado pelo repertório de habilidades sociais, problemas de comportamento e autoconceito da primeira e segunda séries do ensino fundamental. Foram participantes 97 famílias, 99 crianças e 20 
professoras de escolas públicas de um município no interior do estado de São Paulo. Verificaram que o repertório de habilidades sociais, o autoconceito e o desempenho acadêmico das crianças estavam positivamente correlacionados entre si.

Com base em uma revisão de estudos prospectivos e longitudinais, D’Abreu e Marturano (2011) investigaram a associação entre os problemas de comportamento externalizantes e o baixo desempenho escolar no ensino fundamental. Foram analisados 18 artigos, classificados em quatro categorias, a saber: estudos com amostras clínicas; estudos comparando grupos com ou sem comorbidade; estudos que buscaram testar modelos de trajetória de desenvolvimento e estudos sobre precursores da associação entre problemas de comportamento e baixo desempenho escolar. Constataram a associação do baixo desempenho escolar com os problemas externalizantes sugerindo a influência de variáveis como as condições adversas do ambiente e do baixo nível socioeconômico. Apontaram que tal associação é sugestiva de pior prognóstico dada as comorbidades com transtornos psiquiátricos e comportamento anti-social.

Com o objetivo de verificar a associação entre indicadores de desempenho acadêmico e o tempo de exposição da criança à Educação Infantil, competência interpessoal e a percepção de estresse na $2^{\text {a }}$ série do ensino fundamental, Pereira, Marturano, Pizato e Fontaine (2011) realizaram um estudo com 95 crianças de escolas públicas do interior de São Paulo, tendo como informantes seus pais/responsáveis e os seus professores, distribuídos em três grupos: sem frequência à educação infantil, com um ano de frequência e com dois anos de frequência à educação infantil. As avaliações de desempenho acadêmico foram favoráveis às crianças que frequentavam a educação infantil por mais tempo, assim como algumas dimensões de habilidades sociais, principalmente responsabilidade e cooperação. Verificaram relações entre a frequência à educação infantil e a associação com a competência acadêmica.

A importância da relação entre o ambiente familiar e os aspectos da vida escolar das crianças foi abordada por Gomes (2016) tendo por referência uma pesquisa bibliográfica com objetivo de analisar as influências para o desempenho acadêmico das crianças dos recursos materiais, caracterizados pelos recursos financeiros disponíveis no lar que viabilizam o acesso a livros, revistas, brinquedos e outros materiais promotores do desenvolvimento infantil; e os recursos humanos do ambiente familiar, destacando o envolvimento e participação dos pais na vida escolar de seus filhos, a organização e a supervisão nas rotinas infantis e as possíveis interações pais/filhos. Os resultados apontaram que o envolvimento dos pais na educação dos filhos e o recurso econômico familiar, interferem no desempenho acadêmico das crianças. 
Ao analisar tais estudos que abordaram o desempenho acadêmico no período escolar, verificou-se uma associação dos problemas acadêmicos e comportamentais, o que coloca em foco as habilidades sociais, enquanto recursos que podem favorecer a tarefa típica do período expressa pela socialização.

As habilidades sociais são definidas por Del Prette e Del Prette (2013) como diferentes classes de comportamentos sociais do repertório dos indivíduos que lhes permitem lidar com as situações interpessoais, enquanto a competência social remete aos efeitos do desempenho das habilidades no contexto de vida da pessoa. Consideram que a criança ao se inserir no ambiente escolar, enfrenta desafios quanto ao estabelecimento de novos relacionamentos (professores e pares), o que implica na ampliação do seu repertório referente às habilidades sociais. Nesse sentido, o escolar a todo instante, se depara com novos desafios interpessoais, uma vez que a inserção em tal contexto representa o contato com novas pessoas e a necessidade de adaptação a novas demandas.

Bolsoni-Silva e Carrara (2010) consideram as habilidades sociais como comportamentos, emitidos na interação social que parecem colaborar na resolução de problemas, na redução de conflitos e na promoção e/ou manutenção de interações sociais satisfatórias e agradáveis. Em contrapartida, os déficits de habilidades sociais podem comprometer fases posteriores do ciclo vital, em termos de dificuldades de iniciar e manter relacionamentos, pior qualidade de vida e diferentes tipos de transtornos psicológicos (Del Prette \& Del Prette, 2001). Segundo Bolsoni-Silva e Mariano (2014) as meninas tendem a apresentar mais comportamentos habilidosos e os meninos mais problemas de comportamento.

Com o objetivo de caracterizar o repertório de habilidades sociais e problemas comportamentais de crianças e verificar a possível força preditiva de classes específicas de habilidades sociais sobre os problemas de comportamento, Casali-Robalinho, Del Prette e Del Prette (2015) realizaram um estudo com 220 crianças, matriculadas do $3^{\circ}$ ao $6^{\circ}$ ano do Ensino Fundamental e seus respectivos pais. Identificaram as habilidades ou comportamentos emitidos com maior/menor frequência pelas crianças avaliadas, verificando que segundo os pais ou responsáveis, os problemas de comportamento internalizantes foram os mais frequentes. Quanto as habilidades sociais de maior peso preditivo para os problemas comportamentais, segundo a auto avaliação das crianças, foi a responsabilidade e, na avaliação dos informantes externos foi o autocontrole e a civilidade.

Elias e Amaral (2016) desenvolveram um estudo com o objetivo de avaliar as habilidades sociais, os problemas de comportamento e o desempenho acadêmico das crianças 
do $5^{\circ}$ ano do ensino fundamental $\mathrm{I}$, antes e após um treino específico para o desenvolvimento das habilidades sociais. A amostra contou com 54 crianças, de ambos os sexos, regularmente matriculadas em uma escola pública municipal de uma cidade do interior de São Paulo, além de duas professoras. Tal amostra foi distribuída em dois grupos, a saber: (GI) grupo de intervenção e (GC) grupo de comparação, com ausência de intervenção. Verificaram que o treino de habilidades sociais aprimorou o repertório das crianças, bem como promoveu um impacto positivo para o desempenho escolar.

Os problemas comportamentais internalizantes foram correlacionados aos indicadores de práticas educativas parentais, recursos do ambiente familiar e depressão materna por Bolsoni-Silva, Loureiro e Marturano (2016). Participaram 32 mães de crianças com problemas internalizantes e 32 sem problemas, matriculadas em escolas municipais de ensino infantil e fundamental. A análise dos dados indicou que as habilidades sociais tiveram um efeito protetor para os problemas internalizantes na presença do risco representado pela depressão materna, sendo que quanto maior era o escore de depressão materna, menos frequentes foram as habilidades sociais infantis.

Com base em um estudo longitudinal realizado em escolas municipais do interior do estado de São Paulo, Correia-Zanini (2013) investigou o percurso escolar de crianças, sob o enfoque do modelo Bioecológico de Desenvolvimento, considerando as variáveis relacionadas à Pessoa (Criança), ao contexto (Família e Escola), ao Processo e ao Tempo. Participaram da pesquisa 186 crianças do $1^{\circ}$ ano do Ensino Fundamental, 176 do $2^{\circ}$ ano e 151 do $3^{\circ}$ ano, além de 122 famílias de crianças do $1^{\circ}$ ano. Frente a caracterização do componente Pessoa, o Recurso foi considerado como uma das variáveis selecionadas para o estudo, tendo por foco as habilidades sociais. Segundo a avaliação dos professores, as habilidades responsabilidade e cooperação se destacaram, enquanto que a autodefesa foi pouco presente; e as meninas apresentaram mais habilidades sociais que os meninos. Verificou também que as habilidades sociais avaliadas apresentaram correlações positivas com o desempenho acadêmico, competência acadêmica e potencial cognitivo. Foi destacada a importância das habilidades sociais acadêmicas, avaliadas no estudo pelo fator responsabilidade e cooperação como componentes significativos da trajetória acadêmica das crianças no ensino fundamental.

Gavasso, Fernandes e Andrade (2016), realizaram um estudo de revisão sobre as habilidades sociais, tendo por referência artigos em periódicos, publicados nos anos de 2009 a 2013. A recuperação bibliográfica resultou em 85 artigos, divididos em dois grandes eixos temáticos, a saber: estudos sobre habilidades sociais e o contexto escolar; e aspectos familiares relacionados às habilidades sociais. A análise apontou que os aspectos socioemocionais, 
caracterizados pelo vínculo parental, vínculos de amizade e acolhimento institucional escolar, foram essenciais para o desenvolvimento das práticas sociais assertivas de crianças e do jovem adulto. Verificaram também que a parceria entre a instituição escolar e a família pode ser um fator que influencia o desenvolvimento das habilidades sociais dos escolares.

Considerando os estudos citados, pode-se verificar a influência positiva das habilidades sociais para o desempenho acadêmico e para a socialização das crianças. Pode-se pensar que escolares com desempenhos acadêmicos e sociais negativos, possivelmente encontram-se expostos a maiores riscos. Nos anos escolares as adversidades, segundo Marturano (2006), podem ocorrer tanto nos contextos escolares quanto familiares, uma vez que mecanismos de risco e proteção podem operar para trajetórias mais ou menos favoráveis de desenvolvimento.

$\mathrm{Na}$ escola, as crianças se envolvem em atividades ligadas às tarefas formais como pesquisa, leitura dirigida e atividades informais de aprendizagem, como a hora do recreio, excursões e atividades de lazer. Verifica-se que o atendimento às necessidades cognitivas, psicológicas, sociais e culturais são realizados de forma mais estruturada e pedagógica quando comparadas ao ambiente familiar (Dessen \& Polonia, 2007). Entretanto, Marturano (1999) destaca que o progresso no aprendizado escolar, considerando a compatibilidade entre a idade e a série ou qualidade da produção escrita, associa-se à supervisão e à organização das rotinas no lar, a oportunidade de interação com os pais e à oferta de recursos do ambiente físico. Desta forma, os recursos presentes no ambiente familiar podem também funcionar como fatores protetores do desenvolvimento de escolares, enquanto que o número elevado de riscos e poucos recursos podem contribuir para a vulnerabilidade das crianças, dificultando o ajustamento escolar e a adaptação social.

Dada a importância do ambiente familiar enquanto contexto de desenvolvimento emocional e cognitivo das crianças, a seguir abordar-se-á algumas condições estressoras que podem incidir sobre o ambiente familiar e suas implicações para o comportamento dos escolares.

\subsection{O ambiente familiar como contexto de desenvolvimento dos escolares}

A família exerce uma forte influência para o comportamento das crianças, uma vez que transmite os valores, as crenças, as ideias e os significados presentes na sociedade 
(Dessen \& Polônia, 2007). Sob tal enfoque, Macedo (1994) considera que a família desempenha um papel de destaque para o desenvolvimento das funções afetivas, cognitivas e sociais das crianças, sendo as práticas parentais fundamentais para que tais funções se efetivem. Essas práticas consistem na garantia para as crianças de cuidados, proteção, socialização e equilíbrio emocional, além de monitoramento e ajuda no processo de escolarização (Gallart, 2007). A frequência e intensidade das práticas parentais utilizadas pelos genitores influenciam de forma positiva ou negativa o comportamento das crianças e segundo Gomide (2006) os comportamentos pró-sociais se associam às práticas positivas e os comportamentos antissociais às práticas negativas.

Macana e Comim (2015) alertam para a importância de ampliar a compreensão do funcionamento familiar, uma vez que determinadas ocorrências familiares podem incentivar o desenvolvimento das crianças e funcionar como fatores de proteção, ou em contrapartida, podem favorecer os fatores de risco contribuindo para déficits no potencial de desenvolvimento das crianças. Consideram que as famílias apresentam características estruturais e dinâmicas internas que contribuem para os desfechos familiares de risco ou proteção. São aspectos estruturais as variáveis demográficas e socioeconômicas, enquanto arranjo familiar, renda familiar e o grau de escolaridade dos pais, são variáveis dinâmicas as práticas parentais e o estilo de interação entre pais e filhos.

Considerando os objetivos desse trabalho a seguir, serão abordados estudos que destacaram os recursos e as adversidades do ambiente familiar das crianças.

\section{- $\quad$ Recursos do Ambiente familiar}

De acordo com Marturano (1999) o interesse ativo dos pais pelo desenvolvimento da criança se manifesta por meio do investimento de tempo e de recursos destinados à sua educação. Considerando os recursos presentes no ambiente familiar, Guidetti (2007) destaca os recursos humanos e materiais, sendo os primeiros caracterizados pelo envolvimento e participação dos pais na vida escolar dos filhos, na organização e supervisão frente às rotinas infantis e nas interações pais-filhos, enquanto que, os recursos materiais associam-se ao acesso das crianças à livros, revistas, brinquedos, atividades culturais e de lazer, dentre outros materiais promotores do desenvolvimento infantil.

Vários estudos têm investigado a influência dos recursos familiares para as crianças. Dentre eles, destaca-se o estudo realizado por Marturano (2006) com o objetivo de investigar os recursos presentes no contexto familiar para o aprendizado acadêmico das crianças do 
ensino fundamental. Verificou que os recursos passeios, brinquedos, livros e interação pais/filhos associaram-se aos indicadores de competência escolar e bom ajustamento das crianças.

Santos e Graminha (2006) buscaram investigar a influência de diferentes aspectos do contexto familiar sobre o rendimento acadêmico de crianças de $1^{\mathrm{a}}$. e $2^{\mathrm{a}}$. séries, com alto e baixo desempenho escolar. Foram obtidos dados referentes a estruturação familiar e história de desenvolvimento das crianças, além de informações sobre o nível socioeconômico e escolaridade dos pais. Os resultados indicaram que as famílias das crianças com alto rendimento escolar apresentaram um ambiente mais rico em termos materiais e de estímulos para o desenvolvimento, por sua vez, no ambiente familiar das crianças com baixo rendimento escolar foi verificado um número maior de adversidades, com destaque para os baixos níveis socioeconômicos e de escolaridade dos pais.

As relações entre o ambiente familiar e o desempenho escolar das crianças também foram investigadas por Ferreira e Barrera (2010), em um estudo com 30 crianças na faixa etária entre cinco e seis anos de idade matriculadas em uma escola pública do interior de São Paulo e seus responsáveis. Foram obtidos dados referente aos Recursos do ambiente familiar, às condições socioeconômicas e educacionais, além da constituição familiar. Os resultados indicaram a associação entre o desempenho escolar das crianças e os recursos do ambiente familiar, especialmente no que se refere à disponibilidade de brinquedos e objetos culturais (livros, jornais e revistas), bem como à quantidade de atividades e reuniões compartilhadas com os pais. Verificaram ainda associação entre os recursos do ambiente familiar e o grau de escolaridade das mães e o nível socioeconômico das famílias.

A oferta de atividades à criança em seu tempo livre, o estabelecimento de uma rotina diária com horários definidos e arranjos de espaço e tempo para a realização das tarefas escolares foram identificados por Ferrioli et al. (2007) como recursos para diminuir a probabilidade das crianças, entre seis e 12 anos, atendidas em um programa de atenção primária, apresentarem problemas de saúde mental.

Marturano e Elias (2016) realizaram um estudo com o objetivo de testar um modelo de predição de problemas de comportamento em escolares, tendo como preditores variáveis de apoio ao desenvolvimento e adversidade no contexto familiar, bem como a presença da queixa escolar, sinalizando adversidade no contexto escolar. Participaram 60 crianças, de sete a 11 anos, e suas mães, recrutadas em escola pública de Ensino Fundamental e em clínicaescola de psicologia. Constataram a associação da presença de rotina regular no dia a dia da criança com menos problemas de comportamento externalizante e menos problemas sociais; 
além de associações entre mais opções de lazer quando a criança não está na escola com menos problemas internalizantes.

Mendes, Loureiro e Crippa (2008) com base em estudo de revisão sistemática da literatura, relataram que as condições familiares associadas à depressão materna, tais como a organização do ambiente, o nível socioeconômico e a rede de suporte social, foram identificadas como fatores de risco ou de proteção frente à depressão materna, dependendo de como se apresentaram. Segundo os estudos analisados pelos referidos autores, condições relativas a um ambiente familiar organizado, com horários regulares e espaços definidos para a realização das atividades cotidianas, configuraram-se como protetores da saúde mental infantil. Em contrapartida, a discórdia familiar, o clima emocional hostil e conflituoso, os problemas ocupacionais, a instabilidade financeira e o baixo suporte social foram identificados como favorecedores de processos de desadaptação infantil.

\section{- $\quad$ Adversidades do ambiente familiar}

Segundo Matos et al. (2015) vários estudos têm abordado os fatores psicossociais e ambientais por serem esses considerados desencadeadores de estresse e modificadores do ambiente, promovendo interferências no comportamento dos indivíduos. Dentre os fatores psicossociais ressaltaram a desestruturação familiar, o desemprego, a pobreza e a dificuldade de acesso à saúde e a educação, e quanto aos fatores ambientais destacaram as condições de doenças na família, morte de um ente querido, divórcio, entre outros.

As dificuldades econômicas e o baixo nível de escolaridade parental são considerados importantes fatores de risco por se caracterizarem como adversidades crônicas que atingem as famílias (Garmezy \& Masten, 1994). Em um estudo realizado por Lengua, Bush, Long, Kovacs e Trancik (2008), com 189 crianças, na faixa etária de oito a 12 anos de idade, foi verificado que o risco socioeconômico, definido por baixa renda familiar e a baixa escolaridade materna, apresentaram associações positivas e significativas com maiores níveis de problemas internalizantes e externalizantes para as crianças. Destacaram ainda que o risco socioeconômico apresentou maior efeito sobre os problemas de comportamento em comparação aos outros fatores contextuais de risco examinados.

As variáveis baixo nível socioeconômico e a ocupação materna foram identificadas como preditoras de problemas comportamentais em crianças em situações de vulnerabilidade social, em um estudo conduzido por Bele, Bodhare, Valsangkar e Saraf (2014) com 370 crianças na faixa etária de cinco a 10 anos, residentes em favelas urbanas da India. 
Com base em um estudo qualitativo, Sousa (2015) analisou a trajetória social de quatro alunos com baixo rendimento escolar do $3^{\circ}$ ano do Ensino Fundamental. Foram realizadas entrevistas com os pais ou responsáveis das crianças e as análises apontaram para a combinação das condições de baixo nível socioeconômico das famílias e a baixa escolarização dos pais com o desempenho escolar prejudicado das crianças. A baixa renda familiar também foi investigada no estudo de Anhalt, Telzrow e Brown (2007) verificando que tal variável no período perinatal esteve associada a maiores níveis de problemas de comportamento externalizante para crianças na primeira série do ensino fundamental.

A partir de um estudo transversal, Assis, Avanci e Oliveira (2009) analisaram a associação de determinantes sociodemográficas com o desenvolvimento de problemas de comportamento e de competência social das crianças. Participaram 479 crianças com idade entre seis e 13 anos de escolas públicas do interior do Rio de Janeiro. Foram investigadas as variáveis socioeconômicas, a estrutura familiar, a escolaridade dos pais, a cor da pele da criança, os problemas de comportamento e a competência social. Verificaram que as crianças com baixo nível socioeconômico, com cor da pele negra, com pais de baixa escolaridade, e vivendo em famílias monoparentais ou compostas por madrasta/padrasto apresentaram mais prejuízos quanto a competência social e mais problemas de comportamento.

Saur e Loureiro (2014) realizaram um estudo de coorte com 677 crianças, na faixa etária de 10 e 11 anos de idade, objetivando analisar as possíveis associações entre as características familiares e o desempenho comportamental das crianças em idade escolar diferenciadas pelo gênero, visando investigar os problemas comportamentais e emocionais. Dentre os vários achados, as análises dos problemas comportamentais indicaram associação para os meninos com o baixo nível socioeconômico e para as meninas com a baixa escolaridade materna e com famílias mais numerosas.

Carmo e Alvarenga (2012) examinaram as relações entre as variáveis sociodemográficas e as práticas coercitivas das mães de crianças com idade de cinco anos. Participaram do estudo 40 mães casadas ou em união estável distribuídas em dois grupos, 20 mães com nível socioeconômico baixo e 20 mães com nível socioeconômico médio/alto. Constataram que as mães com baixo nível socioeconômico, utilizaram com mais frequência a punição física como prática educativa. Verificaram também correlações entre menor escolaridade materna e mais prática de punição física.

Dentre as variáveis do ambiente familiar consideradas como de risco ao desenvolvimento infantil destacam-se a punição física e o conflito conjugal, tão prejudiciais às crianças quanto as variáveis sociodemográficas. 
Com relação à punição física, Toth e Cicchetti (2010) argumentaram que se trata de uma prática educativa que contribui para as falhas no desenvolvimento da maturação psicológica da criança, devido a problemas na regulação do afeto advindos da exposição à violência. Bordin et al. (2009), conduziram um estudo em Embu, São Paulo, com crianças e jovens na faixa etária de seis a 17 anos de idade, visando examinar a relação entre punição física severa, com tipos específicos de problemas de saúde mental. Verificaram associações entre a punição física severa e os problemas externalizantes, quando as crianças e adolescentes não estavam expostos a ansiedade ou depressão materna.

Ao avaliar os múltiplos problemas de saúde mental de mães e filhas, Loeber, Hipwell, Battista, Sembower e Stouthamer-Loeber (2009) verificaram a associação entre as práticas parentais inadequadas, como a punição física, o pouco afeto materno e a monoparentalidade, à múltiplos problemas de saúde mental de meninas de sete a 11 anos, de classe social baixa.

As crenças educacionais dos pais foram destacadas por Vitolo, Fleitlich-Bilyk, Goodman e Bordin (2005) por meio de um estudo transversal, tendo como participantes 454 crianças de sete a 11 anos de idade de escolas públicas e particulares do interior de São Paulo. Constataram que a crença no valor positivo do castigo físico esteve associada a maior possibilidade de um pai ou responsável agredir uma criança. Também verificaram que a atitude de bater com o cinto esteve associada a problemas de conduta e a problemas de saúde mental dos escolares, quando os pais/cuidadores apresentavam problemas de saúde mental e condições socioeconômicas desfavoráveis.

Por meio de um estudo qualitativo exploratório, Antoni e Batista (2014) objetivaram identificar e avaliar os fatores de risco ocorridos no microssistema familiar. Para tanto, realizaram um estudo de caso, baseado em informações de uma mãe, de 41 anos, casada desde os 17 anos e com sete filhos. Essa família encontrava-se em acompanhamento pelo Conselho Tutelar, Vara da Infância e Juventude, do interior do Rio Grande do Sul, em decorrência de abuso físico e negligência contra as crianças e adolescentes por parte dos pais/cuidadores. Identificaram a presença de múltiplas situações de risco, tais como, histórico de abuso sofrido pelos próprios pais na infância, experiência de baixo apoio familiar, alcoolismo do esposo, estresse parental, sintomatologia psicopatológica dos pais, práticas educativas inadequadas, episódios de violência e a presença de problemas de comportamento nos filhos.

Goodman, Fleitlich-Bilyk, Patel e Goodman (2007) por meio de um estudo realizado no contexto brasileiro, com crianças em idade escolar na faixa etária entre sete e 14 anos, identificaram a punição física como um dos fatores de risco para problemas de saúde mental infantil. Verificaram também que a maior frequência de indicadores de psicopatologia esteve 
relacionada ao sexo masculino, ao convívio numa família não-tradicional, ao estresse dos pais, a saúde geral precária da criança, a vivência em área perigosa, ao baixo Quociente Intelectual (QI) e a repetência de um ano na escola. Além disso, constataram diferenças quanto aos fatores de risco para diferentes tipos de psicopatologia, a saber, os problemas comportamentais em geral, mostraram-se mais associados a viver numa família nãotradicional, ao abuso de álcool na família, ao estresse dos pais e a punição física severa; os sintomas emocionais mostraram-se mais associados ao sexo feminino, ao estresse dos pais, a saúde geral precária; e a hiperatividade mostrou-se associada ao sexo masculino e ao baixo QI.

Outro fator de risco reconhecido por uma associação com problemas comportamentais, cognitivos e emocionais das crianças, diz respeito ao conflito conjugal. Segundo Benetti (2006), a exposição da criança ao conflito conjugal dos pais favorece estados afetivos internos de intenso sofrimento psíquico, com estresse e alterações emocionais e fisiológicas. O autor considera que as crianças se esforçam para controlar ou regular as relações parentais disfuncionais, na tentativa de diminuir a tensão familiar, entretanto, essas situações são dificilmente resolvidas, tendo como resultado a organização de representações do self e dos relacionamentos com adultos de forma agressiva e negativa.

A discórdia conjugal, segundo Ferriolli et al. (2007) foi apontada como um risco familiar que apresenta associação com a saúde mental infantil. Tal dado foi verificado por meio de um estudo transversal com 100 crianças entre seis e 12 anos de idade e seus familiares, cadastradas em um núcleo do Programa Saúde da Família. Foram avaliadas variáveis do contexto familiar como o nível socioeconômico, eventos adversos, estresse materno, depressão materna, organização e estruturação do ambiente familiar. Segundo as referidas autoras, os problemas externalizantes, caracterizados por transtornos de déficit de atenção e hiperatividade e de conduta, foram influenciados pelos fatores de risco, discórdia conjugal severa, desvantagem socioeconômica, tamanho grande da família, criminalidade paterna e transtorno mental da mãe. Inversamente, foram identificados como fatores de proteção, famílias com até quatro filhos, pais apoiadores e adequado estabelecimento de limites e regras. Para os transtornos de déficit de atenção e hiperatividade, destacaram os seguintes fatores de risco: a disfunção conjugal, a ruptura da família, a história psiquiátrica parental e o estresse familiar, acrescidos de práticas disciplinares intrusivas e severas. Com relação ao transtorno de conduta, destacaram o baixo status socioeconômico da família, enquanto os transtornos emocionais foram associados a fatores como exposição precoce a 
ambientes incontroláveis, acúmulo de eventos de vida adversos e a presença de um genitor com transtorno.

Sá, Bordin, Martin e Paula (2010) com base em um estudo realizado em uma comunidade urbana de baixa renda com 67 crianças e adolescentes de quatro a 17 anos de idade, verificaram que as famílias com um fator de risco reconhecido para problemas de saúde mental, geralmente experimentavam também outros fatores de riscos, tais como, violência conjugal física grave contra a mãe, punição física grave de crianças, ideação suicida da mãe e embriaguez do pai/padrasto.

O relacionamento conjugal foi abordado também no estudo de Fantinato e Cia (2015) realizado com 40 pais de crianças pré-escolares visando correlacionar as variáveis relacionamento conjugal, as habilidades sociais educativas paternas e os comportamentos infantis. Verificaram relação entre o baixo repertório de habilidades sociais educativas com variáveis do relacionamento conjugal negativas e problemas de comportamento das crianças.

Cid (2015) realizou um estudo com o objetivo de verificar as possíveis associações das atividades cotidianas familiares à saúde mental das crianças, com 321 responsáveis por crianças do ensino fundamental de escolas públicas de uma cidade do interior de São Paulo. Constatou a associação de prejuízos na saúde mental infantil, quando da presença de brigas familiares. A análise também indicou maiores bons níveis de comportamento pró-social nas famílias que valorizavam as regras e as responsabilidades.

Com base em uma revisão sistemática da literatura nacional e internacional dos últimos dez anos, Hameister, Barbosa e Wagner (2015) examinaram o conflito conjugal e suas reverberações na parentalidade e no desenvolvimento das crianças, tendo analisado 76 artigos com a temática conflito na dinâmica familiar. Verificaram que filhos de casais que apresentaram dificuldades no manejo do conflito conjugal, sofreram com as piores práticas parentais, menor desenvolvimento de estratégias de regulação emocional, dificuldades para lidar adequadamente com os conflitos, além de maiores níveis de ansiedade e depressão.

Em síntese, os estudos citados sinalizaram que a presença de múltiplas condições de risco do ambiente familiar se relacionaram a maior vulnerabilidade das crianças. Segundo Halpern e Figueiras (2004), o efeito cumulativo de múltiplos fatores de risco tem mais impacto que fatores isolados, do mesmo modo que, adversidades duradouras ou que se repetem com frequência, são mais prejudiciais ao desenvolvimento das crianças.

Dentre as condições de adversidades reconhecidas pelo seu impacto para o desenvolvimento infantil, destaca-se a psicopatologia dos pais, em especial a convivência com a depressão materna. Em famílias afetadas pela depressão materna, a provisão de suporte 
social pode ser ainda mais comprometida, devido à dificuldade da mãe em ajudar a criança em idade escolar a manter o foco no ambiente cognitivo, intelectual e social (Goodman et al., 2011).

Considerando o foco de interesse desse estudo, a seguir serão abordados estudos que trataram das implicações da depressão materna para as crianças em idade escolar.

\subsection{A convivência com a Depressão Materna: implicações para as crianças em idade escolar}

A depressão configura-se como um transtorno mental impactante na qualidade de vida da população, podendo afetar a capacidade do indivíduo manter o cuidado e as suas responsabilidades diárias, envolvendo também prejuízos nas suas interações. Trata-se de um transtorno comum e grave, que afeta negativamente os sentimentos e o comportamento das pessoas, com manifestações de tristeza ou perda de interesse em atividades prazerosas. Os sintomas principais característicos do transtorno são: sentimento de tristeza, perda de interesse nas atividades, alterações no apetite, dificuldades com o sono, perda de energia ou fadiga aumentada, sentimento de inutilidade ou culpa, diminuição das capacidades de pensar, se concentrar ou tomar decisões e em casos graves, pensamentos de morte ou suicídio (American Psychiatric Association, 2015).

Segundo a Organização Mundial de Saúde (2017), a depressão pode ser classificada como leve, moderada ou grave, dependendo do número e gravidade dos sintomas apresentados e da capacidade do paciente em desempenhar suas atividades cotidianas, seguindo um padrão episódico, que no seu curso pode se tornar crônico. Considera-se que a associação entre a depressão e os eventos adversos tais como pobreza, desemprego, morte de um ente querido, separação conjugal, doenças físicas, problemas com álcool e drogas, dentre outros, podem aumentar o risco de tal transtorno. Globalmente, estima-se que 350 milhões de pessoas são afetadas pela depressão, dentre essas, incluem-se mais mulheres do que os homens, sendo a depressão uma das principais causas de incapacidade em todo o mundo.

Andrade et al. (2012) avaliaram mais de 5000 adultos na área metropolitana de São Paulo, tendo verificado a prevalência dos transtornos de ansiedade $(19,6 \%)$ e de humor (11\%). Dentre os transtornos de humor, a depressão destacou-se como a mais frequente na população geral $(9,4 \%)$ e apresentou associação com menores níveis econômicos e de 
escolaridade. Baseado em um estudo de prevalência, Molina et al. (2012) destacaram a presença de mais sintomas depressivos nas mulheres, com quatro a sete anos de escolaridade e com baixo nível socioeconômico. Na mesma direção, Cunha, Bastos e Duca (2012) também identificaram relações entre tal transtorno com menor escolaridade e menor renda familiar.

Estudos de prevalência vêm apontando uma maior taxa de depressão para o sexo feminino (Andrade et al., 2012; Cunha et al., 2012; Almeida \& Faro 2016), especialmente no início da idade adulta que inclui o período reprodutivo (Markowitz, 2008), assim, muitas mulheres que apresentam depressão são mães. Pelas peculiaridades do transtorno, incluindo a recorrência, a sintomatologia depressiva interfere negativamente na função materna e na saúde mental das crianças (Mendes et al., 2008).

Considera-se que a recorrência do transtorno depressivo ao longo da vida, pode implicar em desfechos negativos para o exercício da maternidade, para a interação mãecriança e para o ambiente familiar, já que, na maioria das culturas, a mãe exerce o papel de principal cuidadora dos filhos (Loosli, Pizeta \& Loureiro, 2016). Nessa direção, destaca-se que alguns fatores relacionados à tal transtorno, como a falta de envolvimento emocional, desamparo, irritabilidade e a hostilidade, podem interferir de forma significativa na função parental (Duggal, Carlson, Sroufe \& Egeland, 2001).

De acordo com Mian, Tango, Lopes e Loureiro (2009), o transtorno depressivo materno favorece o afastamento da mãe com relação à rotina da família, com a falta de suporte adequado e não fornecimento de apoio e afeto suficientes para o desenvolvimento satisfatório das habilidades esperadas por parte das crianças. Shannon, Beauchaine, Brenner, Neuhaus e Kopp (2007) ressaltaram que as mães com depressão demostram dificuldade de prover atenção, carinho e afeto aos filhos, o que aumenta a probabilidade das crianças apresentarem problemas emocionais, comportamentais e interpessoais. Goodman e Gotlib (1999) verificaram nas comparações entre mães deprimidas e mães sem transtornos, que as primeiras são mais propensas a apresentarem elevados índices de negatividade em seus contatos interpessoais, tendendo a terem um controle mais coercitivo e inconsistente, menos envolvimento no relacionamento com seus filhos, verbalizando mais afirmações críticas e menos afirmações de suporte.

Os filhos de mães com depressão podem apresentar dificuldades diversas, de acordo com a faixa etária em que se encontram (Pilowsky, Wickramaratne, Nomura, \& Weissman, 2006), considerando que tal transtorno se configura como uma condição de adversidade com impacto negativo para o desenvolvimento emocional e comportamental das crianças (Elgar, Waschbusch, Mcgrath, Stewart, \& Curtis, 2004). No período escolar, os estudos vêm 
abordando a influência da depressão materna para os desfechos de problemas comportamentais dada a importância da socialização para esse momento do desenvolvimento (Pizeta, Silva, Cartafina, \& Loureiro, 2013). Diante da magnitude desse transtorno e da amplitude do seu impacto para os desfechos de problemas comportamentais das crianças, justifica-se a relevância de estudos com foco nessa problemática.

Em estudo desenvolvido por Mendes (2009) na atenção primária, com uma amostra de baixo nível socioeconômico, a depressão materna foi considerada como uma condição de adversidade, favorecedora de problemas comportamentais para as crianças em idade escolar, uma vez que as crianças filhas de mães depressivas mostraram 2,8 vezes mais chances de apresentarem problemas comportamentais, quando comparadas às crianças que não conviviam com a depressão materna.

No estudo correlacional de Fanti e Henrich (2010), a co-ocorrência dos problemas comportamentais externalizantes e internalizantes de crianças de dois a 12 anos foi associada à convivência com a depressão materna, sendo esta considerada como um importante fator de risco ambiental ao desenvolvimento infantil. Observaram que, tanto os fatores de risco individuais quanto os ambientais, influenciaram o desenvolvimento dos problemas comportamentais externalizantes das crianças, destacando que os comportamentos internalizantes foram associados exclusivamente à depressão materna.

De acordo com Bagner, Pettit, Lewinsohn e Seeley (2010), a convivência com a depressão materna durante o primeiro ano de vida dos filhos, aumentou os riscos das crianças apresentarem mais problemas de comportamento externalizante e internalizante aos 12 anos de idade. O impacto negativo da depressão materna para o comportamento das crianças foi verificado por Garber e Little (1999), os quais relataram que crianças escolares que conviviam com mães depressivas apresentaram mais sintomas internalizantes e externalizantes, maior déficit de competência acadêmica e social e maiores índices de problemas psiquiátricos, quando comparadas a filhos de mulheres sem depressão.

Com base em uma revisão da literatura, Loosli e Loureiro (2010) relataram a presença de diferenças entre os sexos em crianças expostas à depressão materna na maioria dos estudos empíricos incluídos. As autoras identificaram nos estudos analisados o predomínio de problemas de comportamento externalizante para os meninos no período pré-escolar; dificuldades internalizantes para as meninas e externalizantes para os meninos na fase escolar; e, na adolescência, predomínio de problemas internalizantes para as meninas.

Ao avaliar a saúde mental de crianças e adolescentes de seis a 17 anos, Ghandour, Kogan, Blumberg, Jones e Perrin (2012) constataram que uma condição precária de saúde 
mental por parte das mães, foi significativamente associada aos problemas de saúde mental dos filhos, uma vez que as crianças filhas de mães com problemas de saúde mental demonstraram de quatro a sete vezes mais chances de apresentarem um distúrbio emocional ou comportamental.

A influência da depressão materna para o desenvolvimento de problemas de comportamento nas crianças foi verificada por Conners-Burrow (2016) em um estudo longitudinal, tendo como participantes 1844 famílias. As avaliações ocorreram em um primeiro momento na idade de 14 meses da criança e num segundo momento na idade de 11 anos. As análises mostraram associações entre os sintomas depressivos maternos precoces e o surgimento de problemas comportamentais posteriores das crianças, ou seja, o convívio precoce da criança com sintomas depressivos maternos, considerados leves, possivelmente aumentou os riscos das crianças apresentarem problemas de comportamento internalizante e externalizante no período escolar.

Shaw, Hyde e Brennan (2012) estudando uma coorte de meninos de baixa renda, verificaram que a exposição à depressão materna entre um ano e meio e dois anos de idade mostrou-se um importante fator de risco para a presença de comportamento antissocial na faixa etária dos 10 aos 17 anos dos filhos. Wickramaratne et al. (2011) examinaram as associações entre a remissão da depressão materna e as possíveis mudanças nos sintomas psiquiátricos, problemas comportamentais e funcionamento das crianças e adolescentes, durante um período de um ano após a remissão dos sintomas depressivos maternos. Participaram do estudo 151 crianças e adolescentes, na faixa etária de sete a 17 anos e suas respectivas mães com sintomas depressivos. A análise mostrou associação entre a remissão dos sintomas depressivos maternos e a diminuição dos problemas de comportamento das crianças e adolescentes.

As associações entre sintomas maternos graves de depressão e ansiedade no período pré-natal e posteriores problemas emocionais e comportamentais dos filhos na faixa etária de 10 e 11 anos de idade, foram examinadas por Leis et al. (2014) com uma amostra de 2891 díades mãe-criança. Os problemas das crianças foram avaliados de acordo com o relato das mães e dos professores por meio do instrumento SDQ. Constataram a associação entre a exposição a sintomas depressivos maternos graves durante a gestação com o aumento do escore total de dificuldades no SDQ, de acordo com o relato dos professores.

Considera-se que a depressão materna além de favorecer os problemas de comportamento dos escolares, também é reconhecida por prejudicar o desempenho acadêmico das crianças. De acordo com Papalia e Feldman (2013), a atenção aos indicadores de 
desempenho escolar nessa faixa etária, torna-se uma questão importante, devido ao início da escolarização formal e da alfabetização. A realização de tarefas intelectuais e sociais predominam nessa fase de desenvolvimento, com destaque para os novos aprendizados junto aos pares, à educação formal e à família, que nortearão sua competência e sua capacidade produtiva. Dessa forma, justifica-se a relevância de se colocar em foco a influência de tal transtorno para o desempenho acadêmico dos escolares.

A partir de um estudo de coorte realizado com mais de um milhão de crianças nascidas na Suécia, Shen et al. (2016) verificaram as associações entre a depressão parental e o desempenho escolar das crianças e jovens no final do ensino médio. O estudo envolveu avaliações em diferentes períodos de vida das crianças, a saber: período pré e pós-natal, e durante as idades de um a cinco anos, seis a 10 anos e 11 a 16 anos, tendo constatado a associação tanto da depressão materna como da paterna, a um pior desempenho escolar na faixa etária de 16 anos.

Galéra et al. (2011) relataram que a exposição das crianças à depressão materna pode favorecer as dificuldades relativas à desatenção e hiperatividade. Por meio da avaliação de uma coorte de 2.057 crianças, constataram que a convivência com mães deprimidas aos cinco meses de idade, configurou-se como um dos fatores de risco associados à presença de altos níveis de sintomas de hiperatividade, impulsividade e déficit de atenção por parte das crianças aos oito anos de idade.

Ao comparar crianças filhas de mães que tiveram depressão pós-parto e crianças da comunidade, Kersten-Alvarez et al. (2012) constataram que os filhos de mães com depressão pós-parto, na faixa etária de cinco anos, apresentaram menor capacidade de resiliência e menor competência social na relação com seus pares. Verificaram que as crianças desse grupo apresentaram mais dificuldades com relação ao ajustamento no ambiente escolar, envolvendo a capacidade de lidar com as diferentes situações desse ambiente, e ainda, observaram que as meninas desse grupo apresentaram também mais dificuldades quanto à inteligência verbal.

Pavan, Pizeta e Loureiro (2012) estudaram as influências da depressão materna para o comportamento e desempenho escolar das crianças, em idade escolar, tendo como participantes 38 duplas mães-crianças. Verificaram que aproximadamente dois terços das crianças avaliadas apresentaram dificuldades comportamentais e de desempenho escolar, evidenciando o possível impacto da depressão materna. Identificaram também que as mães das crianças com tais dificuldades comportamentais e de desempenho escolar, apresentavam menos anos de escolaridade. 
Loosli et al. (2016) compararam as diferenças de sexo relativas ao comportamento e ao desempenho escolar de crianças que conviviam com a depressão materna, correlacionando os desfechos comportamentais e escolares. Participaram do estudo 40 crianças na faixa-etária de sete a 12 anos e suas mães com história clínica de Transtorno Depressivo Recorrente. As análises mostraram correlações negativas entre os problemas emocionais das meninas com habilidades de escrita, e problemas de relacionamento com dificuldades escolares gerais e domínios de leitura e escrita, entretanto, quanto ao grupo de meninos, não foram identificadas correlações entre o comportamento e o desempenho escolar.

As crianças quando em contato com a depressão materna encontram-se expostas a outros riscos, que associados, podem potencializar os problemas de desenvolvimento (Mendes et al., 2008).

Diversos estudos têm abordado as múltiplas condições contextuais de risco que coexistem no ambiente familiar das crianças que convivem com a depressão materna. Nesse sentido, é relevante considerar que os efeitos cumulativos de múltiplos fatores de risco, geralmente presente nos contextos de convivência com a depressão materna, pode aumentar a chance de resultados negativos para as crianças (Evans, Li, \& Whipple, 2013). No estudo de revisão realizado por Halpern e Figueiras (2004), o efeito cumulativo de múltiplos fatores de risco foi apontado como uma condição de mais impacto que a presença de fatores isolados, considerando que as adversidades duradouras ou que se repetem com frequência são as mais prejudiciais ao desenvolvimento das crianças.

Baseado em um estudo de revisão da literatura, Pizeta et al. (2013) abordaram as associações da depressão materna ao comportamento e à saúde mental de crianças escolares e verificaram que a depressão materna influenciou o comportamento e a saúde mental infantil, configurando-se como uma condição de risco nas diferentes etapas do desenvolvimento das crianças. Além disso, o estudo também apontou que características do ambiente familiar, tais como dificuldades quanto ao estilo parental, organização familiar e interações intrafamiliares, se configuraram como variáveis associadas a depressão materna, caracterizando condições contextuais adversas, que concorreram para as dificuldades comportamentais e psicopatológicas das crianças.

Dada a importância das associações entre a depressão materna e as variáveis de risco contextuais para os desfechos de desenvolvimento das crianças, a seguir serão abordados alguns estudos que destacaram a associação entre tal transtorno com as variáveis sociodemográficas e as práticas parentais. 
Gross, Shaw, Burwell e Nagin (2009) conduziram um estudo longitudinal ao longo de doze anos, com 289 crianças do sexo masculino e suas respectivas mães com sintomas depressivos, com intuito de verificar as associações entre várias formas de comportamento disruptivo na primeira infância, trajetórias subsequentes de sintomas depressivos maternos e comportamentos problemáticos de adolescentes. Identificaram que a variável renda familiar foi significativamente menor em todas as famílias expostas à trajetória grave crônica da depressão materna.

Riley et al. (2009) constataram que a depressão materna associou-se significativamente à variáveis relacionadas ao ambiente familiar e aos cuidados parentais, destacando que nas famílias de baixa renda, essas variáveis foram consideradas como mediadoras da associação entre a depressão materna e os problemas emocionais e comportamentais dos filhos de quatro a 10 anos. No estudo de Tompson et al. (2010), o transtorno depressivo materno foi fortemente associado à presença de mais transtornos mentais, tais como os transtornos de humor, de ansiedade, de conduta, e desafiador opositivo, por parte dos filhos, entre oito e 12 anos, predominantemente de nível socioeconômico baixo.

Ao realizarem um estudo de coorte longitudinal prospectivo em Québec e Ontário com 240 gestantes, Bouvette-Turcot et al. (2017) examinaram as associações entre as adversidades maternas ocorridas na infância e o desenvolvimento de sintomas depressivos na idade adulta com as condições sociodemográficas familiares. As avaliações ocorreram durante o período gestacional e em vários momentos posteriores por meio de visitas domiciliares e de observações sistemáticas de laboratórios. As análises mostraram que mais adversidades na infância combinados com níveis mais elevados de sintomas depressivos, mostraram-se associados a um ambiente familiar com menos recursos socioeconômicos.

Visando avaliar o impacto preditivo da depressão materna e da exposição da criança a fatores de risco, Barker, Copeland, Maughan, Jaffee e Uher (2012) realizaram um estudo longitudinal acompanhando crianças do primeiro ano de vida até os sete anos de idade. Os resultados apontaram que as crianças filhas de mães com depressão clínica foram significativamente mais propensas a estarem expostas a 10 dos 11 fatores de risco avaliados, dentre eles, baixo nível socioeconômico, monoparentalidade, abuso físico, baixa escolaridade materna, consumo de drogas e álcool e envolvimento com a polícia, quando comparadas às crianças filhas de mães não depressivas.

Outra variável que vem sendo associada à depressão materna refere-se às práticas parentais. De acordo com Cummings e Kouros (2009) alguns sintomas característicos do transtorno depressivo, tais como a instabilidade emocional, negligência e o comportamento 
intrusivo, podem interferir de forma significativa na função parental. Nesse sentido, Psychogiou e Parry (2014) relataram que as dificuldades presentes nos indivíduos deprimidos, tais como o aumento de afetividade negativa, as estratégias empobrecidas de regulação emocional, os déficits das funções executivas, a motivação reduzida e a ruminação parental, associadas à pensamentos negativos e a déficits na resolução de problemas, podem interferir na parentalidade de pais depressivos e nos desfechos infantis.

Em um estudo longitudinal, Callender, Olson, Choe e Sameroff (2012) examinaram as associações entre a depressão parental e o comportamento externalizante dos filhos. As crianças foram avaliadas quanto aos problemas comportamentais na idade de cinco anos, tendo os pais como informantes. As análises indicaram que mais sintomas depressivos de mães e pais estiveram relacionadas a mais avaliações negativas de ambos os pais em relação ao comportamento de seus filhos. Entretanto, mais avaliações negativas no que se refere ao comportamento dos filhos, foram associadas a uma maior frequência de punição física por parte dos pais, sendo que esta foi preditora de maiores níveis de problemas de comportamento externalizante por parte das crianças, aos cinco anos de idade.

A maior gravidade da depressão materna e os padrões de apego de controle, punitivo ou de cuidado, no período pré-escolar, foram preditores de problemas internalizantes e externalizantes para as crianças aos oito anos de idade no estudo conduzido por DuboisComtois, Moss, Cyr e Pascuzzo (2013). Esses autores constataram que a qualidade da interação mãe-criança apresentou um papel moderador da associação entre depressão materna e desenvolvimento de problemas comportamentais na infância.

Muratori (2014) explorou o papel da depressão materna e das práticas parentais frente às mudanças nos problemas agressivos das crianças, após um programa de tratamento de múltiplos componentes para crianças com diagnóstico de transtorno de conduta e comportamento opositivo desafiador. Participaram 62 crianças do sexo masculino, na faixa etária de oito a 11 anos de idade, diagnosticadas com problemas comportamentais. Constatou que a diminuição da disciplina inconsistente e os baixos níveis de sintomas depressivos maternos foram preditores da melhora nos comportamentos agressivos das crianças.

Duncombe, Havighurst, Holland e Frankling (2012) avaliaram a influência das características parentais para os desfechos de problemas de comportamento das crianças e dificuldades quanto à capacidade de regulação emocional em 373 crianças australianas na faixa etária de cinco a nove anos de idade. Os resultados apontaram associações entre os problemas de comportamento das crianças com disciplina inconsistente dos pais, 
expressividade emocional parental negativa e saúde mental dos pais, dentre elas a depressão parental.

Em um estudo longitudinal, com 1364 crianças recrutadas em 24 hospitais de 10 cidades norte americanas, Wang, Christ, Milss-Koonce, Garrett-Peters e Cox (2013), examinaram as associações e os efeitos recíprocos entre sensibilidade materna e comportamento externalizante das crianças da pré-escola à pré-adolescência (quatro a 12 anos) por meio do relato de mães, pais e professores. Verificaram que maior uso de controle rígido e menor escolaridade materna quando os filhos tinham três anos de idade, foi associado com menor sensibilidade materna nessa mesma idade. Além disso, filhos de mães com mais sintomas depressivos e mais rigidez apresentaram mais problemas externalizantes aos quatro anos de idade. Altos níveis de rigidez materna também foram associados a um maior aumento dos comportamentos externalizantes entre quatro e 12 anos.

Baseado em um estudo longitudinal, realizado em Chicago com 412 lactentes e seus cuidadores, Edwards e Hans (2015) investigaram a influência da emoção negativa na infância (temperamento difícil) e do ambiente familiar para o desenvolvimento de futuros problemas de comportamento das crianças. As avaliações foram realizadas nas residências das famílias em três períodos de desenvolvimento das crianças, a saber, cinco meses, dois anos e meio e cinco anos de idade. Dentre vários achados, as análises apontaram que as crianças com mães depressivas mostraram maior probabilidade de apresentarem problemas de comportamento externalizante e internalizante.

Com base nos estudos abordados, verifica-se que a presença de múltiplas variáveis contextuais de riscos no ambiente familiar de convivência com a depressão materna, podem potencializar os problemas de comportamento das crianças. Tal afirmativa é sustentada pela metanálise de Goodman et al. (2011), os quais examinaram a associação entre a depressão materna e os problemas emocionais e comportamentais infantis, por meio da análise de 193 estudos empíricos. Verificaram consistência nos dados quanto ao papel relevante das variáveis contextuais, tais como, pobreza, cuidados monoparentais e pertencer a minorias étnicas; e das variáveis de crianças, como ser mais jovem e do sexo feminino. Tais variáveis mostraram-se associadas ao impacto negativo para os desfechos de crianças escolares que conviviam com a depressão materna. Os autores destacaram que apesar do amplo reconhecimento do impacto negativo da depressão materna para as crianças, poucos estudos têm abordado de forma combinada com uma mesma amostra, enquanto riscos e proteção, as variáveis contextuais, como condições associadas que influenciam os desfechos para o desenvolvimento infantil. 
O presente se insere nessa lacuna ao se propor a abordar, com a mesma amostra, as condições contextuais do ambiente familiar que podem configurar-se como indicadores de adversidades ou de recursos para as crianças que convivem com a depressão materna, tendo como foco o comportamento, enquanto tarefa de desenvolvimento, típica para os escolares. Buscou-se, assim, abordar as variáveis contextuais expressas por recursos e as adversidades do ambiente familiar para grupos de crianças diferenciados pela convivência com a depressão materna e pela presença/ausência de problemas comportamentais, segundo a avaliação de mães e professoras. Considera-se que o presente estudo potencialmente, poderá contribuir com dados que instrumentem o planejamento de programas de orientação familiar, com a finalidade de favorecer às famílias o enfrentamento das adversidades, com possíveis benefícios para o comportamento das crianças.

Estabeleceu-se como hipóteses norteadoras do estudo as seguintes proposições: (a) as crianças que convivem com a depressão materna estão inseridas num ambiente familiar com menos recursos, mais estressores e mais adversidades crônicas; (b) as crianças que apresentam problemas de comportamento estão inseridas num ambiente familiar com menos recursos, mais estressores e mais adversidades crônicas; e (c) as mães avaliam as crianças com mais problemas de comportamento, em comparação a avaliação das professoras. 
2 OBJETIVOS

"





\section{Objetivos Gerais}

Comparar e correlacionar os indicadores relativos aos recursos e aos eventos estressores do ambiente familiar de crianças que convivem com a depressão materna e que, segundo a avaliação de suas mães, apresentam problemas de comportamento, e comparar tais indicadores com os apresentados por crianças que convivem com mães sem indicadores de depressão, e que não apresentam problemas comportamentais, segundo a avaliação de suas mães. Comparar e correlacionar os indicadores comportamentais das crianças, segundo a avaliação de suas mães e de suas professoras.

\section{Objetivos Específicos}

- Caracterizar e comparar o perfil sociodemográfico das famílias e crianças que convivem com a depressão materna em relação a crianças que convivem com mães sem indicadores de depressão.

- Comparar e correlacionar os indicadores relativos aos recursos e aos eventos estressores do ambiente familiar de crianças que convivem com a depressão materna em relação a crianças que convivem com mães sem indicadores de depressão.

- Comparar e correlacionar os indicadores relativos aos recursos e aos eventos estressores do ambiente familiar de crianças que apresentam problemas de comportamento, segundo a avaliação de suas mães, em relação as crianças que não apresentam problemas comportamentais, segundo a avaliação de suas mães.

- Comparar e correlacionar os recursos e eventos estressores do ambiente familiar de crianças com e sem dificuldades de comportamento, tendo por referência a avaliação de problemas de comportamento feita pelas professoras.

- Comparar e correlacionar o desempenho escolar das crianças com e sem dificuldades de comportamento, tendo por referência a avaliação de problemas de comportamento feita pelas mães e pelas professoras. 
3 MÉTODO " 

Adotou-se um delineamento transversal, correlacional, de comparação entre grupos, utilizando-se dados obtidos a partir de distintas técnicas e fontes, a saber, mães, professoras e crianças. Para o estudo correlacional, buscou-se as possíveis relações entre a depressão materna, os recursos e estressores do ambiente familiar, o comportamento infantil e o desempenho escolar. As comparações abrangeram grupos diferenciados pela presença /ausência de depressão materna e de dificuldades comportamentais das crianças, assim como comparou-se as avaliações de mães e professoras e o desempenho escolar das crianças.

\subsection{Aspectos éticos}

O projeto em questão, foi encaminhado para apreciação do Comitê de Ética em Pesquisa da Faculdade de Filosofia, Ciências e Letras de Ribeirão Preto e foi aprovado sob o número 36415514.5.0000.5407. Após a aprovação, realizou-se formalmente a apresentação do estudo à direção e aos professores, em uma reunião regular, da Escola Estadual Adolfo Alfeu Ferrero - São Joaquim da Barra-SP, enfatizando os objetivos propostos e a participação esperada, ressaltando-se o caráter voluntário da mesma. Em contato prévio com a secretária de educação do município e com a direção da referida escola, ambas já tinham dado sua anuência para a realização do estudo (APÊNDICE A).

Após esse processo, iniciou-se a coleta de dados, a partir do contato com as mães das crianças, da referida escola. Mães e professoras foram informados sobre os objetivos do estudo, e a participação ocorreu mediante a assinatura do Termo de Consentimento Livre e Esclarecido (TCLE). Enfatizou-se o compromisso das pesquisadoras com o sigilo das informações relativas a identidade pessoal, assim como a pesquisadora se colocou à disposição para acolher as eventuais dificuldades que as participantes poderiam experimentar no processo de avaliação. Foi oferecida a possibilidade da entrevista devolutiva para todas as participantes, visando orientação e/ou encaminhamento quando necessário. Do conjunto de 85 participantes, seis manifestaram interesse na entrevista devolutiva a qual foi realizada.

\subsection{Contexto do estudo}


A coleta de dados foi realizada na Escola Estadual Adolfo Alfeu Ferrero, da cidade de São Joaquim da Barra, localizada no estado de São Paulo, mesorregião de Ribeirão Preto. A cidade em questão, conta com uma população de 46.524 habitantes, segundo o censo do Instituto Brasileiro de Geografia e Estatística (IBGE/2010) e com Índice de Desenvolvimento Humano (IDH) de 0,81 . Trata-se de uma região agrícola, sendo a economia baseada principalmente na cultura da cana-de-açúcar, soja e milho, bem como na fabricação de peças agrícolas. A referida escola em 2015 apresentou um Índice de Desenvolvimento da Educação Básica (IDEB) de 6.8.

Além da escola onde ocorreu a coleta, São Joaquim da Barra conta com mais oito escolas estaduais, as quais englobam o ensino fundamental e o ensino médio; e com 14 escolas municipais, que atendem à demanda da Educação Infantil.

A escola Adolfo Alfeu Ferrero está localizada no centro da cidade, mas recebe alunos de diferentes bairros. Atualmente funciona com 16 salas de aula (quatro salas de $2^{\circ}$ ano, cinco salas de $3^{\circ}$ ano, quatro salas de $4^{\circ}$ ano e três salas de $5^{\circ}$ ano). No ano de 2015 , no período da manhã, a escola tinha 228 alunos e no período da tarde 199, totalizando 427 alunos. Segundo informações (verbais) da Secretaria da Educação do Estado, a clientela da escola, na sua maioria é de baixo nível socioeconômico.

\subsection{Participantes}

Foram avaliadas 85 díades mãe-criança, estando às crianças em idade escolar, na faixa etária de sete a 10 anos, de ambos os sexos, as quais foram distribuídas em três grupos:

- G1: 26 díades mães-crianças, cujas mães apresentavam indicadores de depressão, sistematicamente avaliados, e as crianças apresentavam problemas de comportamento, segundo a avaliação de suas mães;

- G2: 29 díades mães-crianças, cujas mães apresentavam ausência de indicadores de depressão, sistematicamente avaliados, e as crianças apresentavam problemas de comportamento, segundo a avaliação de suas mães;

- G3: 30 díades mães-crianças, cujas mães apresentavam ausência de indicadores de depressão, sistematicamente avaliados, e as crianças apresentavam ausência de problemas de comportamento, segundo a avaliação de suas mães. 
Adotou-se para as crianças como critérios de inclusão para todos os grupos: a faixa etária, a residência com a mãe biológica, a ausência de deficiência mental e de deficiências físicas aparentes e já ter frequentado pelo menos um ano do ensino fundamental. Como critérios de exclusão para todos os grupos foram considerados: crianças institucionalizadas, com deficiência física aparente, com deficiência mental e crianças que tivessem ingressado no ensino fundamental há menos de um ano.

Para a inclusão das crianças em G1 e G2, essas tinham que apresentar indicadores de dificuldades comportamentais atuais, sistematicamente avaliadas pelo instrumento SDQ, aplicado com as suas mães. Para a inclusão das crianças em G3, estas tinham que apresentar ausência de dificuldades comportamentais atuais, sistematicamente avaliadas pelo referido instrumento aplicado com as suas mães.

Para as mães adotou-se como critérios de inclusão para todos os grupos a faixa etária de 25 a 45 anos, de modo a evitar a inclusão de crianças que tivessem tido mães adolescentes. Ainda, para a inclusão em G1, considerou-se a presença de indicadores de depressão, sistematicamente avaliados pelo instrumento Questionário sobre a Saúde do Paciente-9 (PHQ9), e para a inclusão em G2 e o G3 considerou-se a ausência de tais indicadores.

As professoras foram incluídas no estudo após a autorização explícita das mães quanto a responderem sobre as características comportamentais de seus filhos na escola. Nas séries correspondentes à inclusão no estudo, a escola em questão contava com 16 professoras, e todas participaram do estudo, sendo que em média cada professora avaliou sete alunos, com a variação de 02 a 14 alunos. De modo a garantir a qualidade da avaliação das professoras com relação ao comportamento das crianças, considerou-se ainda como condição para a inclusão no estudo, a professora ter trabalhado com os alunos avaliados há pelo menos três meses.

Todas as mães e crianças contatadas foram avaliadas, sendo feita posteriormente as exclusões daquelas que não se enquadravam nos grupos pretendidos. Foi incluída apenas uma criança por família, adotando-se como critério quando da identificação de duas ou mais crianças na mesma família, a priorização das características sociodemográficas das crianças já incluídas nos grupos, de forma favorecer a homogeneidade dos mesmos.

\subsection{Percurso Amostral}


A pesquisadora, inicialmente, contatou a Diretoria de Ensino da cidade de São Joaquim da Barra afim de verificar a possibilidade de desenvolver um estudo nas escolas da cidade em questão. Foi agendada uma reunião com a Dirigente Regional de Ensino, ocasião em que a pesquisadora apresentou o projeto de pesquisa enfatizando os objetivos do estudo. Após uma avaliação criteriosa da pesquisa em questão, a dirigente aprovou a realização do estudo, disponibilizando à pesquisadora uma listagem com o nome de cinco escolas possíveis para o desenvolvimento do estudo.

Por conveniência optou-se por iniciar o contato com a Escola Estadual Adolfo Alfeu Ferrero, por ser central e reunir alunos de diferentes regiões da cidade. A pesquisadora contatou a diretora da referida escola e em uma reunião previamente agendada apresentou o projeto de pesquisa e seus objetivos, sendo autorizada a coleta de dados. A secretaria da escola disponibilizou informações referentes à quantidade de alunos matriculados no ano de 2015, totalizando 427 alunos, na faixa etária do estudo, matriculados do segundo ao quinto ano escolar.

As 427 famílias foram contatadas por meio de uma filipeta que apresentava, de forma breve, o projeto e convidava as mães para participarem do estudo. Foram enviadas 427 filipetas, por meio das crianças e destas, não retornaram 167 filipetas, e 260 foram devolvidas assinadas. Destas 106 mães/responsáveis não aceitaram participar da pesquisa e 154 mães concordaram de serem participantes do estudo. Foram agendadas por telefone as avaliações com todas as 154 famílias que concordaram em participar, e neste contato inicial, constatou-se que nove crianças entre os convites aceitos, residiam com suas avós, entrando no critério de exclusão. Das 145 famílias elegíveis, 43 mães confirmaram a avaliação, mas não compareceram no horário agendado, após pelo menos três tentativas de reagendamento. Foram avaliadas as 102 famílias elegíveis, e destas, excluiu-se ainda 17 famílias por não atenderem aos critérios de inclusão, a saber, mães adolescentes (2), mães acima de 45 anos de idade (1), crianças que residiam exclusivamente com seus pais (1), crianças sem problemas de comportamento, mas que as mães tinham indicadores de depressão (6) e crianças sem dificuldades comportamentais, mas com características pouco homogêneas com relação aos demais grupos (7).

Incluiu-se assim, 26 díades em que as mães apresentavam indicadores de depressão e as crianças apresentavam indicadores de problemas de comportamento (G1), 29 díades em que as mães não apresentavam indicadores de depressão e as crianças apresentavam indicadores de problemas de comportamento $(\mathrm{G} 2)$ e 30 díades em que as mães não 
apresentavam indicadores de depressão e as crianças não apresentavam indicadores de problemas de comportamento (G3).

A Figura 1 apresenta o percurso amostral.

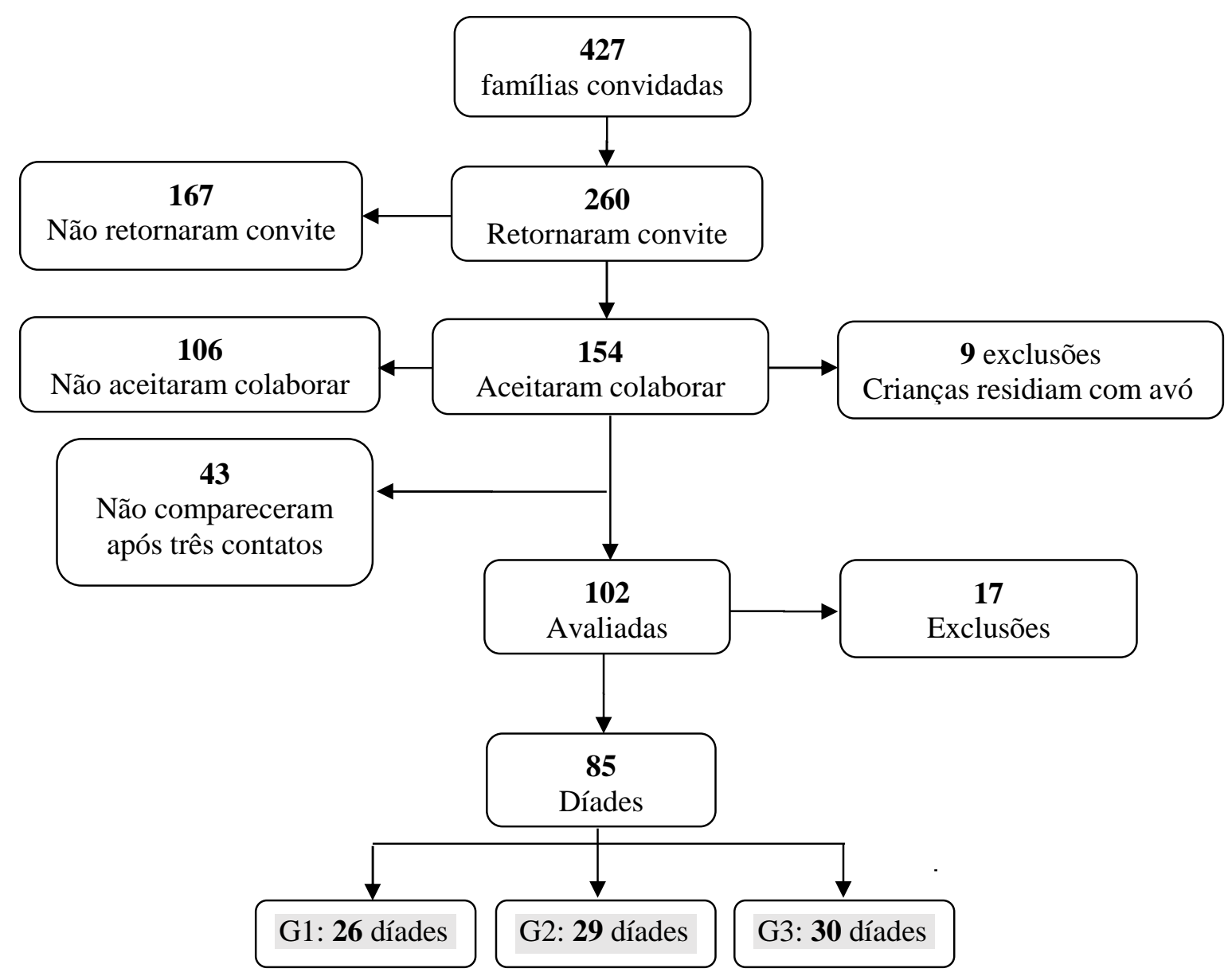

Figura 1. Percurso amostral de G1, G2 e G3.

\subsection{Instrumentos}

Para a inclusão nos grupos:

- Matrizes Progressivas Coloridas de Raven: instrumento padronizado por Angelini, Alves, Custódio, Duarte e Duarte (1999), com a finalidade de avaliar o nível intelectual de 
crianças brasileiras de cinco a 11 anos de idade. Caracteriza-se como um teste de inteligência não verbal, cujo objetivo é avaliar o raciocínio analógico enquanto fator geral. O teste de Raven é constituído por três séries: A, AB e B, cada uma com 12 problemas.

A inclusão no estudo teve por objetivo avaliar o nível cognitivo das crianças, considerado critério de inclusão e exclusão para todos os grupos, tendo por referência para a inclusão o percentil $\geq 25$.

- Questionário Sobre a Saúde do Paciente - 9 (PHQ-9): trata-se de um instrumento adaptado do Primary Care Evaluation of Mental Disorders (PRIME-MD), que possibilita rastrear os sinais e sintomas da Depressão Maior atual, assim como a classificação de níveis de gravidade. O PHQ-9 é baseado nos critérios diagnósticos para Desordem de Depressão Maior do DSM-IV, validado por Spitzer, Kroenke e Williams (1999) e por Kroenke, Spitzer e Williams (2001), sendo composto por nove itens. Cada item é constituído por uma escala ordinal que mede a frequência dos sinais e sintomas da depressão nas últimas duas semanas (ANEXO B).

Tem por suporte as seguintes pontuações possíveis: 0 = nenhuma vez; 1 = vários dias; 2 = mais da metade dos dias; 3 = quase todos os dias. O escore total é obtido pela somatória dos itens que pode variar de zero a 27 , sendo considerado indicador positivo de sinais e sintomas da Depressão Maior valores maiores ou iguais a 10. Quanto à gravidade, o escore é classificado da seguinte forma: de zero a cinco (ausência de indicadores de Depressão Maior); de seis a nove (indicadores de Depressão Maior leve); de 10 a 14 (indicadores de Depressão Maior moderada); maiores de 20 (indicadores de Depressão Maior grave). No presente estudo, considerou-se como presença de depressão os indicadores correspondentes à classificação de gravidade moderada e grave.

$\mathrm{O}$ instrumento apresenta uma excelente validade, com uma área sob a curva ROC de 0,998 ( $\mathrm{p}<0,001$ ), baseado em estudo psicométrico realizado no Brasil. A nota de corte maior ou igual a 10 mostrou-se a mais adequada para rastreamento da depressão, com sensibilidade (S) de 1,00, especificidade (E) de 0,98, valor preditivo positivo de 0,97, valor preditivo negativo de 1,00 e eficácia diagnóstica de 0,999 (Osório et al., 2009). A versão em português utilizada no estudo foi traduzida pela $\operatorname{Pfizer}^{1}$ (1999).

A inclusão no estudo teve por finalidade a identificação de indicadores de depressão, sendo a presença dada por escore $\geq 10$, condição para a inclusão no G1, e a ausência por escore < 10, como indicação para inclusão no G2 e G3.

\footnotetext{
${ }^{1}$ Copyright (C) 2005 Pfizer Inc; Todos os direitos reservados. Reproduzido sob permissão.
} 
- Questionário de Capacidades e Dificuldades (SDQ): elaborado em 1994, por Goodman, objetivando avaliar desordens psiquiátricas relacionadas ao comportamento social. Sua finalidade é a avaliação do comportamento por meio do rastreamento de capacidades e dificuldades de crianças e adolescentes, na faixa etária de quatro a 16 anos. $\mathrm{O}$ instrumento em questão encontra-se gratuitamente disponível na internet em mais de 40 idiomas (www.sdqinfo.com). A aplicação pode ser realizada com pais, professores e jovens a partir de 11 anos. Foi traduzido para o português e adaptado às características sócio culturais brasileiras por Fleitlich, Córtazar e Goodman (2000). Trata-se de um questionário curto, simples e com boa aceitação pelos respondentes (ANEXO F e G).

O SDQ é composto por 25 itens, subdivididos em cinco subescalas: Sintomas Emocionais, Problemas de Conduta, Hiperatividade, Problemas de Relacionamento com Colegas e Comportamento Pró-Social. As alternativas de resposta para cada um dos itens são: verdadeiro, mais ou menos verdadeiro e falso, com pontuação variando entre zero, um e dois, dependendo do item. Cada uma das escalas do questionário pode ser pontuada com escores que variam entre zero a 10 pontos. As pontuações nas escalas de dificuldades (Escalas de Sintomas Emocionais, Escalas de Problemas de Conduta, Escala de Hiperatividade e Escala de Problemas de Relacionamento com Colegas) são somadas para constituir o Escore Total de problemas, com pontuação máxima de 40 pontos, sendo que quanto maior o escore, mais problemas comportamentais. Na Escala de Comportamento Pró-Social, relativa a recursos, quanto maior a pontuação, maior a capacidade. A soma de cada subescala e a soma total, permitem a classificação da criança em três categorias: normal, limítrofe ou anormal. Adotarse-á no estudo como nota de corte indicadora de problema, o escore total maior que 16, tal como proposto por Goodman (1997), que corresponde a categoria anormal considerada com problema, e os escores inferiores a esse valor correspondem as categorias limítrofe e normal, considerados sem problema.

Os dados psicométricos sobre validade e fidedignidade do instrumento no Brasil, foram descritos por Woerner et al. (2004), que utilizaram o método teste-reteste e o cálculo do alfa de Cronbach no estudo da fidedignidade. Os autores evidenciaram ausência de diferenças estatisticamente significativas entre duas avaliações, sendo utilizado intervalo médio de aproximadamente 20 dias entre cada aplicação (teste de amostras pareadas, $\mathrm{p}=0,148$ ) e identificada correlação de 0,79 entre as avaliações e de 0,77 intra classe (ambos com p < 0,001). A validade do SDQ foi verificada por meio da comparação com os questionários de Rutter e o Child Behavior Checklist (CBCL), cujos estudos foram apresentados no Brasil por Fleitlich, Cortazar e Goodman (2000), com correlações de 0,90 e de 0,87, respectivamente, e 
com o instrumento diagnóstico Development and Well-Being Assessment for Children and Adolescents (DAWBA), com correlação satisfatória $\left(x^{2}=13.1 ; \mathrm{p}<0.001\right)$.

A inclusão no estudo teve por finalidade avaliar o comportamento das crianças pelas mães e professoras. Adotou-se para a inclusão no G1 e G2 a presença de problemas (escore > 16), com base na avaliação das mães e para o G3 a ausência de problemas tendo por referência a avaliação das mães (escore $\leq 16$ ).

\section{Para o estudo propriamente dito:}

- Inventário de Recursos do Ambiente Familiar (RAF): elaborado por Marturano (2006), trata-se de um roteiro de entrevista semi-estruturada, com o intuito de rastrear informações acerca dos recursos, disponibilizados pelos pais e pela vida familiar, que possam estar associados ao desempenho escolar. O referido instrumento dispõe de 10 tópicos e cada um desses tópicos são compostos por itens, que correspondem as áreas de recursos: (1) o que a criança faz quando não está na escola, (2) passeios que a criança realizou nos últimos 12 meses, (3) atividades programadas que a criança realiza regularmente, (4) atividades que os pais desenvolvem com a criança em casa, (5) brinquedos que a criança tem ou já teve, (6) disponibilidade de jornais/revistas, (7) disponibilidade de livros, (8) acompanhamento nas atividades escolares, (9) atividades diárias com horário definido, (10) momento em que a família costuma se reunir (ANEXO C).

O inventário é preenchido a partir de informações obtidas junto às mães e, para cada um dos itens, há ponderação dos valores obtidos, tendo em vista o número variável de possíveis respostas. Os estudos de fidedignidade do instrumento, em uma amostra de 100 crianças com queixa escolar, apontaram índices psicométricos considerados aceitáveis, com consistência interna avaliada pela alfa de Cronbach de 0,84 e com boa estabilidade da medida global, com índices entre 92\% e 100\% (Santos, 1999).

Por meio desse instrumento pretendeu-se avaliar, segundo a percepção das mães, os recursos do ambiente familiar.

- Escala de Eventos Adversos (EEA): proposto por Marturano (1999) tem por finalidade identificar os eventos adversos que possam ter ocorrido nos últimos 12 meses ou anteriormente na vida da criança. Formado por 36 itens, abrangendo informações sobre adversidades referentes a vida escolar, familiar e pessoal. A escala é preenchida a partir das respostas das mães, baseado na leitura de uma lista de situações que possam ter ocorrido na vida das crianças, nos últimos 12 meses ou anteriormente (ANEXO D). 
A fidedignidade do instrumento em questão foi verificada mediante teste-reteste, com intervalo de 20 dias entre as aplicações, identificando índice satisfatório de estabilidade (Santos, 1999).

A inclusão no estudo teve por objetivo a avaliação, segundo a percepção das mães, de eventos e adversidades que incidiram sobre a família.

- Escala de Adversidades Crônicas (EAC): proposto por Marturano (1999) visa identificar os eventos adversos que possam ter ocorrido na vida da criança e que tenham duração ou ocorrência repetida por um ano ou mais. Formada por 18 itens que abordam questões relativas às adversidades crônicas referentes a saúde da criança e dos pais, temperamento dos pais e possíveis conflitos familiares e conjugais (ANEXO E).

A escala é preenchida a partir das respostas das mães, baseada na leitura de uma lista de condições adversas prolongadas ou recorrentes que possam ter ocorrido na vida dos filhos, especificando a duração em anos e o período de vida da criança.

A inclusão no estudo teve por finalidade a avaliação, segundo a percepção das mães, de adversidades crônicas que tenham ocorrido na vida das crianças.

- Questionário Geral: elaborado para o levantamento de informações sociodemográficas e algumas condições específicas dos participantes e de suas famílias quanto a: (a) mães - condições de moradia, idade, sexo, cor, naturalidade, estado civil, escolaridade, situação ocupacional, número de filhos biológicos e adotivos, tratamentos, problema de saúde, uso de medicamentos, uso de álcool ou drogas, problemas durante a gravidez, uso de medicação durante a gravidez e histórico de depressão familiar; (b) famílias - constituição, renda mensal e nível socioeconômico; (c) crianças - idade, sexo, escolaridade, tratamentos, uso de medicamentos, desempenho escolar e dificuldades apresentadas pela criança (APÊNDICE E). Para avaliação das condições socioeconômicas, utilizaram-se os itens do Critério de Classificação Econômica Brasil (ANEXO H), desenvolvido pela Associação Brasileira de Empresas de Pesquisas (ABEP / 2015). 


\subsection{Procedimentos}

\subsubsection{Coleta de dados}

A coleta de dados foi realizada preferencialmente na Escola Estadual Adolfo Alfeu Ferrero, em sala reservada nas dependências da escola, colocada à disposição da pesquisadora, e só quando da solicitação das mães, as avaliações foram realizadas nas residências das mesmas. Procurou-se preservar as condições de privacidade e conforto, assim como o cuidado com as devidas interferências externas. Todas as avaliações foram realizadas pela pesquisadora. A coleta de dados com cada família, foi realizada primeiro com as mães, seguido das crianças e professoras.

\section{Avaliação com as mães}

Com base na listagem de alunos fornecida pela escola as famílias foram contatadas, por meio do envio de uma filipeta que apresentava de forma breve o projeto e convidava as mães para a participação no estudo. As filipetas foram entregues as crianças em sala de aula e sua devolução foi realizada pelas próprias crianças.

A psicóloga pesquisadora contatou as mães que aceitaram participar da pesquisa via telefone. Nesse primeiro contato, as mães foram informadas dos objetivos da pesquisa, especificando as atividades e o tempo a ser dispendido. Ao aceitarem colaborar com o estudo, agendou-se um horário para a realização da avaliação.

As mães foram avaliadas individualmente, em sessão única, com duração de aproximadamente 60 minutos cada. Inicialmente às entrevistas, enfatizou-se novamente sobre os objetivos da pesquisa, bem como os benefícios e riscos relativos a participação no estudo. As mães assinaram o TCLE (APÊNDICE B), no qual declaravam a sua participação voluntária no estudo, e autorizavam a realização das avaliações consigo, com a criança e com a professora da criança. Após a concordância da mãe com os termos do estudo, iniciou-se a avaliação.

Posteriormente as mães responderam aos instrumentos: PHQ-9, Questionário Geral, RAF, EEA, EAC e SDQ, de acordo com as instruções específicas de aplicação de cada um deles. Os itens dos instrumentos foram lidos pela pesquisadora, que também foi quem 
assinalava as respostas dadas pelas participantes nos protocolos das técnicas. As participantes tinham em mãos uma cópia dos instrumentos e protocolos de respostas, para acompanharem a leitura.

Os critérios de inclusão e exclusão foram aplicados após as sessões de avaliações, sendo que todas as mães realizaram as avaliações propostas. A possibilidade de entrevista devolutiva foi oferecida a todas as mães participantes. Ao final da coleta dos dados, a psicóloga pesquisadora contatou as 6 mães que manifestaram tal interesse, oferecendo um agendamento prévio para a realização da sessão, entretanto, todas as mães preferiram receber as informações por telefone, o que foi realizado.

\section{Avaliação com as crianças}

As crianças foram avaliadas no período escolar. A psicóloga contatava as professoras previamente ao horário das aulas, que autorizavam a criança a se ausentar da sala de aula, em horário de conveniência estabelecido pela professora. As crianças chegavam às avaliações com um conhecimento prévio sobre o encontro com a psicóloga, uma vez que as mães as informavam sobre o estudo, sendo então, solicitada a anuência das mesmas com relação a participação no estudo.

As crianças foram avaliadas individualmente, em uma única sessão, com duração de aproximadamente 15 minutos. Após um breve rapport, foi aplicado o Teste das Matrizes Progressivas Coloridas de Raven - Escala Especial, seguindo-se as recomendações técnicas previstas. Os critérios de inclusão e exclusão foram aplicados após a sessão de avaliação, sendo que todas as crianças realizaram a avaliação proposta.

\section{Avaliação com as professoras}

O projeto foi apresentado inicialmente às professoras da escola, em uma reunião de Hora de Trabalho Pedagógico Coletivo (HTPC) de modo a convidá-las à participação.

As avaliações foram realizadas na escola, de forma coletiva, em uma reunião regular de HTPC, tendo sido disponibilizado a cada encontro um tempo de aproximadamente uma hora, para a realização da atividade. Os encontros foram previamente agendados com a coordenadora da escola, que autorizava a data de conveniência para a aplicação. Ocorreram vários encontros ao longo do processo de coleta de dados. 
Após a assinatura do TCLE (APÊNDICE D) a psicóloga disponibilizava o instrumento SDQ às professoras, estando cada um identificado com o nome de cada criança a ser avaliada. $\mathrm{Na}$ presença da pesquisadora, as professoras responderam ao questionário sobre os alunos que os pais autorizaram a participação. A aplicação do instrumento foi realizada em pequenos grupos, priorizando a auto-aplicação, tendo como condição estabelecida não exceder a avaliação de cinco alunos por encontro. Os itens do questionário foram precedidos por uma breve avaliação geral sobre o desempenho escolar do aluno, nas disciplinas português e matemática, devendo informar as notas obtidas pelo avaliado nos dois últimos bimestres. As sessões não excederam 60 minutos, contando-se com um tempo médio de 10 minutos para a avaliação de cada criança.

\subsubsection{Tratamento e Análise dos Dados}

Os dados obtidos nos testes e escalas foram codificados de acordo com as proposições de cada instrumento, de forma a se identificar a ausência ou a presença de sintomas depressivos, de dificuldades de comportamento das crianças, bem como dos recursos familiares, dos eventos estressores e das adversidades do ambiente familiar.

As informações obtidas com a base no Questionário Geral, foram codificadas a fim de levantar as características sociodemográficas das mães, das famílias e das crianças, participantes desse estudo. Considerou-se como variáveis sóciodemográficas: quanto às mães, a idade, seu status civil, escolaridade e ocupação; quanto à família, a presença de pai/padrasto da criança no lar, sua escolaridade e ocupação, número de filhos, recebimento de recursos governamentais, renda familiar e classe socioeconômica das famílias; e quanto às crianças, a idade, o sexo e a escolaridade.

A classificação dos escores do PHQ-9 foi utilizada exclusivamente enquanto critério para inclusão das mães nos grupos em relação à presença ou ausência de sintomas depressivos, enquanto a classificação dos escores das crianças no RAVEN foi utilizada para exclusão na amostra de crianças com indicadores cognitivos indicativos de deficiência intelectual.

Os dados codificados referentes aos recursos familiares, aos eventos estressores, adversidades crônicas e as avaliações dos comportamentos das crianças, foram digitados e conferidos por avaliadores independentes. As análises estatísticas realizados ocorreram mediante a utilização do software IBM SPSS Statistics, versão 23. 
Verificou-se, posteriormente, a normalidade dos dados, por meio dos testes de Kolmogorov-Smirnov, com correlação de significância de Liliefors, e de Shapiro-Wilk, cujos resultados permitiram as escolhas posteriores dos métodos de análise de comparação entre grupos.

Procedeu-se à análise estatística descritiva para caracterizar o perfil sociodemográfico dos grupos G1, G2 e G3, em termos de média, desvio padrão e mediana para as variáveis contínuas e frequência e porcentagem para as variáveis categóricas. As amostras referentes aos três grupos quanto às variáveis sociodemográficas foram comparadas pelo teste não paramétrico Qui-quadrado, de forma a caracterizar e comparar os grupos, sendo que para as variáveis com diferenças significativas entre os grupos, procedeu-se à comparação entre pares de média, pelo mesmo teste não paramétrico. A análise referente à presença ou ausência de problemas de comportamento, enquanto variável dicotômica, tendo como referência as classificações "Sem dificuldade" ou "Com dificuldade" a partir das avaliações de mães e professoras no SDQ, também foi realizada mediante o teste Qui-quadrado. Frente às diferenças estatisticamente significativas na comparação dessas variáveis dicotômicas, procedeu-se a comparação entre pares de média pelo mesmo teste. Ainda foi realizada a análise descritiva de tais dados em termos de frequência e porcentagem.

Por meio do teste Kruskal Wallis foram realizadas as análises de comparações entre as amostras dos grupos G1, G2 e G3 quanto aos indicadores de problemas de comportamento dos escolares (SDQ), segundo as avaliações de mães e professoras, considerando os escores totais brutos, sendo realizada ainda a análise descritiva dos dados em termos de média, desvio padrão e mediana. Ainda, procedeu-se à aplicação de tal teste entre pares de média, quando da identificação de diferenças significativas na comparação entre os três grupos. O teste Kruskal Wallis também foi utilizado para realizar as comparações entre os grupos G1, G2 e G3 e entre pares de média quanto aos escores da EEA e da EAC.

A caracterização do ambiente familiar foi analisada em termos de estatística descritiva, sendo os escores obtidos no RAF, EEA e EAC descritos a partir da média, desvio padrão, mediana, escore mínimo e máximo em cada grupo.

O teste da ANOVA foi aplicado para a comparação dos grupos G1, G2 e G3 quanto aos escores do RAF. Esse teste também foi utilizado para comparar os eventos estressores e as adversidades crônicas das famílias que convivem com mães com e sem sintomas depressivos. As análises descritivas dessas variáveis foram realizadas em termos de média, desvio padrão, mediana, escore mínimo e máximo. As comparações entre os grupos referentes ao Desempenho Escolar das crianças, considerando as notas brutas nas disciplinas português e 
matemática, também foram realizadas mediante o teste ANOVA, analisando-se os indicadores do teste Post Hoc de Bonferroni para identificar entre quais grupos se deu as diferenças estatisticamente significativas. Procedeu-se, ainda, a comparação entre os grupos quanto a tais variáveis, analisadas de forma dicotômica (acima e abaixo da mediana), realizando-se posteriormente comparação entre pares de média, quando da identificação de diferenças significativas.

Mediante o teste $U$ de Mann-Whitney foram realizadas as análises de comparação entre as amostras de crianças Com e Sem dificuldades comportamentais, tendo como respondentes as mães e professoras, considerando as variáveis relativas aos recursos (RAF) e adversidades (EEA/EAC) do ambiente familiar.

Ainda, comparou-se as amostras relativas à avaliação das mães e das professoras no SDQ, quanto aos escores brutos das escalas de problemas, recursos pró-sociais e escala total de dificuldades, mediante o teste de Wilcoxon. As análises descritivas dos dados foram realizadas em termos de média, desvio padrão e mediana.

Para as análises das relações entre as variáveis sociodemográficas, recursos (RAF), adversidades do ambiente familiar (EEA e EAC), depressão materna, problemas de comportamento das crianças (SDQ) e desempenho escolar, utilizou-se as correlações de Spearman, analisando-se o tamanho do efeito de cada variável com significância estatística.

Adotou-se o nível de significância de 5\% (p $\leq 0,05)$ em todos os testes. 
4 RESULTADOS 

Os dados serão apresentados atendo-se aos objetivos do estudo, distribuídos em seis tópicos, a saber: (1) dados sociodemográficos das famílias, mães e crianças, (2) dados descritivos e comparativos entre os grupos quanto ao comportamento das crianças (SDQ), (3) dados descritivos e comparativos quanto à presença ou ausência de dificuldades comportamentais das crianças, segundo avaliação das mães e das professoras, (4) dados descritivos e comparativos entre os grupos quanto ao desempenho escolar das crianças, (5) dados descritivos e comparativos entre os grupos quanto aos recursos e eventos estressores do ambiente familiar (RAF, EEA e EAC), considerando ainda comparações para grupos diferenciados pela depressão materna e problemas comportamentais das crianças pelas avaliações das mães, professoras e por ambas avaliadoras, (6) dados correlacionais entre as variáveis do estudo, a saber: sociodemográficas, depressão materna, comportamento de escolares, desempenho escolar e recursos e estressores do ambiente familiar.

\subsection{Caracterização sociodemográfica dos grupos}

No primeiro tópico, serão apresentados dados de caracterização relativos ao perfil sociodemográfico dos grupos: (G1) mães que apresentaram indicadores de depressão e crianças com problemas de comportamento, (G2) mães que não apresentaram indicadores de depressão e crianças com problemas de comportamento e (G3) mães que não apresentaram indicadores de depressão e crianças com ausência de problemas comportamentais, quanto às características das mães, famílias e crianças, bem como relativo ao total da amostra.

A Tabela 1 apresenta as características sociodemográficas das mães e das famílias incluídas no estudo, especificando as comparações entre os grupos (G1, G2 e G3).

Tabela 1 - Comparações entre os grupos (G1, G2 e G3) quanto as variáveis sociodemográficas das mães e das famílias $(n=85)$.

\begin{tabular}{lccccccc}
\hline \multirow{2}{*}{$\begin{array}{c}\text { Grupos } \\
\text { Variáveis }\end{array}$} & $\mathbf{G 1}$ & $\mathbf{G 2}$ & $\mathbf{G 3}$ & & & \\
\cline { 2 - 4 } & $\mathbf{f}(\boldsymbol{\%})$ & $\mathbf{f}(\boldsymbol{\%})$ & $\mathbf{f ( \% )}$ & & Total & $\begin{array}{c}\text { Valor } \\
\text { do teste }\end{array}$ & p-valor* \\
\hline Idade Mães & & & & & & \\
25 a 35 anos & $15(28,9 \%)$ & $19(36,5 \%)$ & $18(34,6 \%)$ & $52(61,1 \%)$ & 0,38 & 0,827 \\
36 a 45 anos & $11(33,3 \%)$ & $10(30,3 \%)$ & $12(36,4 \%)$ & $33(38,8 \%)$ & &
\end{tabular}


(continuação)

\begin{tabular}{cccccccc}
\hline \multirow{2}{*}{$\begin{array}{c}\text { Grupos } \\
\text { Variáveis }\end{array}$} & $\mathbf{G 1}$ & $\mathbf{G 2}$ & $\mathbf{G 3}$ & & $\begin{array}{r}\text { Valor } \\
\text { do teste }\end{array}$ & p-valor* \\
\cline { 2 - 4 } & $\mathbf{f}(\%)$ & $\mathbf{f}(\%)$ & $\mathbf{f}(\%)$ & Total & \\
\hline
\end{tabular}

Estado Civil Mães

Sem Comp.

$\begin{array}{cccccc}09(47,4 \%) & 05(26,3 \%) & 05(26,3 \%) & 19(22,3 \%) & 3,24 & 0,197 \\ 17(25,7 \%) & 24(36,4 \%) & 25(37,9 \%) & 66(77,6 \%) & & \end{array}$

Com Comp.

Escolaridade Mães

$\leq 8$ anos

$\begin{array}{llll}13(59,1 \%) & 07(31,8 \%) & 02(09,1 \%) & 22(25,8 \%) \\ 13(20,6 \%) & 22(34,9 \%) & 28(44,5 \%) & 63(74,1 \%)\end{array}$

$13,70 \quad 0,001$

$>8$ anos

$13(20,6 \%) \quad 22(34,9 \%) \quad 28(44,5 \%) \quad 63(74,1 \%)$

Ocupação Mães

Assalariado

$16(27,6 \%) \quad 21(36,2 \%)$

$21(36,2 \%) \quad 58(68,2 \%)$

$2,65 \quad 0,618$

Benefício

$02(66,7 \%) \quad 00(00,0 \%)$

$01(33,3 \%) \quad 03(03,5 \%)$

Sem Trab.

$08(33,3 \%) \quad 08(33,3 \%)$

$08(33,3 \%) \quad 24(28,2 \%)$

Pai/Padrasto

Presença

$17(25,7 \%) \quad 24(36,4 \%)$

$25(37,9 \%) \quad 66(77,6 \%)$

$3,24 \quad 0,197$

Ausência

$09(47,4 \%) \quad 05(26,3 \%) \quad 05(26,3 \%) \quad 19(22,3 \%)$

\section{Escolaridade Pai/ \\ Padrasto \\ $\leq 8$ anos \\ $>8$ anos}

$$
\begin{array}{llll}
16(39,0 \%) & 13(31,7 \%) & 12(29,3 \%) & 41(48,2 \%) \\
10(22,7 \%) & 16(36,4 \%) & 18(40,9 \%) & 44(51,7 \%)
\end{array}
$$$$
2,79 \quad 0,248
$$

\section{Ocupação Pai/ \\ Padrasto}

Assalariado

$23(29,5 \%) \quad 27(34,6 \%)$

$28(35,9 \%)$

$78(91,7 \%)$

$1,62 \quad 0,805$

Benefício

$01(50,0 \%) \quad 00(00,0 \%)$

$01(50,0 \%) \quad 02(02,3 \%)$

Sem Trab.

$02(40,0 \%) \quad 02(40,0 \%) \quad 01(20,0 \%) \quad 05(05,8 \%)$

\section{Número Filhos}

1 a 3 filhos

$\geq 4$ filhos

$21(28,0 \%) \quad 26(34,7 \%)$

$28(37,3 \%) \quad 75(88,2 \%)$

$2,20 \quad 0,332$

$05(50,0 \%) \quad 03(30,0 \%) \quad 02(20,0 \%) \quad 10(11,7 \%)$

\section{Bolsa Auxilio}

Recebe

$08(44,4 \%) \quad 08(44,4 \%)$

$02(11,1 \%)$

$18(21,1 \%)$

$5,93 \quad 0,052$

Não Recebe

$18(26,9 \%) \quad 21(31,3 \%) \quad 28(41,8 \%) \quad 67(78,8 \%)$

\section{Renda Mensal}

até $2,9 \mathrm{SM}$

$21(44,7 \%)$

$05(15,6 \%)$

$16(34,0 \%)$

$10(21,3 \%)$

$47(55,2 \%)$

$15,62 \quad 0,004$

3 a 5,9 SM

$00(00,0 \%)$

$15(46,9 \%)$

$32(37,6 \%)$

$\geq 6 \mathrm{SM}$ 


\begin{tabular}{|c|c|c|c|c|c|c|}
\hline Grupos & G1 & G2 & G3 & & & \\
\hline Variáveis & $\mathbf{f}(\%)$ & f $(\%)$ & $f(\%)$ & Total & $\begin{array}{c}\text { Valor } \\
\text { do teste }\end{array}$ & p-valor* \\
\hline
\end{tabular}

\section{Classificação}

Socioeconômica**

\begin{tabular}{lllllll} 
A, B1 e B2 & $05(17,9 \%)$ & $12(42,8 \%)$ & $11(39,3 \%)$ & $28(32,9 \%)$ & 3,33 & 0,189 \\
C1, C2, D e E & $21(36,9 \%)$ & $17(29,8 \%)$ & $19(33,3 \%)$ & $57(67,0 \%)$ & & \\
\hline
\end{tabular}

Nota. f = Frequência; \% = Porcentagem; *p-valor referente ao teste não paramétrico Qui-quadrado / p $\leq 0,05 ;$ G1 = mães que apresentaram indicadores de depressão e crianças com problemas de comportamento; $\mathrm{G} 2$ = mães que não apresentaram indicadores de depressão e crianças com problemas de comportamento e G3= mães que não apresentaram indicadores de depressão e crianças com ausência de problemas de comportamento; Comp. = Companheiro; SM = Salário Mínimo;

**Obtida segundo o Critério de Classificação Econômica Brasil desenvolvido pela Associação Brasileira de Empresas de Pesquisas - ABEP.

Descrever-se-á, inicialmente, as variáveis nas quais os grupos não diferiram.

Foram avaliadas 85 mães com idade média de 34,5 anos $(\mathrm{DP}=5,51)$, e a maioria na faixa etária entre 25 a 35 anos $(61,1 \%)$, considerando que para a inclusão no estudo considerou-se a idade entre 25 e 45 anos. Não foram observadas diferenças estatisticamente significativas entre os grupos.

Com relação ao estado civil, observou-se o predomínio no total de mulheres com companheiro, ou seja, casadas ou vivendo em união consensual (77,6\%), seguido de $22,3 \%$ de mulheres que estavam sem companheiro, por serem solteiras, separadas, desquitadas ou viúvas. Não se verificou diferenças estatisticamente significativas entre os grupos.

Referente à ocupação materna, notou-se no geral o predomínio de mulheres que referiram exercer alguma atividade profissional remunerada em todos os grupos $(68,2 \%)$, sem diferença estatisticamente significativa.

Quanto a presença/ausência paterna no ambiente familiar, notou-se que no total da amostra, 77,6\% das crianças conviviam com a presença do pai ou padrasto. Quanto à comparação dos grupos, destaca-se que $47,4 \%$ das crianças de G1 não conviviam com o pai ou padrasto. Apesar das diferenças numéricas entre os grupos, estas não foram estatisticamente significativas.

Sobre a escolaridade paterna, verificou-se que no geral 48,2\% dos pais estudaram por até oito anos e 51,7\% apresentaram mais de oito anos de estudo. No que se refere à ocupação paterna, verificou-se o predomínio no total da amostra de pais exercendo alguma atividade profissional remunerada $(91,7 \%)$, não sendo observadas diferenças estatisticamente significativas entre os grupos quanto a ocupação nem escolaridade paterna.

Para a amostra total, a maioria das mães incluídas no estudo $(88,2 \%)$ relataram apresentar de um a três filhos. Quanto a comparação entre grupos, verificou-se que em G1 
(50\%) predominou a quantidade de quatro ou mais filhos em comparação aos outros grupos, entretanto, não foi detectada diferença estatística significativa entre os grupos.

No que se refere ao recebimento de Bolsa Auxílio, a maioria das famílias (78,8\%) não recebia tal benefício. Quanto à comparação dos grupos, verificou-se que 44,4\% das famílias de G1 e G2 referiram receber o auxílio, enquanto que no grupo G3 essa porcentagem foi de $11,1 \%$. Não foram identificadas diferenças estatísticas significativas.

Quanto à classificação socioeconômica das famílias, detectou-se que a maioria dos participantes $(67,0 \%)$ foi incluída nas classes C1, C2, D e E. Com relação à comparação entre grupos, verificou-se que 17,9\% de G1 foram classificados como pertencentes as classes A, B1 e B2, sendo que em G2, 42,8\% foram incluídos nessa categoria. Entretanto, não se detectou diferença estatísticamente significativa.

Observou-se diferenças significativas entre os grupos para duas variáveis como descrito a seguir.

Quanto à escolaridade no grupo total, 25,8\% das mães relataram ter estudado por até oito anos e 74,1\% referiram ter mais de oito anos de estudo. Quanto a comparação entre os grupos, verificou-se diferença estatisticamente significativa para essa variável, sendo que a maioria das mães de G1 $(59,1 \%)$ apresentaram até oito anos de estudo, enquanto que as mães de G2 (34,9\%) e G3 (44,5\%) apresentaram mais de oito anos. Na comparação grupo a grupo, observou-se que as mães de G1 apresentavam menos anos de escolarização, em relação à G2 $\left[\chi^{2}(1,55)=3,962, p=0,047\right]$ e à $G 3\left[\chi^{2}(1,56)=13,337, p \unlhd 0,001\right]$, não sendo identificadas diferenças significativas entre G2 e G3.

Observou-se diferença estatisticamente significativa nas comparações dos grupos quanto a variável renda mensal familiar. No total, a maioria das famílias $(55,2 \%)$ declararam uma renda mensal de até 2,9 salários mínimos. Nas famílias que declararam uma remuneração de 3 a 5,9 salários mínimos, identificou-se diferença significativa de G1 (15,6\%) em relação a G2(37,5\%) e G3 (46,9\%). Ainda observou-se que 83,3\% dos provedores de G3, receberam mais do que seis salários mínimos. A comparação grupo a grupo identificou diferenças estatisticamente significativas entre G1 e G3 $\left[\chi^{2}(1,56)=13,687, p=0,001\right]$, tendo as famílias de G1 apresentado menor renda. Não foram identificadas diferenças na comparação entre G1 e G2 e entre G2 e G3 quanto a tal variável.

Com relação às variáveis sociodemográficas, foram detectadas diferenças estatisticamente significativas entre os grupos quanto à escolaridade das mães e a renda mensal familiar. Quanto às demais variáveis, destaca-se a homogeneidade entre os grupos G1, G2 e G3. 
A Tabela 2 apresenta as características sociodemográficas das crianças incluídas no estudo, especificando as comparações entre os grupos G1, G2 e G3.

Tabela 2 - Comparações entre os grupos (G1, G2 e G3) quanto às variáveis sociodemográficas das crianças $(\mathrm{n}=85)$.

\begin{tabular}{|c|c|c|c|c|c|c|}
\hline \multicolumn{2}{|c|}{ Grupos G1 } & \multirow{2}{*}{$\begin{array}{c}\text { G2 } \\
f(\%)\end{array}$} & \multirow{2}{*}{\begin{tabular}{c|} 
G3 \\
f $(\%)$
\end{tabular}} & \multirow[b]{2}{*}{ Total } & \multirow[b]{2}{*}{$\begin{array}{c}\text { Valor } \\
\text { do teste }\end{array}$} & \multirow[b]{2}{*}{ p-valor* } \\
\hline Variáveis & $\mathbf{f}(\%)$ & & & & & \\
\hline \multicolumn{7}{|l|}{ Idade (anos) } \\
\hline 7 e 8 anos & $10(24,4 \%)$ & $14(34,1 \%)$ & $17(41,5 \%)$ & $41(48,2 \%)$ & 1,84 & 0,397 \\
\hline 9 e 10 anos & $16(36,4 \%)$ & $15(34,1 \%)$ & $13(29,5 \%)$ & $44(51,7 \%)$ & & \\
\hline \multicolumn{7}{|l|}{ Sexo } \\
\hline Masculino & $16(34,8 \%)$ & $15(32,6 \%)$ & $15(32,6 \%)$ & $46(54,1 \%)$ & 0,84 & 0,654 \\
\hline Feminino & $10(25,6 \%)$ & $14(35,9 \%)$ & $15(38,5 \%)$ & $39(45,8 \%)$ & & \\
\hline \multicolumn{7}{|c|}{$\begin{array}{l}\text { Escolaridade } \\
\text { (Ens. Fundamental) }\end{array}$} \\
\hline $2^{\circ}$ e $3^{\circ}$ ano & $14(30,4 \%)$ & $16(34,8 \%)$ & $16(34,8 \%)$ & $46(54,1 \%)$ & 0,02 & 0,989 \\
\hline $4^{\circ}$ e $5^{\circ}$ ano & $12(30,8 \%)$ & $13(33,3 \%)$ & $14(35,9 \%)$ & $39(45,8 \%)$ & & \\
\hline
\end{tabular}

Participaram do estudo 85 crianças na faixa etária entre sete a 10 anos. Verificou-se para o total da amostra que 51,7\% dos estudantes encontravam-se com nove e 10 anos. Com relação à comparação entre os grupos, notou-se uma maior porcentagem de crianças em G3 com idade de 7 e 8 anos, entretanto, tal diferença não foi estatisticamente significativa entre os grupos.

Referente ao sexo, evidenciou-se no total mais crianças do sexo masculino $(54,1 \%)$. Detectou-se quanto ao sexo que o grupo G3, contou com mais meninas, apesar disso, não foi detectada diferença estatisticamente significativa entre os grupos.

No que diz respeito a escolaridade das crianças, destaca-se que $54,1 \%$ do total das crianças cursavam os anos iniciais do Ensino Fundamental $\left(2^{\circ}\right.$ e $3^{\circ}$ ano), apresentando ausência de diferença estatisticamente significativa na comparação entre os grupos quanto a tal variável.

Com relação às variáveis sociodemográficas das crianças, não foram detectadas diferenças estatisticamente significativas entre os grupos, verificando-se uma homogeneidade entre os grupos G1, G2 e G3 quanto as variáveis idade, sexo e escolaridade. 


\subsection{Caracterização e comparações entre os grupos quanto ao comportamento das crianças}

No segundo tópico, serão apresentadas as comparações entre os grupos G1, G2 e G3 quanto aos indicadores comportamentais das crianças, obtidos pelo SDQ, tendo como referência as avaliações realizadas pelas mães e professoras. Nesse tópico, estarão indicadas ainda as comparações entre os grupos, quanto à ausência ou presença de dificuldades de comportamento das crianças (SDQ), tendo por referência as classificações dos escores Sem dificuldades e Com dificuldades, baseados nas avaliações realizadas por mães e professoras.

Na Tabela 3 são apresentadas as comparações relativas aos escores das escalas específicas e escore total.

Tabela 3 - Comparações entre os grupos (G1, G2 e G3) quanto ao comportamento das crianças (SDQ), segundo a avaliação das mães e professoras $(n=85)$

\begin{tabular}{cccccc}
\hline & Grupos & G1 & G2 & G3 & Valor \\
\cline { 2 - 5 } SDQ & M(DP)/Mediana & $M(D P) /$ Mediana & $M(D P) /$ Mediana & $\begin{array}{c}\text { do } \\
\text { teste }\end{array}$ & p-valor* \\
\hline
\end{tabular}

S. Emocionais

$\begin{array}{lrrrrr}\text { Mãe } & 7,12(1,88) / 8,00 & 5,76(2,05) / 6,00 & 3,33(2,17) / 3,50 & 31,14 & <0,001 \\ \text { Prof. } & 2,31(2.55) / 2.00 & 2,86(2,04) / 3,00 & 1,63(1,42) / 1,50 & 5,29 & 0,071\end{array}$

Prob. Conduta

$\begin{array}{llllrr}\text { Mãe } & 4,58(2,55) / 3,50 & 4,00(2,05) / 4,00 & 1,20(1,52) / 1,00 & 34,61 & <0,001 \\ \text { Prof. } & 2,38(2,36) / 2,00 & 1,79(2,35) / 1,00 & 0,70(1,20) / 0,00 & 8,41 & 0,015\end{array}$

Hiperatividade

$\begin{array}{llllll}\text { Mãe } & 8,23(1,74) / 9,00 & 8,10(1,67) / 8,00 & 4,27(2,59) / 4,00 & 35,45 & <0,001 \\ \text { Prof. } & 5,12(3,10) / 6,00 & 5,17(3,07) / 5,00 & 2,00(2,51) / 1,00 & 18,35 & <0,001\end{array}$

Prob. Rel.Colegas

$\begin{array}{llllrr}\text { Mãe } & 2,69(2,526) / 2,5 & 2,97(2,09) / 2,00 & 1,03(1,45) / 0,00 & 15,57 & <0,001 \\ \text { Prof. } & 1,81(1,98) / 1,00 & 1,79(2,27) / 1,00 & 0,73(1,17) / 0,00 & 6,63 & 0,036\end{array}$

Escore Total Dif.

$\begin{array}{llllll}\text { Mãe } & 22,62(5,00) / 22,22 & 20,83(3,17) / 20,00 & 9,87(3,98) / 11,00 & 58,31 & <0,001 \\ \text { Prof. } & 11,69(7,74) / 11,00 & 11,62(7,32) / 11,00 & 5,07(4,94) / 4,00 & 16,54 & <0,001\end{array}$

Comp. Pró-Social

$\begin{array}{llllll}\text { Mãe } & 8,31(2,65) / 9,50 & 8,86(2,01) / 10,00 & 8,77(1,47) / 9,50 & 1,14 & 0,564 \\ \text { Prof. } & 7,42(2,48) / 7,00 & 7,55(2,88) / 9,00 & 9,20(1,06) / 10,00 & 7,33 & 0,026\end{array}$

Nota. M = Média; DP = Desvio Padrão; *p-valor referente ao teste Teste Kruskal Wallis / p $\leq 0,05$; G1 = mães que apresentaram indicadores de depressão e crianças com problemas de comportamento; G2 = mães que não apresentaram indicadores de depressão e crianças com problemas de comportamento e G3= mães que não apresentaram indicadores de depressão e crianças com ausência de problemas de comportamento; SDQ = Questionário de Capacidades e Dificuldades; Prof. = Professora; S. = sintomas; Prob. = problemas; Rel. = relacionamento; Dif= dificuldades; Comp. = comportamento. 
No que se refere ao comportamento das crianças, segundo a avaliação das mães e professoras, por meio do instrumento SDQ, observou-se que em relação ao Total de Dificuldades e às quatro Escalas de problemas (Sintomas Emocionais, Problemas de Conduta, Hiperatividade e Relacionamento com Colegas), a média geral dos escores de G1 e G2 foram maiores que os de G3. Verificaram-se diferenças estatísticas significativas entre os grupos quanto ao comportamento das crianças avaliadas por mães e professoras quanto ao Total de Dificuldades e nas Escalas de dificuldades do SDQ relativas aos Problemas de Conduta, Hiperatividade e Relacionamento com Colegas. Na Escala Sintomas Emocionais observou-se diferenças significativas entre os grupos exclusivamente na avaliação feita pelas mães.

Nas comparações grupo a grupo para as variáveis com diferenças estatisticamente significativas, identificou-se diferenças entre G1 e G2 quanto à escala de Sintomas Emocionais do SDQ respondido pelas mães [ $p=0,014]$, e quanto a escala de Problemas de Conduta respondido pelas professoras [ $p<0,001]$. Nas comparações entre G1 e G3, observouse diferenças significativas quanto às escalas de Sintomas Emocionais, Problemas de Conduta, Hiperatividade e Total de Problemas $[p<0,001]$ bem como na escala de Problemas de Relacionamento [ $p=0,010]$ do SDQ respondido pelas mães e nas escalas Hiperatividade, Problemas de Conduta e Total de Problemas $[p<0,001]$ e Problemas de Relacionamento $[p=0,009]$ no SDQ respondido pelas professoras. Quando da comparação entre G2 e G3, foram identificadas diferenças estatisticamente significativas quanto às escalas de Sintomas Emocionais, Problemas de Conduta, Hiperatividade, Problemas de Relacionamento e Total de Problemas $[p<0,001]$ do SDQ respondido pelas mães e nas escalas Hiperatividade e Total de Problemas $[p<0,001]$ do SDQ respondido pelas professoras.

Quanto à Escala Comportamento Pró-Social relativa à presença de recursos e capacidades, verificou-se médias semelhantes para os três grupos, segundo as mães, não sendo identificadas diferenças significativas. Já segundo a avaliação das professoras, identificou-se diferença estatística significativa entre os grupos, nas comparações grupo a grupo, observou-se quanto a tal variável, diferenças entre G1 e G3 [ $p=0,014]$ e entre G2 e G3 $[p=0,029]$.

Considerando os escores obtidos e as notas de corte do SDQ, procederam-se as classificações dos escores em Sem dificuldade e Com dificuldade, em relação ao Escore Total de Dificuldades e aos escores das Escalas do SDQ, sendo as comparações apresentadas na Tabela 4. 
Tabela 4 - Comparações entre os grupos (G1, G2 e G3) quanto ao comportamento das crianças, tendo por referência as classificações dos escores em Sem dificuldade ou Com dificuldade (SDQ), tendo como informantes mães e professoras $(\mathrm{n}=85)$.

\begin{tabular}{|c|c|c|c|c|c|c|c|}
\hline & Grupos & G1 & G2 & G3 & & & \\
\hline SDQ & & $f(\%)$ & $f(\%)$ & $f(\%)$ & Total & $\begin{array}{c}\text { Valor } \\
\text { do teste }\end{array}$ & p-valor* \\
\hline
\end{tabular}

\section{S. Emocionais}

$\begin{array}{llllllll}\text { Mãe } & \text { S dificuldade } & 04(12,1 \%) & 09(27,3 \%) & 20(60,6 \%) & 33(38,8 \%) & 16,54 & 0,000 \\ & \text { C dificuldade } & 22(42,3 \%) & 20(38,7 \%) & 10(19,2 \%) & 52(61,1 \%) & & \\ \text { Prof. } & \text { S dificuldade } & 24(30,4 \%) & 26(32,9 \%) & 29(36,7 \%) & 79(92,9 \%) & 4,80 & 0,308 \\ & \text { C dificuldade } & 02(40,0 \%) & 03(60,0 \%) & 00(00,0 \%) & 05(05,8 \%) & & \end{array}$

\section{Prob. Conduta}

$\begin{array}{llllllll}\text { Mãe } & \text { S dificuldade } & 13(24,1 \%) & 13(24,1 \%) & 28(51,8 \%) & 54(63,5 \%) & 17,93 & 0,000 \\ & \text { C dificuldade } & 13(41,9 \%) & 16(51,6 \%) & 02(06,5 \%) & 31(36,4 \%) & & \\ \text { Prof. } & \text { S dificuldade } & 16(23,2 \%) & 24(34,8 \%) & 29(42,0 \%) & 69(81,1 \%) & 11,32 & 0,003 \\ & \text { C dificuldade } & 10(62,5 \%) & 05(31,3 \%) & 01(06,2 \%) & 16(18,8 \%) & & \end{array}$

\section{Hiperatividade}

\begin{tabular}{|c|c|c|c|c|c|c|c|}
\hline Mãe & $\mathrm{S}$ dificuldade & $06(15,8 \%)$ & $08(21,0 \%)$ & $24(63,2 \%)$ & $38(44,7 \%)$ & 23,47 & 0,000 \\
\hline & $\mathrm{C}$ dificuldade & $20(42,6 \%)$ & $21(44,7 \%)$ & $06(12,7 \%)$ & $47(55,2 \%)$ & & \\
\hline Prof. & $\mathrm{S}$ dificuldade & $14(22,5 \%)$ & $20(32,3 \%)$ & $28(45,2 \%)$ & $62(72,9 \%)$ & 11,35 & 0,003 \\
\hline & $\mathrm{C}$ dificuldade & $12(52,2 \%)$ & $09(39,1 \%)$ & $02(08,7 \%)$ & $23(27,0 \%)$ & & \\
\hline Prob. & el. Colegas & & & & & & \\
\hline Mãe & S dificuldade & $15(23,8 \%)$ & $21(33,3 \%)$ & $27(42,9 \%)$ & $63(74,1 \%)$ & 7,64 & 0,022 \\
\hline & $\mathrm{C}$ dificuldade & $11(50,0 \%)$ & $08(36,4 \%)$ & $03(13,6 \%)$ & $22(25,8 \%)$ & & \\
\hline Prof. & S dificuldade & $24(31,2 \%)$ & $23(29,8 \%)$ & $30(39,0 \%)$ & $77(90,5 \%)$ & 7,53 & 0,223 \\
\hline & $\mathrm{C}$ dificuldade & $02(25,0 \%)$ & $06(75,0 \%)$ & $00(00,0 \%)$ & $08(09,4 \%)$ & & \\
\hline
\end{tabular}

\section{Escore Total Dif.}

Mãe $\quad$ S dificuldade
C dificuldade

Prof. S dificuldade

C dificuldade

$\begin{array}{llllll}00(00,0 \%) & 00(00,0 \%) & 30(100 \%) & 30(35,2 \%) & 85,00 & 0,000 \\ 26(47,3 \%) & 29(52,7 \%) & 00(00,0 \%) & 55(64,7 \%) & & \\ 15(23,1 \%) & 22(33,8 \%) & 28(43,1 \%) & 65(76,4 \%) & 9,84 & 0,007 \\ 11(55,0 \%) & 07(35,0 \%) & 02(10,0 \%) & 20(23,5 \%) & & \end{array}$

\section{Comp. Pró-Social}

\begin{tabular}{|c|c|c|c|c|c|c|c|}
\hline \multirow[t]{2}{*}{ Mãe } & $S$ dificuldade & $22(27,8 \%)$ & $27(34,2 \%)$ & $30(38,0 \%)$ & $79(92,94 \%)$ & \multirow[t]{2}{*}{5,02} & \multirow[t]{2}{*}{0,081} \\
\hline & $\mathrm{C}$ dificuldade & $04(66,7 \%)$ & $02(33,3 \%)$ & $00(00,0 \%)$ & $06(07,05 \%)$ & & \\
\hline \multirow[t]{2}{*}{ Prof. } & $S$ dificuldade & $23(29,1 \%)$ & $26(32,9 \%)$ & $30(38,0 \%)$ & $79(92,94 \%)$ & \multirow[t]{2}{*}{3,55} & \multirow[t]{2}{*}{0,169} \\
\hline & $\mathrm{C}$ dificuldade & $03(50,0 \%)$ & $03(50,0 \%)$ & $00(00,0 \%)$ & $06(07,05 \%)$ & & \\
\hline
\end{tabular}


Foram detectadas diferenças estatísticas significativas entre os grupos G1, G2 e G3 quanto ao Total de Dificuldades e em todas as Escalas específicas relativas às dificuldades, tendo as mães como respondentes do SDQ. Segundo a avaliação das professoras, foram observadas diferenças significativas nas escalas Problemas de Conduta, Hiperatividade e Total de dificuldades.

Atendendo ao critério do estudo quanto ao total de dificuldades, segundo as mães, todas as crianças de G1 e G2 apresentaram dificuldade de comportamento, e as mães de G3, avaliaram suas crianças como não apresentando tais problemas.

Segundo a avaliação das professoras mais crianças de G1 apresentaram problemas de comportamento em comparação as crianças de G2 e G3, com significância estatística.

Nas comparações grupo a grupo, foram identificadas diferenças significativas entre G1 e G3 bem como entre G2 e G3, não sendo observadas diferenças estatisticamente significativas entre G1 e G2. Quanto a G1 e G3, foram identificadas diferenças para as escalas Sintomas emocionais $\left[\chi^{2}(1,56)=14,957, p<0,001\right]$, Problemas de conduta $\left[\chi^{2}\right.$ $(1,56)=13,337, p<0,001]$, Hiperatividade $\left[\chi^{2}(1,56)=18,145, p<0,001\right]$, Problemas de Relacionamento $\left[\chi^{2}(1,56)=7,754, p=0,005\right]$ e Total de Problemas $\left[\chi^{2}(1,56)=56,000\right.$, $p<0,001]$ no SDQ respondido pelas mães, bem como na escala Problemas de Conduta $\left[\chi^{2}\right.$ $(1,56)=10,889, p=0,001]$, Hiperatividade $\left[\chi^{2}(1,56)=11,583, p=0,001\right]$ e Total de Problemas $\left[\chi^{2}(1,56)=9,926, p=0,002\right]$ no SDQ respondido pelas professoras. Quando da comparação entre G2 e G3, identificou-se diferenças nas escalas Sintomas Emocionais [ $\chi^{2}$ $(1,59)=7,491, p=0,006]$, Problemas de conduta $\left[\chi^{2}(1,59)=16,321, p<0,001\right]$ e Total de Problemas $\left[\chi^{2}(1,59)=59,000, p<0,001\right]$ no SDQ respondido pelas mães, além de diferenças na escala Hiperatividade $\left[\chi^{2}(1,59)=5,773, p=0,016\right]$ no SDQ respondido pelas professoras.

Com relação ao Comportamento Pró-Social, a maioria das crianças dos três grupos não apresentou dificuldades comportamentais, sem diferença estatística significativa. Destacase que mães e professoras consideraram que todas as crianças de G3 não apresentaram dificuldades. 


\subsection{Comparações entre as avaliações de mães e professoras quanto ao comportamento das crianças}

No terceiro tópico, serão apresentadas as comparações entre as avaliações relativas ao comportamento das crianças (SDQ), tendo por referência mães e professoras como respondentes, conforme a Tabela 5 .

Tabela 5 - Comparações entre as avaliações relativas ao comportamento das crianças (SDQ), tendo por referência mães e professoras como respondentes $(n=85)$.

\begin{tabular}{|c|c|c|c|c|}
\hline Respondentes & Mães & Professoras & & \\
\hline SDQ & M(DP)Mediana & M(DP $)$ Mediana & Valor do teste & p-valor* \\
\hline S. Emocionais & $3,19(2,52) 3,00$ & $2,26(1,89) 2,00$ & 7,08 & $<0,001$ \\
\hline Prob. Conduta & $5,32(2,56) 6,00$ & $1,59(2,23) 1,00$ & 4,82 & $<0,001$ \\
\hline Hiperatividade & $6,79(2,76) 7,00$ & $4,04(3,23) 4,00$ & 6,18 & $<0,001$ \\
\hline Prob. Rel. Colegas & $2,20(2,20) 2,00$ & $1,42(1,90) 1,00$ & 2,84 & 0,004 \\
\hline Escore Total Dif. & $17,51(6,98) 18,00$ & $9,33(7,25) 8,00$ & 6,95 & $<0,001$ \\
\hline Comp. Pró-Social & $8,66(2,06) 10,0$ & $8,09(2,38) 9,00$ & 1,80 & 0,071 \\
\hline
\end{tabular}

Foram detectadas diferenças estatísticas significativas quanto as comparações das respondentes mães e professoras, em relação as quatro escalas específicas de dificuldades e o total de dificuldades. Nota-se que em todas as comparações as médias das mães nas escalas específicas e quanto ao total de dificuldades foram maiores que as médias das professoras. Nas escalas específicas, os escores relativos à hiperatividade e problemas de conduta, segundo as mães, foram os que tiveram maiores escores podendo ser considerados as maiores dificuldades das crianças, enquanto as professoras, consideram a hiperatividade como o maior problema de comportamento das crianças.

Não foram observadas diferenças estatísticas significativas quanto ao comportamento pró-social, referente a comparação de mães e professoras. 


\subsection{Comparações entre os grupos quanto ao desempenho escolar das crianças}

No quarto tópico, serão apresentadas as comparações entre os grupos quanto ao desempenho escolar das crianças nas disciplinas português e matemática, conforme a Tabela 6.

Tabela 6 - Comparações entre os grupos (G1, G2, G3) referente ao desempenho escolar das crianças em português e matemática.

\begin{tabular}{|c|c|c|c|c|c|}
\hline & G1 & G2 & G3 & & \\
\hline $\begin{array}{l}\text { Desempenho } \\
\text { Escolar }\end{array}$ & $\begin{array}{c}\text { M(DP)Mediana } \\
\text { (Mín-Máx) }\end{array}$ & $\begin{array}{c}\text { M(DP)Mediana } \\
\text { (Mín-Máx) }\end{array}$ & $\begin{array}{c}\text { M(DP)Mediana } \\
\text { (Mín-Máx) }\end{array}$ & $\begin{array}{c}\text { Valor } \\
\text { do } \\
\text { Teste } \\
\end{array}$ & p-valor \\
\hline Português & $\begin{array}{c}60,38(15,16) 60,00 \\
(40-90)\end{array}$ & $\begin{array}{c}61,21(17,04) 60,00 \\
(30-100)\end{array}$ & $\begin{array}{c}77,17(17,98) 80,00 \\
(40-100)\end{array}$ & 9,16 & $<0,001$ \\
\hline Matemática & $\begin{array}{c}63,46(15,73) 60,00 \\
(35-90)\end{array}$ & $\begin{array}{c}60,69(14,31) 60,00 \\
(40-90)\end{array}$ & $\begin{array}{c}78,67(19,11) 80,00 \\
(40-100)\end{array}$ & 10,00 & $<0,001$ \\
\hline
\end{tabular}

Verificou-se diferenças estatísticas significativas nas comparações entre os grupos quanto ao desempenho escolar das crianças nas disciplinas português e matemática. Quanto as comparações entre grupos referentes ao desempenho escolar em português, identificou-se diferenças significativas entre G1 e G3 ( $p \leq 0,001)$ e G2 e G3 $(p \leq 0,001)$, tendo as crianças de G3 notas maiores que G1 e G2. Para matemática, foram identificadas diferenças significativas entre G1 e G3 ( $p \leq 0,003)$ e G2 e G3 ( $p \leq 0,001)$, tendo também as crianças de G3 notas maiores que G1 e G2.

\subsection{Comparações entre os grupos quanto aos recursos e eventos estressores do ambiente}

\section{familiar}

No quinto tópico, serão apresentadas as comparações entre os grupos G1, G2 e G3, quanto aos recursos (RAF), eventos estressores (EEA) e as adversidades crônicas (EAC) do 
ambiente familiar das crianças. Além disso, expor-se-ão as comparações quanto esses indicadores, tendo por referência: (a) as famílias que convivem Com depressão materna e as famílias que convivem Sem depressão materna e (b) as crianças classificadas como Com dificuldades e Sem dificuldades comportamentais no SDQ.

$\mathrm{Na}$ Tabela 7 são apresentadas as comparações entre os grupos G1, G2 e G3 quanto aos recursos, estressores e adversidades.

Tabela 7 - Comparações entre os grupos (G1, G2 e G3) quanto aos recursos (RAF), eventos estressores (EEA) e às adversidades crônicas (EAC) do ambiente familiar $(n=85)$.

\begin{tabular}{|c|c|c|c|c|c|}
\hline $\begin{array}{r}\text { Grupos } \\
\text { Instrumentos }\end{array}$ & $\begin{array}{c}\text { G1 } \\
\text { M(DP)Mediana } \\
\text { (Mín-Máx) }\end{array}$ & $\begin{array}{c}\text { G2 } \\
\text { M(DP)Mediana } \\
\text { (Mín-Máx) }\end{array}$ & $\begin{array}{c}\text { G3 } \\
\text { M(DP)Mediana } \\
\text { (Mín-Máx) }\end{array}$ & $\begin{array}{l}\text { Valor } \\
\text { do teste }\end{array}$ & p-valor* \\
\hline$R A F$ & $\begin{array}{c}52,52(8,28) 52,91 \\
(39,50-69,72)\end{array}$ & $\begin{array}{c}54,2(7,24) 55,52 \\
(39,85-65,50)\end{array}$ & $\begin{array}{c}57,06(6,36) 56,78 \\
(42,06-70,44)\end{array}$ & 298,66 & 0,066 \\
\hline$E E A$ & $\begin{array}{c}9,35(3,38) 9,00 \\
(5,00-15,00)\end{array}$ & $\begin{array}{c}7,55(4,09) 7,00 \\
(0,00-16,00)\end{array}$ & $\begin{array}{c}7,70(2,87) 6,50 \\
(3,00-15,00)\end{array}$ & --- & 0,097 \\
\hline$E A C$ & $\begin{array}{c}2,00(1,41) 2,00 \\
(0,00-5,00)\end{array}$ & $\begin{array}{c}1,69(1,49) 1,00 \\
(0,00-6,00)\end{array}$ & $\begin{array}{c}1,03(1,12) 1,00 \\
(0,00-4,00)\end{array}$ & --- & 0,020 \\
\hline $\begin{array}{l}\text { ta. M = Média; DP } \\
\text { EA e EAC) / p } \\
\text { mportamento; } \mathrm{G} 2= \\
\mathrm{G} 3=\text { mães que não } \\
\mathrm{AF}=\text { Inventário d } \\
\text { dversidades Crônic }\end{array}$ & $\begin{array}{l}\text { = Desvio Padrão; *p-va } \\
0,05 ; \mathrm{G} 1=\text { mães qu } \\
\text { nães que não apresenta } \\
\text { presentaram indicador } \\
\text { Recursos do Ambier }\end{array}$ & Familiar; EEA = & $\begin{array}{l}\text { ANOVA (RAF) e ao } \\
\text { ores de depressão e }\end{array}$ & $\begin{array}{l}\text { lemas de } \\
\text { rsos; EA }\end{array}$ & $\begin{array}{l}\text { rruskal-Wall } \\
\text { problemas d } \\
\text { omportament } \\
\text { mportament } \\
=\text { Escala d }\end{array}$ \\
\hline
\end{tabular}

Verificou-se ausência de diferenças estatisticamente significativas entre os grupos nas avaliações relativas aos recursos (RAF) e eventos estressores (EEA). Com relação aos eventos adversos, embora numericamente os valores de G1 tenham sido superiores a G2 e G3, não se observou diferenças com significância estatística. Por meio da comparação entre os grupos, foram identificadas diferenças estatisticamente significativas entre G1 e G3 quanto à variável adversidades crônicas (EAC). Na comparação grupo a grupo para a EAC, detectou-se diferença significativa entre G1 e G3 (p=0,006), não sendo observadas diferenças nas comparações entre G1 e G2, nem entre G2 e G3.

$\mathrm{Na}$ Tabela 8 são apresentadas as comparações relativas aos recursos e adversidades, considerando a distribuição nos grupos, tendo por referência a variável depressão materna. 
Tabela 8 - Comparações quanto aos recursos (RAF), eventos adversos (EEA) e às adversidades crônicas (EAC) do ambiente familiar de crianças que convivem com mães Com depressão $(\mathrm{n}=26)$ e Sem depressão $(\mathrm{n}=59)$.

\begin{tabular}{|c|c|c|c|c|}
\hline Mães & Com Depressão & Sem Depressão & & \\
\hline Instrumentos & $\begin{array}{l}\text { M(DP)Mediana } \\
\text { (Mín-Máx) }\end{array}$ & $\begin{array}{l}\text { M(DP)Mediana } \\
\text { (Mín-Máx) }\end{array}$ & $\begin{array}{c}\text { Valor } \\
\text { do teste }\end{array}$ & p-valor: \\
\hline$R A F$ & $\begin{array}{c}52,52(8,28) 52,91 \\
39,50-69,72\end{array}$ & $\begin{array}{c}55,66(6,90) 56,6 \\
39,85-70,44\end{array}$ & 573,50 & 0,065 \\
\hline$E E A$ & $\begin{array}{c}9,35(3,38) 9,00 \\
05-15\end{array}$ & $\begin{array}{c}7,63(3,49) 7,00 \\
0-16\end{array}$ & 544,50 & 0,033 \\
\hline$E A C$ & $\begin{array}{c}2,00(1,41) 2,00 \\
(0-05)\end{array}$ & $\begin{array}{c}1,36(1,34) 1,00 \\
(0-06)\end{array}$ & 551,00 & 0,034 \\
\hline
\end{tabular}

Nota. $\mathrm{M}$ = Média; DP = Desvio Padrão; Mín = Mínimo; Máx = Máximo; *p-valor referente ao teste ANOVA / $\mathrm{p} \leq 0,05$; RAF = Inventário de Recursos do Ambiente Familiar; EEA = Escala de Eventos Adversos; EAC $=$ Escala de Adversidades Crônicas.

Quanto aos recursos, observou-se que as médias obtidas pelos grupos de mães com e sem depressão, encontram-se aproximadas, com ausência de diferenças estatísticas significativas. Verificaram-se diferenças estatísticas significativas quanto aos eventos adversos (EEA) e as adversidades crônicas (EAC), relativas às condições de risco. Observouse que as médias obtidas pelo grupo que convive com a depressão, para essas escalas, foram maiores em comparação com as obtidas pelo grupo sem a depressão materna.

A Tabela 9 apresenta as comparações relativas aos recursos e adversidades do ambiente familiar considerando a distribuição dos grupos, tendo por referência a variável problemas de comportamento por parte das crianças segundo a avaliação das mães. 
Tabela 9 - Comparações quanto aos recursos (RAF), eventos adversos (EEA) e às adversidades crônicas (EAC) do ambiente familiar de crianças Com dificuldades comportamentais $(n=55)$ e Sem dificuldades comportamentais $(n=30)$, tendo por referência as avaliações das mães.

\begin{tabular}{|c|c|c|c|c|}
\hline \multirow{2}{*}{$\begin{array}{c}\text { Crianças } \\
\text { Instrumentos }\end{array}$} & Com Dificuldade & Sem Dificuldade & \multirow[b]{2}{*}{$\begin{array}{c}\begin{array}{c}\text { Valor do } \\
\text { teste }\end{array} \\
\end{array}$} & \multirow[b]{2}{*}{ p-valor* } \\
\hline & $\begin{array}{l}\text { M(DP)Mediana } \\
\text { (Mín-Máx) }\end{array}$ & $\begin{array}{l}\text { M(DP)Mediana } \\
\text { (Mín-Máx) }\end{array}$ & & \\
\hline$R A F$ & $\begin{array}{c}53,41(7,73) 53,44 \\
(39,5-69,72)\end{array}$ & $\begin{array}{c}57,07(6,37) 56,79 \\
(42,06-70,44)\end{array}$ & 610,50 & 0,049 \\
\hline$E E A$ & $\begin{array}{c}8,40(3,85) 8,00 \\
(0-16)\end{array}$ & $\begin{array}{l}7,70(2,88) 6,50 \\
\quad(03-15)\end{array}$ & 742,50 & 0,445 \\
\hline$E A C$ & $\begin{array}{c}1,84(1,45) 2,00 \\
(0-06)\end{array}$ & $\begin{array}{c}1,03(1,13) 1,00 \\
(0-04)\end{array}$ & 547,50 & 0,009 \\
\hline
\end{tabular}

Nota. M = Média; DP = Desvio Padrão; Mín = Mínimo; Máx = Máximo; *p - valor referente ao teste U de Mann-Whitney / $\mathrm{p} \leq 0,05 ; \mathrm{RAF}=$ Inventário de Recursos do Ambiente Familiar; EEA = Escala de Eventos Adversos; EAC $=$ Escala de Adversidades Crônicas.

Foram detectadas diferenças estatísticas significativas quanto aos recursos do ambiente familiar (RAF) e quanto as adversidades crônicas (EAC), segundo as avaliações das mães quando das comparações de crianças com dificuldades e sem dificuldades comportamentais. Verificou-se que as crianças com dificuldades comportamentais apresentaram com significância estatística menos recursos do ambiente familiar e foram expostas a mais adversidades crônicas. Quanto aos eventos adversos (EEA), não foram observadas diferenças estatísticas significativas nas comparações relativas ao ambiente familiar de crianças com e sem dificuldades comportamentais.

A Tabela 10 apresenta as comparações relativas aos recursos e adversidades do ambiente familiar considerando a distribuição dos grupos, tendo por referência a variável problemas de comportamento por parte das crianças segundo a avaliação das professoras. 
Tabela 10 - Comparações quanto aos recursos (RAF), eventos adversos (EEA) e adversidades crônicas (EAC) do ambiente familiar de crianças Com dificuldades comportamentais $(\mathrm{n}=20) \mathrm{e}$ Sem dificuldades comportamentais $(\mathrm{n}=65)$, tendo por referência as avaliações das professoras.

\begin{tabular}{ccccc}
\hline Crianças & Com Dificuldade & Sem Dificuldade & & \\
\cline { 2 - 3 } Instrumentos & $\begin{array}{c}\text { M(DP)Mediana } \\
\text { (Mín-Máx) }\end{array}$ & $\begin{array}{c}\text { M(DP)Mediana } \\
\text { (Mín-Máx) }\end{array}$ & $\begin{array}{c}\text { Valor do } \\
\text { teste }\end{array}$ & p-valor* \\
\hline \multirow{2}{*}{$R A F$} & $\begin{array}{c}53,77(7,19) 54,07 \\
(39,50-69,78)\end{array}$ & $\begin{array}{c}55,00(7,19) 56,00 \\
(39,55-70,44)\end{array}$ & 598,50 & 0,594 \\
& $\begin{array}{c}8,60(3,97) 9,00 \\
(0-15)\end{array}$ & $\begin{array}{c}8,02(3,41) 7,00 \\
(2-16)\end{array}$ & 580,00 & 0,466 \\
& & & & \\
$E E A$ & $1,45(0,89) 1,5$ & $1,58(1,52) 1,00$ & 625,00 & 0,790 \\
& $(0-3)$ & $(0-6)$ & & \\
\hline
\end{tabular}

Nota. M = Média; DP = Desvio Padrão; Mín = Mínimo; Máx = Máximo; *p - valor referente ao teste U de Mann-Whitney / $\mathrm{p} \leq 0,05 ; \mathrm{RAF}=$ Inventário de Recursos do Ambiente Familiar; EEA = Escala de Eventos Adversos; EAC = Escala de Adversidades Crônicas.

Comparando-se as condições do ambiente familiar de crianças com e sem problemas de comportamento, segundo a avaliação das professoras, referente as três escalas, as médias encontram-se aproximadas, não sendo identificadas diferenças estatísticas significativas.

A Tabela 11 apresenta as comparações quanto aos recursos, estressores e adversidades do ambiente familiar de crianças considerando a distribuição em três grupos, a saber: (a) sem dificuldades comportamentais segundo a avaliação de mães e professoras, (b) com dificuldades comportamentais, segundo a avaliação de mães ou professoras e (c) com dificuldades comportamentais, segundo a avaliação de mães e professoras. 
Tabela 11 - Comparações quanto aos recursos (RAF), eventos estressores (EEA) e às adversidades crônicas (EAC) do ambiente familiar de crianças Sem dificuldades comportamentais, segundo a avaliação de mães e professoras $(\mathrm{n}=28)$, Com dificuldades comportamentais, segundo a avaliação de mães ou professoras $(n=39)$ e Com dificuldades comportamentais, segundo a avaliação de mães e professoras $(n=18)$.

\begin{tabular}{|c|c|c|c|c|c|}
\hline Grupos & $\begin{array}{c}S \text { dif. }(\text { M e P }) \\
(n=28)\end{array}$ & $\begin{array}{c}C \text { dif. (M ou P) } \\
(n=39)\end{array}$ & $\begin{array}{c}\mathrm{C} \text { dif. }(\mathrm{M} \mathrm{e} P) \\
(\mathrm{n}=18)\end{array}$ & & \\
\hline Instrumentos & $\begin{array}{c}\text { M(DP)Mediana } \\
\text { (Mín-Máx) }\end{array}$ & $\begin{array}{c}\text { M(DP)Mediana } \\
\text { (Mín-Máx) }\end{array}$ & $\begin{array}{l}\text { M(DP)Mediana } \\
\text { (Mín-Máx) }\end{array}$ & $\begin{array}{c}\text { Valor do } \\
\text { teste } \\
\end{array}$ & p-valor* \\
\hline$R A F$ & $\begin{array}{c}56,65(6,11) 56,79 \\
(42,06-70,44)\end{array}$ & $\begin{array}{c}54,22(7,98) 55,00 \\
(39,55-69,78)\end{array}$ & $\begin{array}{c}52,72(7,84) 53,23 \\
(39,50-66,36)\end{array}$ & 2,78 & 0,249 \\
\hline$E E A$ & $\begin{array}{c}7,71(2,95) 6,50 \\
(3-15)\end{array}$ & $\begin{array}{c}8,21(3,67) 8,00 \\
(2-16)\end{array}$ & $\begin{array}{c}8,72(4,14) 9,00 \\
(0-15)\end{array}$ & 0,87 & 0,645 \\
\hline$E A C$ & $\begin{array}{c}1,04(1,17) 1,00 \\
(0-4)\end{array}$ & $\begin{array}{c}1,95(1,61) 2,00 \\
(0-6)\end{array}$ & $\begin{array}{c}1,50(0,92) 2,00 \\
(0-3)\end{array}$ & 6,65 & 0,036 \\
\hline
\end{tabular}

Nota. $\mathrm{S}$ = Sem; C = Com; dif. = dificuldades; $\mathrm{M}$ = Média; DP = Desvio Padrão; Mín = Mínimo; Máx = Máximo; *p-valores referentes ao teste ANOVA (RAF) e ao teste Teste de Kruskal-Wallis (EEA e EAC) / p $\leq 0,05 ; \mathrm{RAF}=$ Inventário de Recursos do Ambiente Familiar; EEA = Escala de Eventos Adversos; EAC = Escala de Adversidades Crônicas.

Quanto aos recursos e estressores do ambiente familiar, não foram identificadas diferenças estatísticas significativas nas comparações entre as crianças sem dificuldades de comportamento no SDQ, segundo as duas avaliações e as crianças com dificuldades a partir das avaliações de mães ou professoras ou ambas. Foram observadas diferenças estatisticamente significativas quanto às adversidades crônicas (EAC) segundo a avaliação das mães ou das professoras quanto ao problema de comportamento das crianças $(p=0,036)$. $\mathrm{Na}$ comparação grupo a grupo para a EAC, detectou-se diferença significativa entre as crianças sem dificuldades comportamentais e aquelas que apresentaram dificuldades na avaliação de mães ou professoras $(p=0,016)$, não sendo observadas diferenças nas demais comparações. 


\subsection{Correlações entre as variáveis}

Apresentar-se-ão as correlações significativas entre os indicadores comportamentais das crianças e as variáveis sociodemográficas, depressão materna, desempenho escolar, recursos e estressores do ambiente familiar.

As correlações significativas entre os indicadores comportamentais das crianças (SDQ), segundo a avaliação de mães e professoras e as variáveis sociodemográficas encontram-se apresentadas na Tabela 12.

Tabela 12 - Correlações significativas entre os indicadores comportamentais das crianças, segundo a avaliação de mães e professoras no SDQ e as variáveis sociodemográficas.

\begin{tabular}{|c|c|c|c|c|c|c|}
\hline \multirow[b]{2}{*}{$\begin{array}{c}\text { Indicadores } \\
\text { Comportamentais } \\
\text { SDQ } \\
\end{array}$} & \multicolumn{6}{|c|}{ Variáveis Sociodemográficas } \\
\hline & $\begin{array}{l}\text { Menor } \\
\text { Idade } \\
\text { Materna }\end{array}$ & $\begin{array}{c}\text { Menos } \\
\text { Escolaridade } \\
\text { Materna }\end{array}$ & $\begin{array}{c}\text { Mães } \\
\text { Sem } \\
\text { Trabalho }\end{array}$ & $\begin{array}{l}\text { Maior } \\
\text { Número } \\
\text { Filhos }\end{array}$ & $\begin{array}{l}\text { Baixa } \\
\text { Renda } \\
\text { Mensal }\end{array}$ & $\begin{array}{c}\text { Presença } \\
\text { Bolsa } \\
\text { Auxílio }\end{array}$ \\
\hline S. Emocionais & - & - & - & - & - & $0,349 * * \mathrm{P}$ \\
\hline Prob. Conduta & - & - & - & - & - & $0,265^{*} \mathrm{M}$ \\
\hline Hiperatividade & & $0,261 * \mathrm{M}$ & $0,224 * \mathrm{M}$ & $0,223 * \mathrm{M}$ & $0,222 * \mathrm{M}$ & - \\
\hline Prob. Rel. Colegas & $-0,269 * \mathrm{P}$ & - & - & - & - & - \\
\hline Escore Total Dif. & - & $0,324 * * \mathrm{M}$ & $0,223 * \mathrm{M}$ & - & $0,358 * * \mathrm{M}$ & $0,262 * \mathrm{M}$ \\
\hline Comp. Pró-Social & - & - & - & $-0,260 * \mathrm{M}$ & - & - \\
\hline
\end{tabular}

Foram observadas 12 correlações significativas, classificadas como fracas e moderadas, sendo 10 relativas às avaliações das mães e duas relativas às avaliações das professoras.

Segundo a avaliação das mães, verificou-se associações positivas entre os indicadores de problemas comportamentais hiperatividade e total de dificuldades no SDQ com menor escolaridade materna e menor renda familiar, bem como associações positivas entre tais indicadores comportamentais com a variável mães sem trabalho. Os dados indicaram que os problemas de conduta das crianças e o total de dificuldades no SDQ correlacionaram-se 
negativamente a presença de bolsa auxílio. Ainda segundo as mães, o indicador hiperatividade associou-se positivamente a maior número de filhos presentes no ambiente familiar, enquanto que o comportamento pró-social se associou negativamente a tal variável.

Quanto à avaliação das professoras, identificou-se relação positiva entre a presença de problemas na escala de sintomas emocionais e presença de auxílio financeiro governamental (bolsa auxílio), bem como correlação positiva entre presença de problemas de relacionamento com colegas e menor idade materna.

A Tabela 13 apresenta as correlações significativas entre os indicadores de depressão materna e as variáveis sociodemográficas.

Tabela 13 - Correlações significativas entre a presença de indicadores de depressão materna e as variáveis sociodemográficas.

\begin{tabular}{cccc}
\hline Depressão & V. Sociodem. & r & $\begin{array}{c}\text { p- } \\
\text { valor }\end{array}$ \\
\hline Presença & Menor Escolaridade materna & $0,366^{* *}$ & 0,001 \\
Presença & Mães sem trabalho & $0,283^{* *}$ & 0,009 \\
Presença & Menor Renda mensal & $0,350^{* *}$ & 0,001 \\
Presença & Menor Classif. Socioecon. & $0,232^{*}$ & 0,032 \\
\hline $\begin{array}{l}\text { Nota. } \mathrm{r}=\text { Coeficiente de correlação referente ao teste de Spearman / } \\
\text { Sociodem. } \text { p }<0,01 \text { e }{ }^{*}<0,05 ; \text { Variáveis Sociodemográficas; Classif. Socioecon.=Classificação Socioeconômica. }\end{array}$
\end{tabular}

A análise das correlações entre os indicadores de depressão materna e as variáveis sociodemográficas escolaridade materna, ocupação materna e renda mensal familiar evidenciaram a presença de valores significativos classificados como positivos e moderados, enquanto que a variável classificação socioeconômica apresentou correlação significativa classificada como fraca. Verificou-se correlações entre a presença de depressão materna e menor escolaridade materna, menor renda mensal familiar, mães sem trabalho e piores classificações socioeconômicas.

A Tabela 14 apresenta as correlações significativas entre os indicadores comportamentais das crianças no SDQ, segundo a avaliação das mães e professoras e a presença de indicadores de depressão materna. 
Tabela 14 - Correlações significativas entre os indicadores comportamentais das crianças no SDQ, segundo a avaliação de mães e professoras e a presença de indicadores de depressão materna.

\begin{tabular}{|c|c|c|c|}
\hline $\begin{array}{c}\text { Indicadores } \\
\text { Comportamentais } \\
\text { (SDQ) }\end{array}$ & $\begin{array}{c}\text { Indicadores } \\
\text { Depressão }\end{array}$ & $\mathbf{r}$ & p-valor \\
\hline S. Emocionais & Presença & $0,319^{* *}(\mathrm{M})$ & 0,003 \\
\hline Prob. Conduta & Presença & $0,333 * *(\mathrm{P})$ & 0,002 \\
\hline Hiperatividade & $\begin{array}{l}\text { Presença } \\
\text { Presença }\end{array}$ & $\begin{array}{c}0,289 * *(\mathrm{M}) \\
0,285 * *(\mathrm{P})\end{array}$ & $\begin{array}{l}0,007 \\
0,008\end{array}$ \\
\hline Prob. Rel. Colegas & Presença & $0,249 *(\mathrm{M})$ & 0,022 \\
\hline Escore Total Dif. & $\begin{array}{l}\text { Presença } \\
\text { Presença }\end{array}$ & $\begin{array}{c}0,490 * *(\mathrm{M}) \\
0,294 * *(\mathrm{P})\end{array}$ & $\begin{array}{c}<0,001 \\
0,006\end{array}$ \\
\hline Comp. Pró-social & Presença & $-0,216^{*}(\mathrm{M})$ & 0,047 \\
\hline
\end{tabular}

Foram detectadas oito correlações significativas entre os indicadores comportamentais das crianças e a depressão materna, com classificações fracas e moderadas, sendo cinco correlações relativas às avaliações das mães e três para as avaliações das professoras. Segundo a avaliação das mães, os indicadores de sintomas emocionais, hiperatividade, problema de relacionamento e escore total de dificuldades se associaram à presença de depressão materna. Tendo como referência a avaliação das professoras, verificou-se correlações positivas dos indicadores problemas de conduta, hiperatividade e total de dificuldades com a variável depressão materna. Evidenciou-se correlação negativa referente ao indicador comportamento pró-social, segundo a avaliação das mães.

A Tabela 15 apresenta as correlações significativas entre os indicadores comportamentais das crianças no SDQ, segundo a avaliação de mães e professoras e o desempenho escolar em português e matemática. 
Tabela 15 - Correlações significativas entre os indicadores comportamentais das crianças no SDQ, segundo a avaliação de mães e professoras e o Desempenho Escolar em português e matemática.

\begin{tabular}{|c|c|c|c|}
\hline $\begin{array}{c}\text { Indicadores } \\
\text { comportamentais } \\
\text { (SDQ) } \\
\end{array}$ & $\begin{array}{l}\text { Desempenho } \\
\text { Escolar }\end{array}$ & $\mathbf{r}$ & p-valor \\
\hline \multirow[t]{2}{*}{ Prob. Conduta } & Português & $-0,364 * *(\mathrm{P})$ & 0,001 \\
\hline & Matemática & $-0,341 * *(\mathrm{P})$ & 0,001 \\
\hline \multirow[t]{2}{*}{ Hiperatividade } & Português & $-0,524 * *(\mathrm{P})$ & $<0,001$ \\
\hline & Matemática & $-0,458 * *(\mathrm{P})$ & $<0,001$ \\
\hline \multirow[t]{4}{*}{ Prob. Rel. Colegas } & Português & $-0,276^{*}(\mathrm{M})$ & 0,011 \\
\hline & & $-0,307 * *(\mathrm{P})$ & 0,004 \\
\hline & Matemática & $-0,272 *(\mathrm{M})$ & 0,012 \\
\hline & & $-0,324 * *(\mathrm{P})$ & 0,003 \\
\hline \multirow[t]{4}{*}{ Escore Total Dif. } & Português & $-0,431 * *(\mathrm{M})$ & $<0,001$ \\
\hline & & $-0,403 * *(\mathrm{P})$ & $<0,001$ \\
\hline & Matemática & $-0,422 * *(\mathrm{M})$ & $<0,001$ \\
\hline & & $-0,388 * *(\mathrm{P})$ & $<0,001$ \\
\hline Comp. Pró-social & Matemática & $-0,230 *(\mathrm{P})$ & 0,034 \\
\hline
\end{tabular}

Segundo a avaliação das mães verificaram-se quatro correlações significativas negativas entre os indicadores comportamentais das crianças e o desempenho escolar, classificadas como moderadas, e nove correlações significativas negativas com classificações fraca, moderadas e forte, segundo as professoras.

Evidenciou-se segundo a avaliação das mães correlações entre os indicadores de dificuldade relacionamento com colegas e total de dificuldades com menor desempenho nas disciplinas português e matemática.

Segundo a avaliação das professoras os indicadores comportamentais problema de conduta, hiperatividade, problema de relacionamento com colegas e escore total de dificuldades foram associados ao menor desempenho escolar das crianças nas disciplinas português e matemática, enquanto que o comportamento pró-social se associou somente à matemática.

A Tabela 16 apresenta as correlações entre os indicadores comportamentais das crianças no SDQ e o desempenho escolar nas disciplinas português e matemática, considerando a distribuição em três grupos, a saber: (a) presença de problemas comportamentais segundo a avaliação das mães, 
(b) presença de problemas comportamentais segundo a avaliação das professoras e (c) presença de problemas comportamentais segundo a avaliação das mães e professoras, conjuntamente.

Tabela 16 - Correlações significativas entre os problemas comportamentais das crianças no SDQ e desempenho escolar nas disciplinas português e matemática, considerando as avaliações das mães, das professoras e mães/professoras em conjunto.

\begin{tabular}{|c|c|c|c|}
\hline $\begin{array}{c}\text { Indicadores } \\
\text { comportamentais } \\
\text { (SDQ) }\end{array}$ & $\begin{array}{l}\text { Desempenho } \\
\text { Escolar }\end{array}$ & $\mathbf{r}$ & p-valor \\
\hline Escore Total Dif. (M) & $\begin{array}{l}\text { Português } \\
\text { Matemática }\end{array}$ & $\begin{array}{l}0,431 \\
0,422\end{array}$ & $\begin{array}{l}<0,001 \\
<0,001\end{array}$ \\
\hline Escore Total Dif. $(P)$ & $\begin{array}{l}\text { Português } \\
\text { Matemática }\end{array}$ & $\begin{array}{l}0,403 \\
0,388\end{array}$ & $\begin{array}{l}<0,001 \\
<0,001\end{array}$ \\
\hline Escore Total Dif. (M e P) & $\begin{array}{l}\text { Português } \\
\text { Matemática }\end{array}$ & $\begin{array}{l}0,517 \\
0,504\end{array}$ & $\begin{array}{l}<0,001 \\
<0,001\end{array}$ \\
\hline
\end{tabular}

Evidenciou-se seis associações significativas positivas entre o escore total de problemas comportamentais das crianças e menor desempenho escolar nas disciplinas português e matemática, segundo as avalições das mães, das professoras e das mães/professoras em conjunto. Identificou-se correlações moderadas nas avaliações das mães e das professoras, enquanto que nas avaliações das mães/professoras em conjunto, foram detectadas relações fortes.

A Tabela 17 apresenta as correlações significativas entre os indicadores comportamentais no SDQ e as variáveis contextuais familiares.

Tabela 17 - Correlações significativas entre indicadores comportamentais das crianças no SDQ e os recursos (RAF) e adversidades crônicas (EAC) do ambiente familiar.

\begin{tabular}{cccc}
\hline $\begin{array}{c}\text { Indicadores } \\
\text { Comportamentais } \\
\text { (SDQ) }\end{array}$ & $\begin{array}{c}\text { Variáveis } \\
\text { Contextuais }\end{array}$ & r & $\begin{array}{c}\text { p- } \\
\text { valor }\end{array}$ \\
\hline S. Emocionais & EAC & $0,287^{* *(M)}$ & 0,008 \\
Escore Total Dif. & RAF & $-0,215^{*}(\mathrm{M})$ & 0,048 \\
& EAC & $0,287^{* *}(\mathrm{M})$ & 0,008
\end{tabular}

Nota. $\mathrm{r}=$ Coeficiente de correlação referente ao teste de Spearman / ** $\mathrm{p}<0,01 \mathrm{e} * \mathrm{p}<0,05$; $\mathrm{M}=$ avaliação das mães. 
Verificaram-se três correlações significativas entre os indicadores comportamentais das crianças, segundo a avaliação das mães, e as variáveis contextuais, sendo uma classificada como fraca e duas moderadas.

Os indicadores sintomas emocionais e escore total de dificuldades se associaram positivamente às adversidades crônicas do ambiente familiar. Identificou-se uma associação negativa entre o escore total de dificuldades e menos recursos do ambiente familiar.

A Tabela 18 apresenta as correlações significativas entre as variáveis contextuais do ambiente familiar e os indicadores de depressão materna.

Tabela 18 - Correlações significativas entre os eventos estressores (EEA) e adversidades crônicas (EAC) do ambiente familiar e os indicadores de depressão materna.

\begin{tabular}{clcc}
\hline $\begin{array}{c}\text { Variável } \\
\text { contextual }\end{array}$ & Depressão & r & $\begin{array}{c}\text { p- } \\
\text { valor }\end{array}$ \\
\hline$E E A$ & Presença & $0,233^{*}$ & 0,032 \\
$E A C$ & Presença & $0,232^{*}$ & 0,033 \\
\hline Nota. $\mathrm{r}=$ Coeficiente de correlação referente ao teste de Spearman $/ * \mathrm{p}<0,05$.
\end{tabular}

Foram observadas duas correlações positivas significativas entre as variáveis contextuais estressores e adversidades crônicas e a depressão materna, classificadas como fracas. 
5 DISCUSSÃO 

A discussão dos dados terá como eixo os objetivos gerais e específicos do presente estudo, que serão tratados em quatro tópicos como descritos a seguir. O primeiro apresentará as análises dos dados do estudo de comparação entre G1, G2 e G3 com relação às características sociodemográficas das crianças, mães e famílias da amostra, assim como as análises do estudo correlacional entre a depressão materna e as variáveis sociodemográficas. O segundo tópico abordará as condições de recursos, eventos adversos e adversidades crônicas familiares, por meio das análises de comparações e correlações, considerando o comportamento das crianças, segundo a avaliação das mães e professoras. No terceiro tópico, serão apresentadas as análises do estudo de comparação e correlação envolvendo os indicadores comportamentais das crianças, tendo como avaliadores mães e professoras, considerando ainda as variáveis contextuais e a depressão materna. No quarto tópico abordarse-á o desempenho escolar das crianças, tendo por referência a avaliação de problemas de comportamento realizadas por mães e professoras, de acordo com as análises de comparações e correlações.

\subsection{Características sociodemográficas da amostra e peculiaridades relativas à depressão}

De modo a contextualizar o estudo, analisar-se-á o perfil sociodemográfico das crianças, mães e famílias, comparando os grupos G1, G2 e G3, de acordo com as respostas das mães, mediante a aplicação do Questionário Geral, para o levantamento das informações sociodemográficas.

Quanto ao perfil das crianças, verificou-se uma distribuição similar referente à idade, à escolaridade e ao sexo, sendo que todas elas frequentavam o Ensino Fundamental e apresentavam idade média de 8,8 anos. Referente ao sexo, evidenciou-se no geral um leve predomínio de crianças do sexo masculino, contudo, detectou-se no grupo G3 (mães com ausência de indicadores de depressão e crianças sem dificuldades comportamentais), mais meninas em comparação aos meninos, sem diferenças estatisticamente significativas entre os grupos.

Com relação ao perfil sociodemográfico das mães e famílias, observou-se também uma homogeneidade entre os grupos quanto às variáveis: idade, estado civil e ocupação materna; escolaridade e ocupação paterna; número filhos e recebimento de bolsa auxílio. Destaca-se na comparação dos grupos um predomínio em G1 (indicadores de depressão 
materna e problemas de comportamento das crianças) de ausência paterna, de famílias com maior número de filhos, assim como um menor número de famílias pertencentes às classes econômicas mais favorecidas, contudo, sem diferenças significativas.

Verificou-se diferenças entre os grupos quanto as variáveis escolaridade das mães e renda mensal familiar, com predomínio de menor escolaridade e menor renda para o grupo G1. Referente à escolaridade materna, a maioria das mães de G1 apresentaram até oito anos de estudo, sendo que na comparação dos grupos, as mães de G1 apresentaram menos anos de escolarização em relação à G2 (mães sem indicadores de depressão e crianças com problemas de comportamento). Tal dado sugere que as mães com indicadores de depressão apresentam menos anos de estudo em comparação às mães com ausência de tal transtorno, na presença de problema de comportamento das crianças.

Quanto a variável renda mensal, as diferenças foram detectadas nas famílias com remuneração de 3 a 5,9 salários mínimos, tendo-se observado menor renda para o grupo das mães com depressão e crianças com problemas de comportamento (G1), quando comparado aos demais grupos (G2 e G3). Nas comparações dos grupos identificou-se menor renda familiar para o grupo das mães com depressão e crianças com problemas de comportamento (G1) em relação às mães com ausência de depressão e crianças com ausência de problemas comportamentais (G3).

O presente estudo ainda identificou associações entre a depressão materna e a ausência de ocupação materna, o que de certo modo também guarda relação com a menor renda. Tal dado é concordante com o estudo de Molina et al. (2012) que destacou a presença de mais sintomas depressivos em mulheres, com quatro a sete anos de escolaridade e com baixo nível socioeconômico, assim como com os estudos de Andrade et al. (2012) e Cunha et al. (2012) que verificaram uma maior probabilidade de depressão em mulheres com menor grau de escolaridade e menor nível socioeconômico.

A análise de tal perfil, coloca em foco o impacto negativo dos fatores contextuais para o desenvolvimento infantil, considerando que os recursos escolaridade materna e condições econômicas das famílias configuram-se como favorecedoras da adaptação infantil (Price \& Zwolinski, 2010). Sob a perspectiva teórica da psicopatologia do desenvolvimento, adotada pelo estudo, considera-se que as condições contextuais podem tanto favorecer o desenvolvimento de competências quanto as dificuldades apresentadas pelas pessoas (Yunes, 2003). Considerando que os fatores de risco ao desenvolvimento infantil são todos os eventos que aumentam a vulnerabilidade das crianças para apresentarem as dificuldades (Masten \& Gewirtz, 2006), pode-se pensar que as características sociodemográficas referentes à baixa 
escolaridade das mães e o baixo nível socioeconômico das famílias, identificadas no grupo G1, sugerem que tais crianças se encontram expostas além da depressão materna, a outras condições de risco.

Verificou-se que outros estudos analisaram a influência de fatores sociodemográficos para o comportamento das crianças, mesmo na ausência da depressão materna. Conforme relatado no estudo de Assis et al. (2009) o qual identificou, em uma amostra da comunidade, como condições de risco as variáveis do contexto familiar baixo nível socioeconômico, baixa escolaridade dos pais e famílias monoparentais. Na mesma direção, o risco socioeconômico, definido por baixa renda familiar e a baixa escolaridade materna, foi apontado no estudo de Lengua et al. (2008) como tendo maior efeito sobre os problemas de comportamento das crianças em comparação aos outros fatores contextuais de risco. Segundo Saur e Loureiro (2014), com base em um estudo de coorte, para os meninos foi identificada associação de problemas comportamentais com o baixo nível socioeconômico das famílias e para as meninas, a baixa escolaridade materna e as famílias mais numerosas foram de mais impacto.

As associações entre a depressão materna com as variáveis sociodemográficas foram analisadas no estudo longitudinal preditivo realizado por Barker et al. (2012), tendo verificado que a baixa escolaridade materna e o baixo nível socioeconômico, foram preditores de depressão materna. A baixa renda familiar, segundo Bouvette-Turcot et al. (2017) e o desenvolvimento de sintomas depressivos na idade adulta guarda associação com a presença de mais adversidades na infância e com menos recursos socioeconômicos. Também na revisão sistemática da literatura de Mendes et al. (2008) relataram que condições familiares de instabilidade financeira e os problemas ocupacionais mostraram-se associados a depressão materna, sendo considerados favorecedores de processos de desadaptação infantil.

Ao se analisar o perfil sociodemográfico da amostra, com foco em condições de risco em separado ou associado à depressão materna, verificou-se a relevância de tais condições para os problemas comportamentais dos escolares. No próximo tópico, analisar-se-á de forma mais ampliada outras condições contextuais reconhecidas pela sua influência para o desenvolvimento infantil, tais como os eventos estressores, as adversidades crônicas, e os recursos do ambiente familiar, considerando suas implicações para os aspectos comportamentais dos escolares. 


\subsection{Depressão materna, recursos e estressores do ambiente familiar: implicações para o comportamento das crianças}

Os recursos, os estressores e as adversidades crônicas do ambiente familiar foram avaliados mediante a aplicação de instrumentos respondidos pelas mães quanto aos recursos (RAF) e eventos adversos (EEA e EAC) do contexto familiar. Os recursos do ambiente familiar são caracterizados como possíveis fatores de proteção à criança, tanto os recursos materiais como humanos (Guidetti, 2007) são considerados fundamentais para a adaptação infantil (Pesce et al., 2004; Pinheiro, 2004). Em contrapartida, as adversidades se relacionam com múltiplos estressores (Masten \& Gewirtz, 2006), com destaque para os fatores de risco, os quais são favorecedores de desfechos negativos de desenvolvimento. Condições diversas tem sido consideradas como risco ao desenvolvimento, sendo exemplos a exposição das crianças à condição de pobreza, ao conflito conjugal, ao desemprego, à exposição à violência, a doenças na família, a morte de um ente querido, ao divórcio, entre outros (Pesce et al., 2004; Matos et al., 2015).

A análise dos dados relativos aos indicadores de recursos, eventos estressores e as adversidades crônicas do ambiente familiar dos grupos de crianças diferenciados pela presença de depressão materna e problemas comportamentais das crianças, atendeu ao objetivo geral do estudo, a saber: Comparar e correlacionar os indicadores relativos aos recursos e aos eventos estressores do ambiente familiar de crianças que convivem com a depressão materna e que, segundo a avaliação de suas mães, apresentam problemas de comportamento, e comparar tais indicadores com os apresentados por crianças que convivem com mães sem indicadores de depressão, e que não apresentam problemas comportamentais, segundo a avaliação de suas mães. Considerou-se como hipóteses norteadoras: (a) as crianças que convivem com a depressão materna, apresentam um ambiente familiar com menos recursos, mais estressores e mais adversidades crônicas; e (b) as crianças com problemas de comportamento, avaliadas por mães e professoras, convivem em ambientes familiares com menos recursos, mais estressores e mais adversidades crônicas.

Nas comparações entre os grupos G1, G2 e G3 quanto aos recursos, eventos estressores e adversidades crônicas do ambiente familiar, não foram identificadas diferenças estatísticas significativas entre os grupos nas avaliações relativas aos recursos e eventos estressores, sendo identificada diferença significativa quanto a variável adversidade crônica, tendo o grupo G1 apresentado mais indicadores que o G3. 
Identificou-se a presença de mais adversidades crônicas no ambiente familiar das crianças que convivem com mães com depressão e apresentam problemas de comportamento (G1) em comparação à um ambiente familiar com ausência de depressão e ausência de problemas comportamentais das crianças (G3). Tal dado coloca em destaque a presença de múltiplas condições de riscos associadas à depressão materna, sendo concordante com os estudos de Ferriolli et al. (2007) que apontaram associação entre os riscos familiares e os problemas de comportamento das crianças, identificando a influência dos fatores de risco discórdia conjugal severa, desvantagem socioeconômica, tamanho grande da família, criminalidade paterna e transtorno mental da mãe como condições associadas aos problemas externalizantes infantis. De modo semelhante, tais dados corroboram também com o relato de Antoni e Batista (2014) que ao analisarem estudos de caso referiram que múltiplas situações de risco do ambiente familiar, tais como, histórico de abuso sofrido pelos próprios pais na infância, experiência de baixo apoio familiar, alcoolismo do esposo, estresse parental, sintomatologia psicopatológica dos pais, práticas educativas inadequadas, episódios de violência, foram associadas à presença de problemas de comportamento nos filhos.

A constatação da presença de mais indicadores de condições de risco para G1 evidenciou a exposição das crianças à outras condições de adversidades além da depressão materna (Mendes et al., 2008) com mais impacto negativo para as crianças (Evans et al., 2013). Assim, os dados do presente estudo referendam estudos prévios que afirmam que a depressão materna se configura como uma adversidade ao desenvolvimento infantil (Goodman et al., 2011), que em associação com outros fatores de risco promovem um prejuízo ainda maior ao desenvolvimento das crianças (Halpern \& Figueiras, 2004).

Considerando o reconhecimento da influência da depressão materna associada aos riscos contextuais para os problemas comportamentais das crianças, o presente estudo buscou examinar os recursos, estressores e adversidades crônicas do ambiente familiar das crianças que convivem com a depressão em comparação aquelas que não convivem com tal transtorno. Com relação aos grupos diferenciados pela depressão materna, não foram observadas diferenças significativas quanto aos recursos do contexto familiar, sinalizando para a possibilidade de tais famílias estarem se organizando para o enfrentamento das adversidades, comumente associadas a depressão materna, o que é sugestivo de recursos de resiliência familiar, tal como definido por Walsh (2005).

Contudo, quando da comparação do grupo com depressão (G1) com os outros dois grupos sem depressão (G2 e G3) verificou-se a presença, com significância estatística, de mais indicadores de estressores e de adversidades crônicas. Tal dado é concordante com o 
estudo de Sá et al. (2010) que destacou associações entre problemas de saúde mental familiar com outros fatores de riscos recorrentes, tais como, violência conjugal física grave contra a mãe, punição física grave de crianças, ideação suicida da mãe e embriaguez do pai/padrasto. As associações entre a depressão materna e adversidades do ambiente familiar foram apontadas também na revisão sistemática de Pizeta et al. (2013) no qual relataram a associação da depressão materna à adversidades relativas ao estilo parental, a organização familiar e interações intrafamiliares. Tais dados corroboram também com o relatado por Wang et al. (2013) referente às associações entre a depressão materna e riscos contextuais como o controle rígido dos pais e menor escolaridade materna.

Analisar-se-á à seguir as fontes de informações sobre o comportamento das crianças. Atendendo ao objetivo do estudo de comparar os recursos, estressores e adversidades crônicas do ambiente familiar das crianças tendo por foco o comportamento dos escolares, foram realizadas comparações de tais fatores em grupos diferenciados pela presença e ausência de dificuldades comportamentais dos escolares, segundo a avaliação das mães. Verificou-se com significância estatística menos recursos e mais adversidades crônicas para o ambiente familiar de crianças com dificuldades comportamentais, contudo tais diferenças não foram identificadas para a variável eventos adversos.

Tais dados são concordantes com o exposto por Marturano (1999) que apontou que os recursos presentes no ambiente familiar podem funcionar como fatores protetores do desenvolvimento de escolares, enquanto que o número elevado de riscos e poucos recursos podem contribuir para a vulnerabilidade das crianças, dificultando o ajustamento escolar e a adaptação social. Com amostras da comunidade, Goodman et al. (2007) identificaram associações entre os problemas comportamentais das crianças com a convivência numa família não-tradicional, ao abuso de álcool na família, o estresse dos pais e a punição física severa; e Vitolo et al. (2005), verificaram associações entre os problemas de comportamento das crianças com a punição física, os problemas de saúde mental dos cuidadores e as condições socioeconômicas desfavoráveis.

Quanto à comparação dos recursos e adversidades das crianças com e sem dificuldades comportamentais, segundo a avaliação das professoras, verificou-se a ausência de diferenças estatisticamente significativas, o que difere das avaliações feitas pelas mães. As discordâncias nas comparações dos dados obtidos segundo a avaliação das mães e professoras, podem ser decorrentes dos diferentes contextos em que os comportamentos foram observados (Leis et al., 2014), ou ainda podem decorrer de diferenças nas percepções e observações feitas de uma mesma criança (Stivanin et al., 2008). 
Dado o interesse em se analisar de forma mais ampla os problemas comportamentais segundo os avaliadores, destacar-se-á a seguir os aspectos identificados quanto ao comportamento das crianças nos dois contextos, família (avaliado pelas mães) e escola (avaliado pelas professoras).

$\mathrm{Na}$ comparação dos recursos, eventos estressores e adversidades crônicas entre os grupos diferenciados pela ausência/presença de problemas comportamentais, de acordo com a avaliação combinada de mães e professoras, os grupos se diferenciaram quanto às adversidades crônicas. Nas comparações entre os grupos, referentes às adversidades crônicas, foram observadas diferenças significativas entre as crianças sem dificuldades comportamentais nos dois contextos (avaliação de mães e professoras) e as crianças com dificuldades comportamentais (avaliação de mães ou professoras), sinalizando para a presença de mais adversidades crônicas no ambiente familiar das crianças que manifestam problemas de comportamento no contexto familiar ou escolar, quando comparados às crianças sem problemas na avaliação conjunta de mães e professoras.

Tais dados apontaram para a presença de mais adversidades crônicas no ambiente familiar das crianças com problemas de comportamento, sinalizando ainda uma maior vulnerabilidade das crianças aos riscos quando os problemas comportamentais são identificados também no contexto escolar, além do familiar. Considerando que no período escolar, pode ocorrer a exposição a mais eventos estressores no contexto familiar e escolar (Poletto et al., 2009; Marturano, 2006) verifica-se a necessidade de ampliar a compreensão sobre tais fatores, atentando para os dois ambientes, de forma a se ter uma visão mais integrada das condições de desenvolvimento dos escolares.

Ressalta-se que diversos estudos vêm reconhecendo a relevância de avaliações realizadas também pelos professores, além das mães, uma vez que esses tomam como parâmetro a convivência diária com diferentes crianças em situações mais estruturadas que as vivenciadas no contexto familiar (Berg-Nielsen et al., 2012), embora poucos estudos tenham investigado as dificuldades comportamentais das crianças com ênfase em múltiplos informantes. O predomínio da participação da mãe como único informante pode trazer vieses às avaliações, especialmente quando a mãe apresenta algum transtorno psicopatológico (Leis at al., 2014), como a depressão, a qual pode influenciar a percepção dos comportamentos infantis, justificando a utilização de fontes distintas e combinadas para a informação sobre os aspectos comportamentais de escolares.

Concluindo esse tópico, abordar-se-á as hipóteses formuladas. Considerando a convivência com a depressão materna, verificou-se a presença, com significância estatística, 
de mais indicadores de estressores e de adversidades crônicas, assim a hipótese formulada foi parcialmente confirmada, uma vez que verificou-se semelhanças nos dados referentes aos recursos do ambiente familiar de crianças que convivem com a depressão materna e as diferenças previstas com relação aos estressores e adversidades.

Quanto às análises para os dados relativos as crianças com e sem dificuldades comportamentais, segundo a avaliação das mães, verificou-se a presença, com significância estatística, de menos recursos e mais adversidades crônicas no ambiente familiar das crianças com problemas de comportamento. Entretanto, na avaliação das professoras, observou-se semelhanças nas médias dos recursos e adversidades, sem diferenças significativas. A hipótese formulada, inicialmente, foi parcialmente confirmada, considerando que identificouse semelhanças nos dados referentes aos eventos estressores e as diferenças previstas quanto aos recursos e adversidades crônicas, na avalição das mães, enquanto que na avalição das professoras, ocorreram semelhanças nos dados referentes aos recursos e adversidades.

No próximo tópico serão expostas as análises que contemplam o comportamento dos escolares, considerando a influência da depressão materna, dos aspectos contextuais e as comparações das avaliações de mães e professoras.

\subsection{Indicadores comportamentais das crianças: avaliações de mães e professoras}

O comportamento das crianças, no presente estudo, foi avaliado mediante a aplicação de um instrumento de rastreamento de problemas comportamentais (SDQ), respondido pelas mães e pelas professoras. Na idade escolar o comportamento das crianças se caracteriza como uma das tarefas típicas de desenvolvimento (Dessen \& Polonia, 2007), estando a avaliação do sucesso ou fracasso associados aos indicadores de adequação das crianças às demandas de socialização, enquanto competência comportamental de auto-regulação, o que juntamente com a competência cognitiva para o aprendizado escolar formal, expressam os recursos de adaptação ao meio social mais amplo (Marturano et al., 2009). Dificuldades de adaptação ou disfunção nessas tarefas, pode ser considerado indicadores de problemas (Wrigth \& Masten, 2006) com desvio das normas específicas para essa etapa do desenvolvimento (Price \& Zwolinski, 2010). No presente estudo, os indicadores comportamentais foram avaliados pelo SDQ, a partir da nota de corte proposta por Goodman (1997), referida para o contexto brasileiro por Fleitlich, Cortázar e Goodman (2000). 
Os problemas comportamentais das crianças se destacam como relevantes tanto no contexto familiar como escolar, por representarem as dificuldades mais frequentes apresentadas pelos escolares (Achenbach et al., 2008), o que justifica, a relevância de mães e professoras avaliarem o comportamento das crianças. Sob essas considerações foi estabelecido o segundo objetivo geral do estudo, a saber: comparar e correlacionar os indicadores comportamentais das crianças, segundo a avaliação de suas mães e das suas professoras. Definiu-se como hipóteses: (a) que as mães avaliarão mais problemas de comportamento em comparação às professoras; e (b) que as crianças que convivem com mães depressivas apresentarão mais problemas de comportamento, segundo a avaliação das mães e professoras, em comparação as crianças que convivem com mães sem indicadores de depressão.

Considerando que os indicadores comportamentais das crianças se destacam pela importância que assumem no período escolar (Marturano \& Loureiro, 2003), analisou-se a influência da depressão materna e dos aspectos contextuais para os aspectos comportamentais dos escolares, assim como foi realizada a comparação das avaliações de mães e professoras quanto a tais indicadores, o que será abordado separadamente nos próximos tópicos.

\subsubsection{Indicadores comportamentais das crianças e influência da depressão materna}

A depressão vem sendo associada a maior frequência no sexo feminino (Andrade et al., 2012), especialmente na faixa etária que inclui o período reprodutivo (Markowitz, 2008). Considera-se que as mães com tal transtorno são mais propensas a apresentarem dificuldades de relacionamento com seus filhos, com mais verbalizações críticas e menos afirmações de suporte, além de tenderem a ter um controle coercitivo e inconsistente com seus filhos (Goodman \& Gotlib, 1999) o que tem um impacto negativo para o exercício da maternidade, na interação mãe-criança e no ambiente familiar (Loosli et al., 2016).

A influência da depressão materna para os desfechos de problemas comportamentais das crianças vem sendo abordada em vários estudos (Pizeta et al., 2013), considerando que tal transtorno se configura como uma condição de adversidade com impacto negativo para o desenvolvimento das crianças, caracterizando-se pelo aumento das dificuldades comportamentais e emocionais (Elgar et al., 2004) dos escolares (Wickramaratne et al., 2011). No presente estudo, combinou essas duas condições ao se constituir o G1, adotando-se como 
condições necessárias para a inclusão das díades a presença da depressão materna, avaliada pelo PHQ-9, e o problema comportamental das crianças avaliado pelo SDQ, respondido pelas mães.

Foram realizadas correlações entre os indicadores comportamentais, segundo a avaliação das mães e professoras, com a presença de indicadores de depressão materna. As análises apontaram associações entre a depressão materna com o escore total de dificuldades e hiperatividade, na avaliação de mães e professoras; enquanto que somente na avaliação das mães a depressão se associou aos problemas emocionais, e somente na avaliação das professoras, a depressão se associou aos problemas de conduta.

Ao se verificar as associações da depressão materna com o escore total de dificuldades comportamentais, segundo mães e professoras, mostra-se a relevância dessa condição associada a mais problemas nos dois contextos, familiar e escolar. Além dessa associação, verificou-se ainda várias associações específicas em cada contexto, o que remete as considerações de Pilowsky et al. (2006) quanto a presença de diversas dificuldades nas crianças que convivem com a depressão materna. Tais dados corroboram com os dados de dois estudos longitudinais, a saber, o de Bagner et al. (2010) que identificou associações entre o comportamento das crianças com o transtorno materno, destacando que a convivência com a depressão materna durante o primeiro ano de vida dos filhos, favoreceu os problemas de comportamento externalizante e internalizante até os 12 anos de idade; e o estudo de Galéra et al. (2011) que relataram a relação entre a depressão materna aos cinco meses de vida com o comportamento hiperativo e impulsivo das crianças, na faixa etária de oito anos. Estudos longitudinais recentes também relataram associações da depressão materna a mais problemas de comportamento externalizante e internalizante, conforme apontado por Edwards e Hans (2015); assim como associações entre os sintomas depressivos maternos precoces e o surgimento de problemas comportamentais posteriores na criança (Conners-Burrow et al., 2016).

Verifica-se que tais associações vêm sendo abordadas também nos estudos transversais, conforme relatado por Tompson et al. (2010) que apontaram associações entre o transtorno depressivo materno com a ansiedade e problemas de conduta por parte dos filhos na idade de oito a 12 anos, e por Loosli e Loureiro (2010) que identificaram mais problemas de comportamento internalizante e externalizante nas crianças que convivem com mães depressivas. 


\subsubsection{Indicadores comportamentais das crianças e aspectos contextuais}

Conforme já mencionado, os riscos psicossociais e ambientais (Matos et al., 2015) se caracterizam como eventos negativos ocorridos durante a trajetória de vida, que prejudicam o desenvolvimento saudável do indivíduo (Yunes et al., 2007). No presente estudo, foi focalizada a influência de tais riscos para as crianças no período escolar. Considerando que os riscos envolvem uma rede complexa de acontecimentos anteriores e posteriores a um determinado evento negativo, e que variam conforme as circunstâncias de vida (Rutter, 1987), o estudo analisou as correlações entre o comportamento das crianças e as variáveis sociodemográficas e do ambiente familiar, segundo a avaliação das mães e professoras.

Constatou-se segundo a avaliação das mães associações entre: os indicadores de hiperatividade e do escore total de dificuldades com menos escolaridade materna; assim como, o escore total de dificuldade se associou com baixa renda familiar e presença de bolsa auxílio. Os dados ainda indicaram associações entre os indicadores problemas de conduta e a presença de bolsa auxílio, assim como de menos comportamento pró-social com maior número de filhos. Quanto à avaliação das professoras, identificou-se relações entre sintomas emocionais e a presença de bolsa auxílio e de problemas de relacionamento com menor idade materna. Também foram realizadas análises correlacionais dos indicadores comportamentais das crianças com os recursos e adversidades crônicas familiares, apontando para associações entre os problemas emocionais e escore total de dificuldades com as adversidades crônicas.

Outros estudos analisaram a influência dos fatores contextuais para o comportamento das crianças, tal como relatado por Anhalt et al. (2007) que identificaram associações entre a baixa renda familiar no período perinatal com maiores níveis de problemas de comportamento externalizante das crianças da primeira série do ensino fundamental, e com os achados de Saur e Loureiro (2014) que indicaram associações entre os problemas comportamentais nos meninos com o baixo nível socioeconômico familiar, e nas meninas, com a baixa escolaridade materna e com famílias mais numerosas. Com relação as adversidades crônicas, Bordin et al. (2009) examinaram as relações entre a variável punição física severa com problemas de saúde mental, tendo identificado associações entre tal variável e os problemas externalizantes das crianças.

Quanto aos recursos, as análises identificaram negativas e fracas associações entre o escore total de dificuldades com os recursos do ambiente familiar das crianças, apontando para a presença de menos recursos no contexto familiar das crianças com dificuldades gerais 
de comportamento, portanto, no presente estudo os recursos se mostraram com associações mais frágeis com relação ao comportamento das crianças, colocando em foco a relevância das adversidades para tais crianças. Nesse sentido, tal dado difere de outros estudos que relataram que os recursos do ambiente familiar influenciam positivamente o comportamento das crianças, conforme observado no estudo de Marturano e Elias (2016) tendo identificado associações entre a rotina regular das crianças com menos problemas de comportamento externalizante e menos problemas sociais, assim como associações entre o recurso lazer com menos problemas internalizantes. Assim como os dados relatados por Ferrioli et al. (2007) que identificaram a rotina diária com horários definidos e a oferta de atividades no tempo livre, como recursos protetores à saúde mental das crianças entre seis e 12 anos de idade.

Os achados neste tópico chamam a atenção para vulnerabilidade das crianças quando expostas à múltiplos fatores de riscos, o que é concordante com o relatado por Halpern e Figueiras (2004), ao considerarem que a exposição das crianças à vários riscos promove mais impacto negativo ao desenvolvimento infantil, quando comparado à presença de riscos isolados. Considera-se ser relevante no contexto da depressão materna, verificar a influência para o comportamento das crianças de outros fatores de risco, enquanto determinantes sociais e variáveis do ambiente familiar. $\mathrm{O}$ contexto em que se expressam as dificuldades das crianças será abordado no próximo tópico, onde serão apresentadas as análises que contemplam o comportamento dos escolares, segundo a avaliação de mães e professoras.

\subsubsection{Indicadores comportamentais das crianças e comparações de avaliadores}

Nas comparações entre as avaliações relativas ao comportamento das crianças, tendo por referência mães e professoras como respondentes, verificou-se diferenças significativas nas quatro escalas de dificuldades e total de dificuldades, com destaque para a avaliação das mães que identificaram mais problemas de comportamento, em comparação à percepção das professoras. Tal dado é concordante com o relatado por Stivanin et al. (2008) indicando a presença na avaliação dos pais de mais respostas que preencheram critérios para a categoria “desenvolvimento anormal" do que as respostas dos professores, quando da avaliação de crianças escolares; e com o estudo de prevalência realizado por Cury e Golfeto (2003) que identificou mais problemas de comportamento na avaliação realizada pelos pais $(18,7 \%)$, quando comparada com a avaliação dos professores $(8,3 \%)$. 
Considera-se que uma possível explicação para as discordâncias entre os relatos de mães e professoras se refere às diferenças dos contextos nos quais os comportamentos são observados, uma vez que o ambiente familiar permite um quadro mais detalhado sobre o comportamento do avaliado (Leis et al., 2014; Achenbach, 1991), tendo como parâmetro a avaliação individual, em contrapartida, verifica-se que em sala de aula, o professor avalia as crianças de forma coletiva, sendo adotado como critério de avaliação, a comparação do comportamento das crianças ao de um conjunto de crianças. Ainda, pode-se considerar que tais discordâncias ocorrem devido à influência da saúde mental materna (Leis et al., 2014), sobretudo a depressão, uma vez que tal transtorno pode influenciar a percepção da mãe sobre os problemas das crianças (Mendes et al., 2008).

Quanto à comparação entre os grupos G1, G2 e G3 em relação aos indicadores comportamentais das crianças, segundo a avaliação das mães, verificou-se a presença de diferenças significativas para as quatro escalas de dificuldades e total de dificuldades. Tais dados encontram-se em consonância com o critério do estudo, uma vez que todas as crianças de G1 e G2, por critério, deveriam apresentar dificuldade de comportamento, enquanto as crianças de G3 deveriam apresentar ausência de problemas.

Nas comparações entre os grupos, identificou-se diferenças estatísticas significativas entre G1 e G2, quanto à escala emocional, sinalizando que as mães com depressão identificam mais problemas emocionais nas crianças, em comparação as mães que não apresentam tal transtorno. Esse dado remete ao estudo de Fanti e Henrich (2010) que verificaram associações entre os problemas de comportamento internalizante das crianças com a depressão materna; e com os achados de Bolsoni-Silva et al. (2016) que constataram associações dos problemas internalizantes, com a depressão materna e menos habilidade social infantil.

Nas avaliações realizadas pelas professoras quanto ao comportamento das crianças frente as comparações dos grupos G1, G2 e G3, verificou-se diferenças significativas para as escalas problemas de conduta, hiperatividade, relacionamento com colegas e total de dificuldades, destacando-se nesta avaliação o predomínio do comportamento externalizante. Em concordância com tais achados, no estudo de Kovess et al. (2015) os professores avaliaram as crianças com mais problemas externalizantes e menos problemas internalizantes em comparação à avaliação dos pais. Com relação ao sexo das crianças, os professores identificaram níveis mais elevados de problemas externalizantes para os meninos, em comparação às mães que identificaram mais comportamento internalizante para as meninas (Goodman et al., 2005; Bolsoni-Silva et al., 2006). 
Conforme já mencionado, no contexto escolar, as professoras avaliam o comportamento das crianças de forma coletiva, ou seja, enquadrando-as no modelo comportamental esperado em sala de aula, sendo que as crianças que não se enquadram nesse padrão, tendem a ser avaliadas como desadaptadas (Bolsoni-Silva et al., 2006). Destaca-se que tanto os problemas internalizantes como os externalizantes expressam dificuldades quanto ao desenvolvimento infantil, caracterizando-se como os déficits ou excessos comportamentais vivenciados nas interações (Bolsoni-Silva, 2003). Os problemas internalizantes favorecem as dificuldades de relacionamento com os pares ou com os adultos, enquanto que os conflitos provenientes dos problemas externalizantes promovem rejeições por parte de pais, professores e colegas (Bolsoni-Silva et al., 2006).

$\mathrm{Na}$ comparação entre os grupos identificou-se diferenças estatísticas significativas entre G1 e G3, quanto à escala relacionamento com colegas, sinalizando que as professoras identificam mais problemas de relacionamento nas crianças que convivem com a depressão materna, em comparação as crianças sem problemas de comportamento e que não convivem com tal transtorno (G3). Tal achado permite detalhar as dificuldades das crianças expostas à depressão materna, especialmente quando da identificação dos problemas também no contexto escolar.

Ainda quanto as análises de comparações entre os grupos G1, G2 e G3, segundo a avaliação das professoras, verificou-se diferenças estatísticas significativas quanto às capacidades e recursos das crianças, tendo as professoras identificado menos indicadores de comportamento pró-social nas crianças, em comparação às mães.

Nas comparações entre os grupos, identificou-se diferenças entre os grupos G1 e G3 e G2 e G3, sendo que as crianças com problemas comportamentais apresentaram também menos indicadores de comportamento pró-social, portanto, têm mais dificuldades e também menos recursos, independente da condição de convivência com a depressão materna. As crianças de G2 ao apresentarem menos recursos, denotaram também as suas dificuldades potenciais para a tarefa de socialização típica do período (Marturano \& Loureiro, 2003).

Tais dados remetem a outros estudos que abordaram os recursos das crianças, tais como o de Gavasso et al. (2016) o qual destacou os aspectos socioemocionais, caracterizados pelo vínculo parental, vínculos de amizade e acolhimento institucional escolar, como favorecedores do desenvolvimento das práticas sociais assertivas das crianças e o de Gomide (2006) que identificou associações entre os comportamentos pró-sociais com as práticas parentais positivas, ressaltando que práticas parentais positivas ou negativas, interferem diretamente no comportamento das crianças. 
Considerando as comparações dos grupos G1, G2 e G3, tendo as professoras como avaliadoras do comportamento das crianças, mais crianças de G1 apresentaram problemas de comportamento em comparação as crianças de G2 e G3, com significância estatística. Ao se verificar mais dificuldades comportamentais nas crianças com mães com depressão, tem-se ampliado a compreensão sobre a influência de tal transtorno para os problemas das crianças, considerando a concordância nas avaliações realizadas quanto a presença de problemas nos dois contextos, família e escola.

Nas comparações dos grupos, evidenciou-se diferenças significativas entre G1 e G3 para o escore total de dificuldades, problemas de conduta e hiperatividade, e entre os grupos G2 e G3 para a hiperatividade, sinalizando para a presença de mais comportamento externalizante nas crianças que convivem com a depressão materna, na avaliação das professoras. Entretanto, destaca-se a presença de mais hiperatividade nos grupos de crianças com problemas que convivem com a depressão materna e naquelas que não convivem com tal transtorno, o que evidencia a influência de outros fatores de risco, além da depressão materna, para os problemas comportamentais dos escolares.

Baseado em tais achados, considera-se importante atentar para a vulnerabilidade das crianças quando da identificação de problemas comportamentais em dois ambientes distintos, conforme o critério de avaliação adotado pelo presente estudo, uma vez que a concordância de dois avaliadores sobre tais problemas, permite um quadro mais detalhado sobre o comportamento das crianças (Achenbach, 1991). Tal dado chama a atenção para a amplitude e peculiaridades dos dois ambientes, família e escola, e ainda para os diferentes critérios de adaptação considerados pelas duas fontes de avaliações, o que coloca em destaque a relevância da contribuição do presente estudo.

Em suma, os achados desse tópico confirmaram as hipóteses inicialmente formuladas, uma vez que: (a) as mães identificaram mais problemas de comportamento nas crianças, em comparação às avaliações das professoras; e (b) as crianças que convivem com mães depressivas apresentaram mais problemas de comportamento, segundo a avaliação das mães e professoras, em comparação as crianças que convivem com mães sem indicadores de depressão.

No período escolar, além da importância dos indicadores comportamentais como tarefa típica do desenvolvimento das crianças, o desempenho acadêmico se configura como um outro indicador de desenvolvimento, tão importante quanto o comportamento (Marturano \& Loureiro, 2003), sob tal enfoque, o próximo tópico abordará o desempenho escolar das crianças e os indicadores de comportamento, avaliados por mães e professoras. 


\subsection{Desempenho escolar e indicadores comportamentais de crianças: avaliações de mães e professoras}

A cada estágio de desenvolvimento as crianças se deparam com novas demandas de aprendizagem, que requerem habilidades e conhecimentos ainda não adquiridos (Marturano, 2013). Nesse sentido, o desempenho acadêmico assume no período escolar a importância de um indicador que expressa a capacidade adaptativa, por ser reconhecido como parte de uma tarefa típica do período (Marturano \& Loureiro, 2003) frente a qual as crianças podem apresentar sucesso ou dificuldades acadêmicas (Wright \& Masten, 2006; Price \& Zwolinski, 2010).

Considerando que as dificuldades acadêmicas podem favorecer as dificuldades comportamentais e emocionais dos escolares (Marturano \& Loureiro, 2003; D'abreu \& Marturano, 2010), o presente estudo, analisou o desempenho escolar das crianças mediante uma breve avaliação geral, baseada nas informações das professoras, referente às disciplinas português e matemática, por meio das notas obtidas pelas crianças nos dois últimos bimestres anteriores à avalição. A análise das notas, baseou-se na definição de desempenho escolar relatada por Bernard et al. (2006), os quais referiram como baixo desempenho escolar a presença de notas abaixo do nível esperado para a idade ou para as habilidades e potencial da criança.

Nesse cenário, se insere um dos objetivos do presente estudo, que visou comparar $e$ correlacionar o desempenho escolar das crianças com e sem dificuldades de comportamento, tendo por referência a avaliação de problemas de comportamento feita pelas mães e pelas professoras. Assim, tendo como foco os problemas comportamentais das crianças, formulou-se como hipótese norteadora que as crianças com problemas comportamentais, segundo a avaliação de mães e professoras, apresentarão menor desempenho escolar em comparação às crianças sem problemas comportamentais.

As análises de comparações entre os grupos referentes ao desempenho escolar das crianças nas disciplinas português e matemática, segundo a avaliação das professoras, indicaram diferenças significativas entre os grupos nas duas disciplinas. Nas comparações entre os grupos, identificou-se diferenças significativas entre G1 e G3 e entre G2 e G3, tendo as crianças de G3 maiores notas em relação as crianças de G1 e G2 nas duas disciplinas. Tais dados apontaram que as crianças com dificuldades comportamentais, independente da depressão materna (G1), apresentaram também menor desempenho escolar. Os achados são 
concordantes com o estudo de Cia e Barham (2009) que abordou as associações entre os problemas comportamentais das crianças e variáveis como as habilidades sociais e o baixo desempenho escolar; e o estudo de Elias e Amaral (2016) que verificou que o treino de habilidades sociais, teve impacto positivo para o comportamento e o desempenho escolar.

Considerando a constatação das dificuldades escolares para as crianças dos grupos G1 e G2, evidencia-se a influência negativa da depressão materna (G1) e de outros fatores de riscos familiares para os problemas comportamentais e para o baixo desempenho acadêmico. Verificou-se em estudos prévios que as variáveis relativas ao desempenho escolar das crianças, foram em sua maioria, analisadas enquanto associadas aos riscos contextuais familiares. Nesse sentido, pode-se pensar que outras condições familiares adversas podem influenciar negativamente o comportamento das crianças, que por sua vez promovem prejuízos no desempenho escolar, conforme observado no presente estudo. Tais achados remetem ao estudo de revisão realizado por D’Abreu e Marturano (2010) que constataram associações entre o baixo desempenho escolar e os problemas externalizantes das crianças, sugerindo a influência de variáveis como as condições familiares adversas.

Com sentido semelhante, Loosli et al. (2016) correlacionaram os desfechos comportamentais e escolares de crianças que conviviam com a depressão materna, considerando as diferenças de sexo, tendo identificado associações entre os problemas emocionais das meninas e as habilidades de escrita, assim como entre problemas de relacionamento com colegas e dificuldades escolares no total e nos domínios de leitura e escrita; e Pavan et al. (2012) analisaram a influência da depressão materna para o comportamento e o desempenho escolar das crianças, tendo identificado que dois terços das crianças avaliadas apresentaram dificuldades comportamentais e de desempenho escolar, evidenciando a influência da depressão materna para as duas variáveis.

Outros estudos destacaram a influência dos riscos familiares para o desempenho escolar das crianças, mesmo na ausência da variável depressão materna, como ilustrado pelos achados de Santos e Graminha (2005) que identificaram associações entre o maior número de adversidades no ambiente familiar das crianças, sobretudo a baixa renda familiar e baixa escolaridade parental, com o baixo rendimento escolar; em contrapartida, verificaram que o ambiente familiar das crianças com alto rendimento escolar, tinha mais recursos materiais e de estímulos para o desenvolvimento infantil. A influência dos recursos do ambiente familiar para o aprendizado acadêmico das crianças também foi analisada por Marturano (2006) relatando que a interação pais e filhos, assim como os recursos passeios, brinquedos e livros associaram-se aos indicadores de competência escolar e ao bom ajustamento das crianças. 
Considerando a importância da relação entre o comportamento das crianças e o desempenho escolar, foram realizadas no presente estudo, análises correlacionais entre os indicadores comportamentais dos escolares, tendo como avaliadores mães e professoras, e o desempenho escolar em português e matemática. Quanto às análises, tendo como respondentes as mães, os dados apontaram para associações entre os problemas de relacionamento e escore total de dificuldades com menor desempenho nas duas disciplinas; enquanto que na avaliação das professoras, as análises indicaram associações entre os indicadores problema de conduta, hiperatividade, dificuldade de relacionamento e escore total de dificuldades com menor desempenho em português e matemática.

Os achados sinalizam para a presença de associações entre os problemas comportamentais das crianças e o baixo desempenho escolar, tanto na avaliação das mães, como das professoras. Constata-se, segundo as mães que as crianças que tem dificuldades escolares, apresentam também dificuldades de socialização, e segundo as professoras, as crianças com baixo desempenho escolar, tem múltiplos problemas de comportamento, com predomínio dos externalizantes conduta e hiperatividade. Destaca-se segundo a avalição das professoras a presença de negativas e fortes associações entre o indicador hiperatividade e menor desempenho em português, chamando a atenção para a forte influência da hiperatividade sobre tais dificuldades de desempenho nessa disciplina.

Referente às associações entre o escore total de dificuldades (SDQ) das crianças com o desempenho escolar nas disciplinas português e matemática, segundo as avaliações das mães e professoras, os dados mostraram associações entre o escore total de dificuldades com menor desempenho nas duas disciplinas, tanto na avaliação das mães, como na avaliação das professoras. A presença de fortes associações positivas entre as duas variáveis, sinalizou a concomitância dos indicadores de problemas comportamentais e das dificuldades escolares, colocando em evidência a maior vulnerabilidade de tais crianças.

Dessa forma, os achados desse tópico confirmaram as hipóteses inicialmente formuladas, considerando que mães e professoras identificaram a presença de menor desempenho escolar para as crianças com problemas comportamentais, quando comparadas às crianças sem problemas comportamentais.

Considera-se que tais achados são relevantes, pois poucos estudos têm investigado a influência das dificuldades comportamentais das crianças para o desempenho escolar, tendo por base dois informantes. 
6 CONSIDERAÇÕES FINAIS 

Ao se concluir o presente estudo apresentar-se-á algumas considerações sobre os limites metodológicos e contribuições do mesmo, com destaque para os principais resultados e sua aplicabilidade.

Ao se analisar os aspectos metodológicos do estudo, faz-se necessário apontar alguns limites, relativos ao delineamento adotado, e aos recursos utilizados para a avaliação da depressão e do desempenho escolar. O presente estudo adotou um delineamento transversal, o qual não permitiu a verificação da sequência temporal da influência da depressão materna e das demais variáveis de risco do contexto familiar para os comportamentos das crianças, o que poderia ser investigado com maior precisão por meio de um delineamento longitudinal, com medidas das variáveis avaliadas em diversos momentos da vida das crianças. Quanto à avaliação da depressão da materna, foi utilizada uma medida de rastreamento, e não foi realizada uma medida de diagnóstico de tal transtorno, não sendo obtidas informações referentes às condições clínicas, especialmente a gravidade, a recorrência, recaídas e tempo de exposição da criança à sintomatologia materna. Referente ao desempenho escolar, procedeu-se a avaliação por meio das notas obtidas pelas crianças nos dois bimestres que antecederam a inclusão no estudo, embora tenha homogeneidade quanto a fonte de informação, cada professora tem particularidades ao atribuir notas, o que torna tal avaliação menos sistemática, do que seria por exemplo, se tivesse sido adotado medidas de avaliação por meio de testes padronizados como o Teste de desempenho escolar (TDE) ou ainda a Provinha Brasil, o que possibilitaria a avaliação da criança de forma mais ampla, de modo a compará-la com um parâmetro coletivo. Outro limite a ser assinalado diz respeito aos dados terem sido coletados com uma amostra advinda de uma única escola, o que limita a generalização dos resultados, embora se possa relativizar tal limite quando se tem em conta o IDH da cidade e sua semelhança com outros tantos municípios.

Em contrapartida, faz-se necessário apontar também alguns cuidados adotados que favoreceram a qualidade metodológica do estudo, tais como: (a) a realização da coleta de dados pela própria pesquisadora, com boa experiência clínica e treinada para o uso das técnicas de avaliação; (b) a utilização de duas fontes de informações, mães e professoras, na coleta de dados referentes aos indicadores comportamentais das crianças, o que favoreceu a ampliação da avaliação de tais indicadores; (c) bem como a inclusão de variáveis diversas, relativas ao ambiente familiar, de modo a identificar os fatores de risco que favorecem os problemas comportamentais dos escolares e as condições de proteção para tais dificuldades; e ainda (d) a avaliação com uma mesma amostra desse conjunto de indicadores, o que permitiu uma visão ampliada sobre a questão de pesquisa do estudo. 
Considerando-se os objetivos do presente estudo destacar-se-á e analisar-se-á os principais resultados relativos: (a) as comparações quanto aos recursos e eventos estressores do ambiente familiar de grupos de crianças diferenciados pela convivência com a depressão materna e com problemas de comportamento; (b) as comparações das avaliações de mães e professoras quanto ao comportamento das crianças; e (c) as correlações referentes aos indicadores comportamentais das crianças, as variáveis contextuais e o desempenho escolar.

Ao se analisar as variáveis do contexto familiar quanto às condições de risco e proteção dos grupos, detectou-se que: (a) as crianças que convivem com a depressão materna estão expostas a mais eventos adversos e mais adversidades crônicas do ambiente familiar em comparação às que não convivem com tal transtorno; e (b) as crianças com dificuldades comportamentais, segundo a avaliação das mães, contam com menos recursos e mais adversidades crônicas do ambiente familiar em comparação às crianças sem problemas comportamentais, contudo, tais diferenças não foram identificadas nas avaliações das professoras.

Quanto aos indicadores comportamentais das crianças, foram identificadas diferenças significativas nas comparações das avaliações de mães e professoras nas quatro escalas de dificuldades (Sintomas Emocionais, Problemas de Conduta, Hiperatividade, Problemas de Relacionamento com Colegas), sendo detectado mais problemas de comportamento nas avaliações das mães, em comparação às avaliações das professoras. Verificou-se que a depressão materna se associou aos problemas emocionais, somente na avaliação das mães e aos problemas de conduta, somente na avaliação das professoras.

No que se refere à comparação do desempenho escolar das crianças nas disciplinas Português e Matemática, nas avaliações das professoras verificou-se, com diferenças significativas, menores notas para as crianças que convivem com a depressão materna e para as que tem dificuldades comportamentais. Nas avaliações das professoras constatou-se associações entre os indicadores comportamentais escore Total de Dificuldades e as escalas Problemas de Conduta, Hiperatividade e Problemas de Relacionamento com Colegas, com menor desempenho escolar nas disciplinas Português e Matemática; e nas avaliações das mães foram observadas associações entre o escore Total de Dificuldades e a escala Problemas de Relacionamento com Colegas, com o menor desempenho escolar nas duas disciplinas.

Podem ser ressaltadas como principais contribuições do presente estudo: (a) a verificação da presença de múltiplas adversidades no ambiente familiar das crianças que convivem com a depressão materna e de crianças com problemas de comportamento, caracterizando um contexto de desenvolvimento com riscos cumulativos, mostrando as 
semelhanças de tais grupos quanto aos indicadores de adversidades; (b) a presença de menos recursos no ambiente familiar das crianças com problemas comportamentais, o que com a presença de mais adversidades aponta para a vulnerabilidade de tais crianças; (c) a identificação de divergências nas avaliações de mães e professoras quanto aos problemas de comportamento das crianças, evidenciando os diferentes parâmetros de avaliação utilizados nos contextos familiar e escolar, avançando quanto ao reconhecimento sobre a relevância do uso de múltiplos informantes; e (d) a verificação da associação entre os problemas comportamentais dos escolares e o baixo desempenho escolar, na avaliação de mães e professoras, apontando para a vulnerabilidade de tais crianças nos dois domínios que caracterizam as tarefas típicas de desenvolvimento no período escolar, a saber, a socialização e o desempenho escolar.

Nesse sentido, considera-se que o presente estudo, dentro dos seus limites, avançou quanto ao conhecimento sobre as lacunas da literatura apontadas por Goodman et al (2011), uma vez que pôde-se verificar com uma mesma amostra, as variáveis contextuais de riscos familiares e de proteção para as crianças que convivem com a depressão materna, como condições associadas que influenciam as dificuldades comportamentais de escolares, tendo por base as informações de dois avaliadores, mães e professoras, abrangendo assim, os contextos familiar e escolar.

Quanto às implicações para novas pesquisas com base nos dados obtidos, propõe-se que estudos futuros adotem delineamentos longitudinais que considerem a influência dos riscos contextuais ao longo do desenvolvimento infantil, incluindo outras fontes de informação além do relato materno; que ampliem as análises dos aspectos clínicos da depressão materna, para melhor compreensão das peculiaridades das influências de tais indicadores do transtorno depressivo para o desenvolvimento infantil; que examinem as especificidades das adversidades e suas possíveis influências; e ainda que na avaliação do desempenho escolar das crianças seja adotado instrumentos padronizados considerando um parâmetro coletivo de avaliação.

Com relação a aplicabilidade, os dados deste estudo chamam a atenção para um grupo de crianças mais vulneráveis, considerando as dificuldades comportamentais e as dificuldades de desempenho escolar, o que coloca em foco a relevância do planejamento de programas de prevenção na escola voltados para as tarefas de desenvolvimento das crianças no período escolar, de modo a permitir identificar as condições de riscos e favorecer as condições de promoção do desenvolvimento das crianças. Assim, como do ponto de vista clínico, tais dados sugerem a relevância do planejamento de programas de intervenção familiar, especialmente, 
quando identificado sintomas depressivos maternos e múltiplas adversidades do contexto familiar, enquanto condições ou eventos que demandam atenção para a proposição de ações que favoreçam o enfrentamento das adversidades, com possíveis benefícios para o comportamento das crianças.

Tendo em vista as referidas considerações, conclui-se que os objetivos do presente estudo foram alcançados e que seus resultados contribuíram para uma melhor compreensão dos recursos, eventos estressores e adversidades crônicas do ambiente familiar das crianças, escolares, que convivem com a depressão materna e que apresentam problemas de comportamento, tendo como informantes mães e professoras, o que pode favorecer o planejamento de programas de prevenção em escolas e de intervenções com familiares. 

Achenbach, T. M. (1991). Manual for the youth self-report and 1991 profile. Burlington: Department of Psychiatry, University of Vermont.

Achenbach, T. M., \& Edelbrock, C. S. (1979). The Child Behavior Profile: II. Boys aged $12-$ 16 and girls aged 6-11 and 12-16. Journal of Consulting and Clinical Psychology, 47(2), 223-233. doi: 10.1037//0022-006X.47.2.223.

Achenbach, T. M., Becker, A., Döpfner, M., Heiervang, E., Roessner, V., Steinhausen, H. C., et al. (2008). Multicultural assessment of child and adolescent psychopathology with ASEBA and SDQ instruments: research findings, applications, and future directions. Journal of Child Psychology and Psychiatry, 49(3), 251-275. doi: 10.1111/j.14697610.2007.01867.

Almeida, L. G. R., \& Faro, A. (2016). Levantamento e principais achados de estudos nacionais sobre a depressão. Revista Interdisciplinar de Pesquisa e Inovação, 2(1). Recuperado de https://seer.ufs.br/index.php/revipi/article/view/5066/4384 .

American Psychiatric Association. (2015). What Is Depression? Recuperado de http://www. psychiatry.org/patients-families/depression/what-is-depression.

Andrade, L. H., Wang, Y. P., Andreoni, S., Silveira, C. M., Alexandrino-Silva, C., Siu, E. R., ... \& Viana, M. C. (2012). Mental disorders in megacities: findings from the Sao Paulo megacity mental health survey, Brazil. PloS one, 7(2), e 31879. doi: 10.1371/journal.pone.0031879.

Angelini, A. L., Alves, I. C. B., Custódio, E. M., Duarte, W. F., \& Duarte, J. L. M. (1999). Matrizes progressivas coloridas de Raven: escala especial. São Paulo: Centro Editor de Testes e Pesquisas em Psicologia.

Anhalt, K., Telzrow, C. F., \& Brown, C. L. (2007). Maternal stress and emotional status during the perinatal period and childhood adjustment. School Psychology Quarterly, 22(1), 74. doi: 10.1037/1045-3830.22.1.74.

Antoni, C., \& Batista, F. A. (2014). Violência familiar: Análise de fatores de risco e proteção. Diaphora, 14(2), 26-35. Recuperado de http://www.sprgs.org.br/diaphora/ojs/index. php/diaphora/article/view/62/62.

Antunes, C., \& Fontaine, A. M. (2005). Percepção de apoio social na adolescência: análise fatorial confirmatória da escala Social Support Appraisals. Paidéia, 15(32), 355-366. Recuperado de http://oaji.net/articles/2014/6551404757488.pdf.

Assis, S. G., Avanci, J. Q., \& Oliveira, R. D. V. C. D. (2009). Socioeconomic inequalities and child mental health. Revista de saúde pública, 43, 92-100. doi: 10.1590/S003489102009000800014. 
Bagner, D. M., Pettit, J. W., Lewinsohn, P. M., \& Seeley, J. R. (2010). Effect of maternal depression on child behavior: a sensitive period?. Journal of the American Academy of Child \& Adolescent Psychiatry, 49(7), 699-707. doi:10.1016/j.jaac.2010.03.012.

Barker, E. D., Copeland, W., Maughan, B., Jaffee, S. R., \& Uher, R. (2012). Relative impact of maternal depression and associated risk factors on offspring psychopathology. The British Journal of Psychiatry, 200(2), 124-129. doi: 10.1192/bjp.bp.111.092346.

Bee, H. (2003). A criança em desenvolvimento. Porto Alegre: Artmed.

Bele, S. D., Bodhare, T. N., Valsangkar, S., \& Saraf, A. (2013). An epidemiological study of emotional and behavioral disorders among children in an urban slum. Psychology, health \& medicine, 18(2), 223-232. doi: 10.1080/13548506.2012.701751.

Benetti, S. P. C. (2006). Conflito conjugal: impacto no desenvolvimento psicológico da criança e do adolescente. Psicologia, Reflexão e Crítica, 19(2), 261-268. doi: 10.1590/S0102-79722006000200012.

Berg-Nielsen, T. S., Solheim, E., Belsky, J., \& Wichstrom, L. (2012). Preschoolers' psychosocial problems: In the eyes of the beholder? Adding teacher characteristics as determinants of discrepant parent-teacher reports. Child Psychiatry \& Human Development, 43(3), 393-413. doi: 10.1007/s10578-011-0271-0.

Bernard, M. E., Ellis, A., \& Terjesen, M. (2006). Rational-emotive behavioral approaches to childhood disorders: History, theory, practice and research. In A. Ellis \& M. E. Bernard, Rational emotive behavioral approaches to childhood disorders: Theory, Practice and Research (pp. 3-84). New York: Springer US.

Bolsoni-Silva, A. T. (2003). Habilidades sociais educativas, variáveis contextuais e problemas de comportamento: comparando pais e mães de pré-escolares (Doctoral dissertation, Universidade de São Paulo). doi: 10.11606/T.59.2003.tde-10082004134158.

Bolsoni-Silva, A. T., \& Carrara, K. (2010). Habilidades sociais e análise do comportamento: compatibilidades e dissensões conceitual-metodológicas. Psicologia em revista, 16(2), 330-350. Recuperado de http://pepsic.bvsalud.org/scielo.php?script=sci_arttext\&pid= S1677-11682010000200007.

Bolsoni-Silva, A. T., \& Mariano, M. L. (2014). Práticas educativas de professores e comportamentos infantis, na transição ao primeiro ano do Ensino Fundamental. Estudos e Pesquisas em Psicologia, 14(3), 814-833. Recuperado de http://pepsic.bvsalud.org. 
Bolsoni-Silva, A. T., Loureiro, S. R., \& Marturano, E. M. (2016). Comportamentos internalizantes: associações com habilidades sociais, práticas educativas, recursos do ambiente familiar e depressão materna. Psico, 47(2), 111-120. doi: 10.15448/19808623.2016.2.20806.

Bolsoni-Silva, A. T., Mariano, M. L., Loureiro, S. R., \& Bonaccorsi, C. (2013). Contexto escolar: práticas educativas do professor, comportamento e habilidades sociais infantis. Psicologia Escolar e Educacional, 259-269. doi:10.1590/S1413-85572013000200008.

Bolsoni-Silva, A. T., Marturano, E. M., Pereira, V. A., \& Manfrinato, J. D. S. (2006). Habilidades sociais e problemas de comportamento de pré-escolares: comparando avaliações de mães e de professoras. Psicologia: reflexão e crítica, 19(3), 460-469. doi: 10.1590/S0102-79722006000300015.

Bordin, I. A., Duarte, C. S., Peres, C. A., Nascimento, R., Curto, B. M., \& Paula, C. S. (2009). Severe physical punishment: risk of mental health problems for poor urban children in Brazil. Bulletin of the World Health Organization, 87(5), 336-344. doi: 10.1590/S004296862009000500010.

Borsa, J. C., Souza, D. S. D., \& Bandeira, D. R. (2011). Prevalência dos problemas de comportamento em uma amostra de crianças do Rio Grande do Sul. Psicologia: teoria e prática, 13(2), 15-29. Recuperado de http://pepsic.bvsalud.org/scielo.php?script= sci_arttext\&pid=S1516-36872011000200002.

Bouvette-Turcot, A. A., Unternaehrer, E., Gaudreau, H., Lydon, J. E., Steiner, M., Meaney, M. J., \& MAVAN Research Team. (2017). The joint contribution of maternal history of early adversity and adulthood depression to socioeconomic status and potential relevance for offspring development. Journal of affective disorders, 207, 26-31. doi: 10.1016/j.jad.2016.08012.

Callender, K. A., Olson, S. L., Choe, D. E., \& Sameroff, A. J. (2012). The effects of parental depressive symptoms, appraisals, and physical punishment on later child externalizing behavior. Journal of abnormal child psychology, 40(3), 471-483. doi: 10.1007/s10802011-9572-9.

Carmo, P. H. B. D., \& Alvarenga, P. (2012). Práticas educativas coercitivas de mães de diferentes níveis socioeconômicos. Estudos de Psicologia (Natal), 17(2), 191-198. doi: 10.1590/S1413-294X2012000200001.

Casali-Robalinho, I. G., Del Prette, Z. A. P., \& Del Prette, A. (2015). Habilidades Sociais como Preditoras para Problemas de Comportamento em Escolares. Psicologia: Teoria e Pesquisa, 31(3), 321-330. doi: 10.1590/0102-37722015032110321330. 
Cia, F., \& Barham, E. J. (2009). Social skills repertory, behavioral problems, self-concept and academic performance among children in their early school years. Estudos de Psicologia (Campinas), 26(1), 45-55. doi: 10.1590/S0103-166X2009000100005.

Cid, M. F. B. (2015). Cotidiano familiar: refletindo sobre a saúde mental infantil e a prática de atividades familiares. Revista de Terapia Ocupacional da Universidade de São Paulo, 26(3), 428-438. doi:10.11606/issn.2238-6149.v26i3p428-438.

Cid, M. F. B., \& Matsukura, T. S. (2014). Problemas de saúde mental em escolares e seus responsáveis: um estudo de prevalência. Revista de Terapia Ocupacional da Universidade de São Paulo, 25(1), 1-10. doi: 10.11606/issn.2238-6149.v25i1p1-10.

Conners-Burrow, N. A., McKelvey, L., Perry, D., Whiteside-Mansell, L., Kraleti, S., Mesman, G., ... \& Kyzer, A. (2016). Low-level symptoms of depression in mothers of young children are associated with behavior problems in middle childhood. Maternal and child health journal, 20(3), 516-524. doi: 10.1007/s10995-015-1849-0.

Correia-Zanini, M. R. G. (2013). Um estudo prospectivo sobre o percurso escolar de crianças nos primeiros anos do Ensino Fundamental (Doctoral dissertation, Universidade de São Paulo). Recuperado de http://www.teses.usp.br.

Cummings, E. M., \& Kouros, C. D. (2009). Maternal depression and its relation to children's development and adjustment. Encyclopedia on early childhood development, 1-6. Recuperado de http://www.child-encyclopedia.com/sites/ default/files/dossiers-complets/en/maternal-depression.pdf\#page $=9$.

Cunha, R. V. D., Bastos, G. A. N., \& Duca, G. F. D. (2012). Prevalence of depression and associated factors in a low income community of Porto Alegre, Rio Grande do Sul. Revista Brasileira de Epidemiologia, 15(2), 346-354. doi: 10.1590/S1415-790X201 2000200012.

Cury, C. R., \& Golfeto, J. H. (2003). Strengths and difficulties questionnaire (SDQ): a study of school children in Ribeirão Preto. Revista Brasileira de Psiquiatria, 25(3), 139-145. doi:10.1590/S1516-44462003000300005 .

D'Abreu, L. C. F., \& Marturano, E. M. (2010). Associação entre comportamentos externalizantes e baixo desempenho escolar: uma revisão de estudos prospectivos e longitudinais. Estudos de Psicologia (Natal), 15(1), 43-51. doi: 10.1590/S1413$294 X 2010000100006$.

D'Abreu, L. C. F., \& Marturano, E. M. (2011). Identificação de problemas de saúde mental associados à queixa escolar segundo o DAWBA. Psico, 42(2), 152-158. Recuperado de http://revistaseletronicas.pucrs.br/ojs/index.php/revistapsico/article/view/8487/6516. 
Del Prette, Z. A. P., \& Del Prette, A. (2012). Habilidades sociais e educação: Pesquisa e atuação em psicologia escolar/educacional. In Z. A. P. Del Prette (Org.), Psicologia escolar e educacional: saúde e qualidade de vida (pp. 113-41), Campinas: Alínea. Mudar data introdução (data 2001 - 2012).

Del Prette, Z.A.P., \& Del Prette A. (2013). Social Skills Inventory (SSI-Del-Prette): Characteristics and studies in Brazil. In F. L. Osório (Org.), Social Anxiety Disorders: From Theory to Pratice (pp.49-62). Nova Yorque: Nova Science Publishers. Recuperado de http://www.rihs.ufscar.br/wp-content/uploads/2015/02/social-skillsinventory-ssi-del-prette-characteristics-and-studies-in-brazil.pdf.

Dessen, M. A., \& Polonia, A. D. C. (2007). A família e a escola como contextos de desenvolvimento humano. Paidéia, 17(36), 21-32. Recuperado de http://www.scielo. br/pdf/paideia/v17n36/v17n36a03.

Dubois-Comtois, K., Moss, E., Cyr, C., \& Pascuzzo, K. (2013). Behavior problems in middle childhood: The predictive role of maternal distress, child attachment, and mother-child interactions. Journal of abnormal child psychology, 41(8), 1311-1324. doi: 10.1007/s10802-013-9764-6.

Duggal, S., Carlson, E. A., Sroufe, L. A., \& Egeland, B. (2001). Depressive symptomatology in childhood and adolescence. Development and psychopathology, 13(01), 143-164. Recuperado de https://www.cambridge.org/core/services/aop-cambridge-core/content/ view/S0954579401001109.

Duncombe, M. E., Havighurst, S. S., Holland, K. A., \& Frankling, E. J. (2012). The contribution of parenting practices and parent emotion factors in children at risk for disruptive behavior disorders. Child Psychiatry \& Human Development, 43(5), 715-733. doi: 10.1007/s10578-012-0290-5.

Edwards, R. C., \& Hans, S. L. (2015). Infant risk factors associated with internalizing, externalizing, and co-occurring behavior problems in young children. Developmental psychology, 51(4), 489. doi:10.1037/a0038800.

Elgar, F. J., McGrath, P. J., Waschbusch, D. A., Stewart, S. H., \& Curtis, L. J. (2004). Mutual influences on maternal depression and child adjustment problems. Clinical psychology review, 24(4), 441-459. doi:10.1016/j.cpr.2004.02.002.

Elias, L. C. D. S., \& Amaral, M. V. (2016). Habilidades Sociais, Comportamentos e Desempenho Acadêmico em Escolares antes e após Intervenção. Psico-USF, 21(1), 4961. doi:10.1590/1413-82712016210105.

Erikson, E. (1976). Infância e Sociedade. Rio de Janeiro: Zahar. 
Evans, G. W., Li, D., \& Whipple, S. S. (2013). Cumulative risk and child development. Psychological Bulletin, 139(6), 1342. doi: 10.1037/a0031808.

Fanti, K. A., \& Henrich, C. C. (2010). Trajectories of pure and co-occurring internalizing and externalizing problems from age 2 to age 12: Findings from the National Institute of Child Health and Human Development Study of Early Child Care. Developmental psychology, 46(5), 1159. doi: 10.1037/a0020659.

Fantinato, A. C., \& Cia, F. (2015). Habilidades sociais educativas, relacionamento conjugal e comportamento infantil na visão paterna: um estudo correlacional. Psico, 46(1), 120128. doi:10.15448/1980-8623.2015.1.17330.

Ferreira, S. H. A., \& Barrera, S. D. (2010). Ambiente familiar e aprendizagem escolar em alunos da educação infantil. Psico, 41(4). Recuperado de http://revistaseletronicas. pucrs.br/ojs/index.php/revistapsico/article/view/5686/0.

Ferriolli, S. H. T., Marturano, E. M., \& Puntel, L. P. (2007). Family context and child mental health problems in the Family Health Program. Revista de Saúde Pública, 41(2), 251259. doi:10.1590/S0034-89102006005000017.

Fleitlich, B. W., Cortázar, P. G., \& Goodman, R. (2000). Questionário de capacidades e dificuldades (SDQ). Infanto - Revista de Neuropsiquiatria da Infância e da Adolescência, 8(1), 44-50.

Galéra, C., Côté, S. M., Bouvard, M. P., Pingault, J. B., Melchior, M., Michel, G., ... \& Tremblay, R. E. (2011). Early risk factors for hyperactivity-impulsivity and inattention trajectories from age 17 months to 8 years. Archives of General Psychiatry, 68(12), 1267-1275. doi:10.1001/archgenpsychiatry.2011.138.

Gallart, I. S. (2007). A organização social da educação: práticas educativas e desenvolvimento humano. In C. Coll (Org.). Psicologia da educação. Porto Alegre: Artmed.

Garber, J. \& Little, S. (1999). Predictors of competence among offspring of depressive mothers. Journal of Adolescent Research, 14(1), 44-71. doi: 10.1177/ 0743558499141004.

Garmezy N., \& Masten, A. (1994). Chronic adversities. In M. Rutter, E. Taylor, \& L. Herson (Eds), Child and adolescente psychiatry (pp. 191- 207). Oxford: Blackwell.

Gavasso, M. S. B, Fernandes, J. D. S. G., \& de Andrade, M. S. (2016). Revisão sistemática de estudos sobre habilidades sociais: avaliação e treinamento. Ciências \& Cognição, 21(1). Recuperado de http://cienciasecognicao.org/revista/index.php/cec/article/view/1050/pdf_70. 
Ghandour, R. M., Kogan, M. D., Blumberg, S. J., Jones, J. R., \& Perrin, J. M. (2012). Mental health conditions among school-aged children: geographic and sociodemographic patterns in prevalence and treatment. Journal of Developmental \& Behavioral Pediatrics, 33(1), 42-54. doi: 10.1097/DBP.0b013e31823e18fd.

Gomes, J. A. M. (2016). Os Recursos do Ambiente Familiar e a Influência no Rendimento Acadêmico. Revista Lugares de Educação, 6(12), 103-124. Recuperado de http:// periodicos.ufpb.br/ojs2/index.php/rle.

Gomide, P. I. C. (2006). Inventário de estilos parentais: modelo teórico, manual de aplicação, apuração e interpretação. Petrópolis: Vozes.

Goodman, A., Fleitlich-Bilyk, B., Patel, V., \& Goodman, R. (2007). Child, family, school and community risk factors for poor mental health in Brazilian schoolchildren. Journal of the American Academy of Child \& Adolescent Psychiatry, 46(4), 448-456. doi: 10.1097/chi.0b013e31803065b5.

Goodman, R. (1997). The strengths and difficulties questionnaire: a research note. Journal of Child Psychology and Psychiatry, 38, 581-586. doi: 10.1111/j.1469-7610.1997. tb01545.x.

Goodman, R., Dos Santos, D. N., Nunes, A. R., de Miranda, D. P., Fleitlich-Bilyk, B., \& Almeida Filho, N. (2005). The Ilha de Maré study: a survey of child mental health problems in a predominantly African-Brazilian rural community. Social Psychiatry and Psychiatric Epidemiology, 40(1), 11-17. doi: 10.1007/s00127-005-0851-z.

Goodman, S. H. \& Gotlib, I. H. (1999). Risk for psychopathology in the children of depressed mothers: a developmental model for understanding mechanisms of transmission. Psychological Review, 106(3), 458-490. doi: 10.1037/0033-295X.106.3.458.

Goodman, S. H.; Rouse, M. H.; Connell, A. M.; Broth, M. R; Hall, C. M., \& Heyward, D. (2011). Maternal Depression and Child Psychopathology: A Meta-Analytic Review. Clinical child and family psychology review, 14(1), 1-27. doi: 10.1007/s10567-0100080-1.

Gross, H. E., Shaw, D. S., Burwell, R. A., \& Nagin, D. S. (2009). Transactional processes in child disruptive behavior and maternal depression: A longitudinal study from early childhood to adolescence. Development and psychopathology, 21(01), 139-156. doi:10.1017/S0954579409000091.

Guidetti, A. A. (2007). Ambiente familiar e desempenho acadêmico de crianças do ensino fundamental. (Dissertação de Mestrado, Universidade Estadual de Campinas). Recuperado de http://repositorio.unicamp.br/jspui/handle/REPOSIP/252061. 
Halpern, R., \& Figueiras, A. C. M. (2004). Influências Ambientais na saúde mental da criança. Jornal de pediatria, 80(2), 104-110. doi: 10.1590/S0021-75572004000300013.

Hameister, Bianca da Rocha, Barbosa, Paola Vargas, \& Wagner, Adriana. (2015). Conjugalidade e parentalidade: uma revisão sistemática do efeito spillover. Arquivos Brasileiros de Psicologia, 67(2), 140-155. Recuperado de http://pepsic.bvsalud.org/ scielo.php?script=sci_arttext\&pid=S1809-52672015000200011.

Kersten-Alvarez, L. E., Hosman, C. M., Riksen-Walraven, J. M., van Doesum, K. T., Smeekens, S., \& Hoefnagels, C. (2012). Early school outcomes for children of postpartum depressed mothers: comparison with a community sample. Child Psychiatry \& Human Development, 43(2), 201-218. doi: 10.1007/s10578-011-0257-y.

Kovess, V., Carta, M. G., Pez, O., Bitfoi, A., Koç, C., Goelitz, D., ... \& Otten, R. (2015). The School Children Mental Health in Europe (SCMHE) Project: Design and First Results. Clinical Practice \& Epidemiology in Mental Health, 11(1). doi: 10.2174/ 1745017901511010113.

Kroenke, K, Spitser, R.L., \& Williams, J. B.W. (2001). The PHQ-9: validity of a brief depression severity measure. Journal of General Internal Medicine, 16(9), 606-613. doi: 10.1046/j.1525-1497.2001.016009606.x.

Leis, J. A., Heron, J., Stuart, E. A., \& Mendelson, T. (2014). Associations between maternal mental health and child emotional and behavioral problems: does prenatal mental health matter?. Journal of abnormal child psychology, 42(1), 161-171. doi: 10.1007/s10802013-9766-4.

Lengua, L. J., Bush, N.R., Long, A. C., Kovacs, E. A., \& Trancik, A. M. (2008). Effortful control as a moderator of the relation between contextual risk factors and growth in adjustment problems. Developmental Psychopathology, 20(2), 509-528. doi: $10.1017 / \mathrm{S} 0954579408000254$.

Loeber, R., Hipwell, A., Battista, D., Sembower, M., \& Stouthamer-Loeber, M. (2009). Intergenerational transmission of multiple problem behaviors: prospective relationships between mothers and daughters. Journal of abnormal child psychology, 37(8), 10351048. doi: 10.1007/s10802-009-9337-x.

Loosli, L., \& Loureiro, S. R. (2010). Associação entre depressão materna e diferenças de gênero no comportamento de crianças: uma revisão sistemática. Revista de Psiquiatria do Rio Grande do Sul, 32(3), 94-101. doi:10.1590/S0101-81082010005000001.

Loosli, L., Pizeta, F. A., \& Loureiro, S. R. (2016). School-age Children who Live with Recurrent Maternal Depression: Differences between the Sexes. Psicologia: Teoria e Pesquisa, 32(3). doi:10.1590/0102-3772e32322. 
Lyra, G. F. D., Assis, S. G., Njaine, K., Oliveira, R. V. C., \& Pires, T. O. (2009). A relação entre professores com sofrimento psíquico e crianças escolares com problemas de comportamento. Ciência \& Saúde Coletiva, 14(2), 435-444. Recuperado de http://scielo.br/pdf/csc/v14n2/a12v14n2.pdf.

Macana, E. C., \& Comim, F. (2015). O papel das práticas e estilos parentais no desenvolvimento da primeira infância. In G.A. Pluciennik, M. C. Larazzari, M. F. Chicaro, Fundamento da família como promotora do desenvolvimento infantil: parentalidade em foco, 1 (pp. 34 - 47). Recuperado de http://ocomecodavida.com. br/fundamentos-familia/.

Macedo, R. M. (1994). A família do ponto de vista psicológico: lugar seguro para crescer? Caderno de Pesquisa, 91, 62-68. Recuperado de http://publicacoes.fcc.org.br/ojs/ index.php/cp/article/view/877/883.

Markowitz, J. (2008). Depressed Mothers, Depressed Children. American Journal of Psychiatry, 165(9), 1086-1088. doi:10.1176/appi.ajp.2008.08060861.

Marturano, E. M. (1999). Recursos no ambiente familiar e dificuldades de aprendizagem na escola. Psicologia: Teoria e Pesquisa, 15(2), 135-142. Recuperado de http://www. scielo.br/pdf/ptp/v15n2/a06v15n2.pdf.

Marturano, E. M. (2006). O inventário de recursos do ambiente familiar. Psicologia: Reflexão e Crítica, 19(3), 498-506. doi:10.1590/S0102-79722006000300019.

Marturano, E. M. (2013). A criança, a família, a escola e a transição para o ensino fundamental. In E. C., Konkiewitz (Org), Aprendizagem, comportamento e emoções na infância e adolescência: uma visão transdisciplinar (47). Dourados: UFGD. Recuperado de http://www.unilas.com.br/arquivos/Download/Ebooks/Aprendizagem comportamentoeemocoesnainfanciaeadolescentes.pdf\#page $=47$.

Marturano, E. M., \& Elias, L. C. D. S. (2016). Family, learning disabilities and behavior problems in schoolchildren. Educar em Revista, (59), 123-139. doi: 10.1590/01044060.44617 .

Marturano, E. M., \& Elias, L. C. S. (2006). O atendimento psicológico a crianças com dificuldades escolares. In E. F. S. Matos (Org.), Atendimento psicológico em clínicasescola (pp. 75-90) Campinas: Alínea.

Marturano, E. M., \& Loureiro, S. R. (2003). O desenvolvimento socioemocional e as queixas escolares. In A. Del Prette \& Z. A. P. Del Prette (Orgs.), Habilidades sociais, desenvolvimento e aprendizagem (pp. 259-291). Campinas: Alínea. 
Marturano, E. M., \& Pizato, E. C. G. (2015). Preditores de Desempenho Escolar no $5^{\circ}$ Ano do Ensino Fundamental. Psico, 46(1), 16-24. doi:10.15448/1980-8623.2015.1.14850.

Marturano, E. M., Trivellato-Ferreira, M. D. C., \& Gardinal, E. C. (2009). Estresse cotidiano na transição da $1^{a}$ série: percepção dos alunos e associação com desempenho e ajustamento. Psicologia: Reflexão e Crítica, 22(1), 93-101. doi: 10.1590/S010279722009000100013.

Masten, A. S., \& Gewirtz, A. H. (2006). Vulnerability and Resilience in Early Child Development. In: K. Mccartney, \& D. Phillips (Eds), Blackwell Handbook of Early Childhood Development, (pp. 22-43). Oxford: Blackwell Publishing.

Matos, M. B., Cruz, A. C. N, Dumith, S. C., Dias, N. C., Carret, R. B. P. \& Quevedo, L. A. (2015). Eventos estressores na família e indicativos de problemas de saúde mental em crianças com idade escolar. Ciência \& Saúde Coletiva, 20(7), 2157-2163. doi:10.1590/1413-81232015207.17452014.

Mendes, A. V. (2009). Cuidados primários à saúde mental: depressão materna e aspectos comportamentais de crianças em idade escolar (Doctoral dissertation, Universidade de São Paulo). doi:10.11606/D.17.2009.tde-26032009-202413.

Mendes, A. V., Loureiro, S. R., Crippa, J. A., de Meneses Gaya, C., García Esteve, L., \& Martín Santos, R. (2012). Mothers with Depression, School Age Children with Depression? A Systematic Review. Perspectives in psychiatric care, 48(3), 138-148. doi: 10.1111/j.1744-6163.2011.00318.x.

Mendes, A. V.; Loureiro, S. R.; \& Crippa, J. A. S. (2008). Depressão materna e a saúde mental de escolares. Revista de Psiquiatria Clínica, 35 (5), 178 - 186. doi: 10.1590/S0101-60832008000500002.

Mian, L., Tango, L. A., Lopes, J., \& Loureiro, S. R. (2009). A depressão materna e o comportamento de crianças em idade escolar. Psicologia: Teoria e Pesquisa, 25(1), 2937. doi: 10.1590/S0102-37722009000100004.

Molina, M. R. A. L., Wiener, C. D., Branco, J. C., Jansen, K., de Souza, L. D. M., Tomasi, E., ... \& Pinheiro, R. T. (2012). Prevalence of depression in users of primary care settings/Prevalencia de depressao em usuarios de unidades de atencao primaria. Revista de Psiquiatria Clínica, 39(6), 194-198. doi: 10.1590/S0101-60832012000600003.

Muratori, P., Milone, A., Nocentini, A., Manfredi, A., Polidori, L., Ruglioni, L., ... \& Lochman, J. E. (2015). Maternal depression and parenting practices predict treatment outcome in Italian children with disruptive behavior disorder. Journal of Child and Family Studies, 24(9), 2805-2816. doi: 10.1007/s10826-014-0085-3. 
Osório, F. L., Vilela Mendes, A., Crippa, J. A., \& Loureiro, S. R. (2009). Study of the Discriminative Validity of the PHQ-9 and PHQ-2 in a Sample of Brazilian Women in the Context of Primary Health Care. Perspectives in psychiatric care, 45(3), 216-227. doi: 10.1111/j.1744-6163.2009.00224.x.

Papalia, D. E., \& Feldman, R. D. (2013). Desenvolvimento humano. Porto Alegre: AMGH.

Pavan, M., Pizeta, F. A., \& Loureiro, S. R. (2012). Maternal depression, behavioral profile and school performance in school-age children. Psicologia: Reflexão e Crítica, 25(1), 121-129. doi:10.1590/S0102-79722012000100015.

Pereira, M. T., Marturano, E. M., Gardinal-Pizato, E. C., \& Fontaine, A. M. G. (2011). Possíveis contribuições da educação infantil para o desempenho e a competência social de escolares. Psicologia Escolar e Educacional, 15(1), 101-109. doi:10.1590/S141385572011000100011.

Pesce, R. P., Assis, S. G., Santos, N., \& Oliveira, R. V. C. (2004). Risco e proteção: em busca de um equilíbrio promotor de resiliência. Psicologia: Teoria e Pesquisa, 20 (2), 135143. doi: 10.1590/S0102-37722004000200006.

Pilowsky, D. J., Wickramaratne, P., Nomura, Y., \& Weissman, M. M. (2006). Family discord, parental depression, and psychopathology in offspring: 20-year follow-up. Journal of the American Academy of Child \& Adolescent Psychiatry, 45(4), 452-460. doi: 10.1097/01.chi.0000198592.23078.8d.

Pinheiro, D. P. N. (2004). A resiliência em discussão. Psicologia em Estudo, 9(1), 67-75. doi: 10.1590/S1413-73722004000100009.

Pizeta, F. A. (2014). Depressão materna, estressores e resiliência: Preditores do comportamento de escolares (Doctoral dissertation, Universidade de São Paulo). doi: 10.11606/T.17.2014.tde-10112014-213910.

Pizeta, F. A., Silva, T. B. F., Cartafina, M. I. B., \& Loureiro, S. R. (2013). Depressão materna e riscos para o comportamento e a saúde mental das crianças: Uma revisão. Estudos de Psicologia (Natal), 18(3), 429-437. doi:10.1590/S1413-294X2013000300003.

Poletto M, Koller, S.H., \& Dell'Aglio, D. D. (2009). Eventos estressores em crianças e adolescentes em situação de vulnerabilidade social de Porto Alegre. Ciência \& Saúde Coletiva, 14(2), 455-466. doi:10.1590/S1413-81232009000200014.

Price, J. M., \& Zwolinski, Jennifer. (2010). The Nature of child and Adolescent Vulnerability: History and Definitions. In R. E. Ingram \& J. M. Price (Eds.) Vulnerability to Psychopathology - Risk across the Lifespan, (pp. 18 - 38). New York: Guilford Press. 
Psychogiou, L., \& Parry, E. (2014). Why do depressed individuals have difficulties in their parenting role?. Psychological medicine, 44(07), 1345-1347. doi: 10.1017/S0033291 713001931.

Regalla, M. A., Guilherme, P.R., \& Serra-Pinheiro, M. A. (2007). Resiliência e transtorno do déficit de atenção/hiperatividade. Jornal Brasileiro de Psiquiatria, 56 (1), 45-49. doi: 10.1590/S0047-20852007000500010

Riley, A. W., Coiro, M. J., Broitman, M., Colantuoni, E., Hurley, K. M., Bandeen-Roche, K., \& Miranda, J. (2009). Mental health of children of low-income depressed mothers: Influences of parenting, family environment, and raters. Psychiatric Services, 60(3), 329-336. doi:10.1176/ps.2009.60.3.329.

Rutter, M. (1987). Psychosocial resilience and protective mechanisms. American Journal of Orthopsychiatry, 57(3), 316-331. doi: 10.1111/j.1939-0025.1987.tb03541.x.

Sá, D. G. F., Bordin, I. A. S., Martin, D., \& Paula, C. S. (2011). Fatores de risco para problemas de saúde mental na infância/adolescência. Psicologia: Teoria e Pesquisa, 26(4), 643-652. doi: 10.1590/S0102-37722010000400008.

Sameroff, A. J. (2000). Developmental systems and psychopathology. Development and Psychopathology, 12(03), 297 - 312. doi: 10.1017/S0954579400003035.

Santos, L. C. (1999). Crianças com dificuldades de aprendizagem: estudo de seguimento. (Dissertação de Mestrado, Universidade de São Paulo).

Santos, P. L., \& Graminha, S. S. V. (2006). Problemas emocionais e comportamentais associados ao baixo rendimento acadêmico. Estudos de Psicologia, 11(1), 101-109. doi:10.1590/S1413-294X2006000100012.

Saur, A. M., \& Loureiro, S. R. (2012). Qualidades psicométricas do Questionário de Capacidades e Dificuldades: revisão da literatura. Estudos de Psicologia (Campinas), 29(4), 619-629. doi:10.1590/S0103-166X2012000400016.

Saur, A. M., \& Loureiro, S. R. (2014). Problemas comportamentais e emocionais de escolares segundo o gênero. Arquivos Brasileiros de Psicologia, 66(1). Recuperado de http://pepsic.bvsalud.org/scielo.php?script=sci_arttext\&pid=S180952672014000100009

Shannon, K. E., Beauchaine, T. P., Brenner, S. L., Neuhaus, E., \& Gatzke-Kopp, L. (2007). Familial and temperamental predictors of resilience in children at risk for conduct disorder and depression. Development and psychopathology, 19(03), 701-727. doi: $10.1017 /$ S0954579407000351. 
Shaw, D. S., Hyde, L. W., \& Brennan, L. M. (2012). Early predictors of boys' antisocial trajectories. Development and psychopathology, 24(03), 871-888. doi: 10.1017/S0954 579412000429.

Shen, H., Magnusson, C., Rai, D., Lundberg, M., Lê-Scherban, F., Dalman, C., \& Lee, B. K. (2016). Associations of parental depression with child school performance at age 16 years in sweden. Jama psychiatry, 73(3), 239-246. doi:10.1001/jamapsychiatry. 2015.2917.

Silberg, J., Rutter, M., Neale, M., \& Eaves, L. (2001). Genetic moderation of environmental risk for depression and anxiety in adolescent girls. The British Journal of Psychiatry, 179(2), 116-121. doi: 10.1192/bjp.179.2.116.

Sousa, L. R. G. D. (2015). Trajetórias escolares no ensino fundamental: estudo de uma escola pública (Dissertação de Mestrado, Universidade Estadual Paulista Júlio de Mesquita Filho). Recuparado de http://hdl.handle.net/11449/132711.

Spitzer, R. L., Kroenke, K., \& Williams, J. B. W. (1999). Validation and utility of a selfreport version of PRIME-MD: the PHQ primary care study. Journal of the American Medical Association, 282(18), 1737-1744. doi:10.1001/jama.282.18.1737.

Stivanin, L., Scheuer, C.I., \& Assumpção Jr, F.B. (2008). SDQ (Strengths and Difficulties Questionnaire): Identificação de características comportamentais de crianças leitoras. Psicologia: Teoria e Pesquisa, 24(4), 407-413. Recuperado de http://producao.usp. $\mathrm{br} / \mathrm{handle/BDPI} / 9235$.

Szelbracikowski, A. \& Dessen, M. A. (2005). Compreendendo a agressão na perspectiva do desenvolvimento humano. In M. A. Dessen, \& A. L. C. Junior (Orgs.), A ciência do desenvolvimento: tendências atuais e perspectivas futuras (pp. 113-131). Porto Alegre: ArtMed.

Tompson, M. C., Pierre, C. B., Boger, K. D., McKowen, J. W., Chan, P. T., \& Freed, R. D. (2010). Maternal depression, maternal expressed emotion, and youth psychopathology. Journal of abnormal child psychology, 38(1), 105-117. doi 10.1007/s10802-009-93496.

Toth, S. L., \& Cicchetti, D. (2010). The historical origins and developmental pathways of the discipline of developmental psychopathology. The Israel journal of psychiatry and related sciences, 47(2), 95-104. Recuperado de http://web.a-ebscohost-com.ez67. periodicos.capes.gov.br.

Vitolo, Y. L., Fleitlich-Bilyk, B., Goodman, R., \& Bordin, I. A. (2005). Parental beliefs and child-rearing attitudes and mental health problems among schoolchildren. Revista de Saúde Pública, 39(5), 716-724. doi:10.1590/S0034-89102005000500004. 
Walsh, F. (2005). Bases de Abordagem da Resiliência Familiar. In F. Walsh, Fortalecendo a Resiliência Familiar (pp. 3 - 23). São Paulo: Roca.

Wang, F., Christ, S. L., Mills-Koonce, W. R., Garrett-Peters, P., \& Cox, M. J. (2013). Association between maternal sensitivity and externalizing behavior from preschool to preadolescence. Journal of applied developmental psychology, 34(2), 89-100. doi:10.1016/j.appdev.2012.11.003.

Wickramaratne, P., Gameroff, M. J., Pilowsky, D. J., Hughes, C. W., Garber, J., Malloy, E., ... \& Trivedi, M. H. (2011). Children of depressed mothers 1 year after remission of maternal depression: findings from the STAR* D-Child study. American Journal of Psychiatry, 168(6), 593-602. doi: 10.1176/appi.ajp.2010.10010032.

Woerner, W., Fleitlich-Bilyk, B., Martinussen, R., Fletcher, J., Cucchiaro, G., Dalgalarrondo, P., ... \& Tannock, R. (2004). The Strengths and Difficulties Questionnaire overseas: evaluations and applications of the SDQ beyond Europe. European Child \& Adolescent Psychiatry, 13(2), 47-54. doi: 10.1007/s00787-004-2008-0.

World Health Organization. (2017). Depression and other common mental disorders: global health estimates. Recuperado de http://apps.who.int/iris/bitstream/10665/254610/ 1/WHO-MSD-MER-2017.2-eng.pdf.

Wright, M. O.; Masten, A. S. (2006). Resilience process in development: Fostering positive adaptation in the context of adversity. In: S. Goldstein, R. B. Brooks (Orgs.). Handbook of resilience in children (pp. 17-37). New York: Business Media.

Yunes, M. A. M. (2003). Psicologia Positiva e resiliência: o foco no indivíduo e na família. Psicologia em Estudo, 8(1), 75 - 84. Recuperado de http://www.scielo.br/pdf/\%0D/ pe/v8nspe/v8nesa10.pdf.

Yunes, M. A. M., \& Szymanski, H. (2001). Resiliência: noção, conceitos afins e considerações críticas. In J. Tavares (Org.), Resiliência e educação, 13-42. São Paulo: Cortez.

Yunes, M. A. M., Garcia, N. M., \& Albuquerque, B. D. M. (2007). Monoparentalidade, pobreza e resiliência: entre as crenças dos profissionais e as possibilidades da convivência familiar. Psicologia: Reflexão e Crítica, 20(3), 444-453. doi: 10.1590/S0102-79722007000300012. 
APÊNDICES 



\section{APÊNDICE A - Solicitação de autorização para coleta de dados}

Săo Joaquim da Barra, 23 de maio de 2014.

Prezados Senhora,

Apresentamos a solicitaçāo de autorizaçăo da Diretoria de Ensino da Regialo de São Joaquim da Barra para a realização do estudo: "Depressào materna e familias expostas a máltiplos estressores: comportamento de escolares", em escolas estaduais da cidade de Săo Joaquim da Barra. Trata-se de um projeto de Mestrado (Programa de Pós Graduaço em Psicologia, da Faculdade de Filosofia, Ciências e Letras de Ribeirâo Preto-USP-FFCLRP-USP), tendo como objetivo principal caracterizar e comparar os indicadores de depressäo matema e os eventos adversos do ambiente familiar de crianças em idade escolar com problemas comportamentais.

As atividades propostas no projeto nåo trazem riscos nem exposição das escolas, dos professores mâes e crianças, sendo tomados todos os cuidados necessários para garantir o sigilo das informaçひes e a năo interferência nas atividades rotineiras das escolas, $O$ referido projeto só será realizado após a aprovaçâo pelo Comitê de Ética em Pesquisa da FFCLRP-USP. Nos dispomos a oferecer orientaçōes e encaminhamentos às mâes participantes que tenham tal interesse.

A discente responsável em conduzir as pesquisa é Ana Karina Braguim Martineli, Psicóloga, e candidata ao mestrado junto ao Programa de Pós Graduação em Psicologia (FFCLRP-USP).

A orientadora do projeto ê a Prof.. Dr" - Sonia Regina Lourciro, Psicóloga, Professora doutora do Departamento de Neurociências e Ciências do Comportamento da Faculdade de Medicina de Ribeirăo Preto - Universidade de São Paulo (FMRP-USP).

Colocamo-nos à disposiç̧ơ para possiveis esclarecimentos.

Atenciosamente,

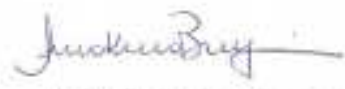

Ana Karina Braguim Martineli Psicóloga e-mail: karinabraguim@bol.com.br Telefone: (16) 999724383

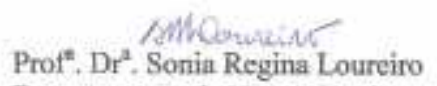

Departamento de Neurociencias e Ciências do Comportamento - FMRP-USP

E-mail: srilourci@fmrp.usp.br

Telefone: (16) 3602-4616
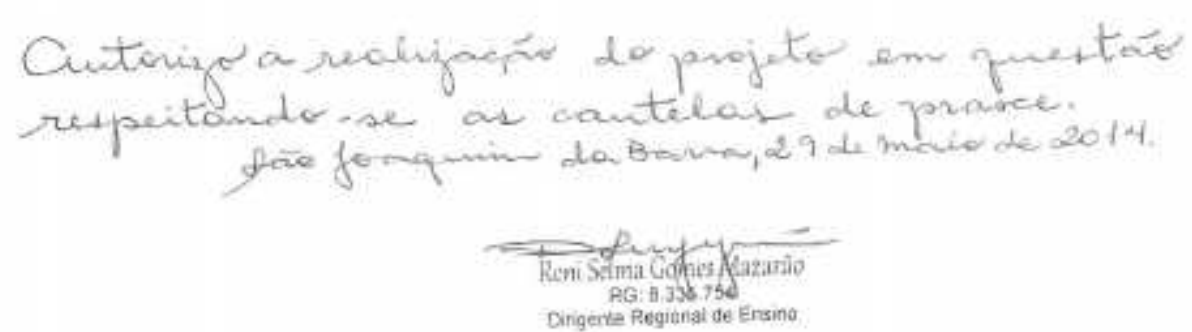


\title{
APÊNDICE B - Termo de Consentimento Livre e Esclarecido (Mães)
}

\author{
TERMO DE CONSENTIMENTO LIVRE E ESCLARECIDO
}

Nome da Pesquisa: Depressão materna e famílias expostas a múltiplos estressores: comportamento de escolares.

Pesquisador Responsável: Ana Karina Braguim Martineli - CRP: 06/56396-8

Orientadora: Prof. a Dr. ${ }^{\text {a }}$ Sonia Regina Loureiro - CRP: 06/0347

\section{ESCLARECIMENTO AO PARTICIPANTE DA PESQUISA}

Você está sendo convidada a participar da pesquisa, "Depressão materna e famílias expostas a múltiplos estressores: comportamento de escolares", que é parte do mestrado da psicóloga Ana Karina Braguim Martineli, sob a orientação da psicóloga Prof. a Dr. ${ }^{a}$ Sonia Regina Loureiro, junto ao Programa de Pós-Graduação em Psicologia, da Faculdade de Filosofia, Ciências e Letras de Ribeirão Preto - USP. A apresentação da pesquisa, a obtenção do consentimento e a coleta das informações, será realizada pela psicóloga Ana Karina Braguim Martineli.

O estudo para o qual você está sendo convidada a participar tem como interesse conhecer o modo como condições do ambiente familiar, dentre essas, a experiência de convivência com a depressão materna, podem influenciar o comportamento do seu(ua) filho(a). Para isso, pretendemos estudar famílias em que as mães já tiveram a experiência de depressão e famílias sem esta experiência, para tanto, você será avaliada quanto a esse aspecto. Esse conhecimento poderá ser útil para o planejamento de orientação a pais e para a prevenção de dificuldades das crianças.

A sua participação e a autorização para a participação de seu(ua) filho(a) serão muito importantes para conhecermos mais sobre como as situações familiares do dia a dia podem influenciar o comportamento da criança em casa e na escola.

Estamos consultando as mães com filhos com idade entre 7 a 10 anos, que estudam na Escola Estadual Adolfo Alfeu Ferrero, na cidade de São Joaquim da Barra- SP e que se disponham a participar deste estudo. A sua participação e a autorização para a participação de seu(ua) filho(a) são muito importantes para conhecermos mais sobre o tema proposto por este estudo. Sendo assim, pedimos a sua colaboração no sentido de participar e autorizar a participação de seu(ua) filho(a). Caso você autorize, convidarei o seu filho a também participar do estudo. Também pedirei ao(à) professor(a) dele(a) que responda um questionário sobre o comportamento de seu(ua) filho(a) em sala de aula. A participação do professor não terá nenhuma implicação na vida escolar de seu(ua) filho(a) ou de sua avaliação pela escola. Vou precisar de um encontro com você de cerca de 70 minutos e também um encontro com seu(ua) filho(a) de 15 a 20 minutos e com o professor(a) dele(a) de 10 minutos.

Com você, solicitaremos que responda um questionário sobre o comportamento de seu(ua) filho(a) e também três questionários sobre algumas características do seu ambiente familiar. Tais informações serão complementadas com um questionário sobre manifestações emocionais.

Com seu(ua) filho(a), vamos realizar uma atividade parecida com as que as crianças realizam na escola, para conhecer o jeito dele(a) raciocinar. E com o professor dele(a), pediremos que responda um questionário sobre o comportamento de seu(ua) filho(a).

A participação no estudo pode colocar os participantes em contato com comportamentos e sintomas, os quais não haviam pensado anteriormente, e isso pode despertar dúvidas e eventual ansiedade. Contudo, nos dispomos a esclarecer e orientar quanto a estes aspectos. Os resultados deste estudo podem contribuir para a prática e intervenções em saúde mental infantil.

Vocês não serão identificados, e tomaremos todos os cuidados para garantir o sigilo das informações. Os resultados individuais não serão divulgados, a não ser para vocês mesmos, se assim desejarem. Os resultados da pesquisa vão ser publicados, mas sem identificar as crianças, mães ou professores que participaram.

Não haverá qualquer tipo de despesas com as atividades ou material e vocês não receberão dinheiro para participar do estudo. As atividades serão realizadas na escola, ou em local da sua escolha. A qualquer momento você ou seu(ua) filho(a) poderão desistir da participação neste estudo, sem nenhum prejuízo.

Esta é uma atividade de pesquisa, não é um atendimento psicológico. Contudo, caso você tenha interesse, poderemos conversar sobre os seus dados, para isso entre em contato com a pesquisadora Ana Karina Braguim Martineli, pelo telefone abaixo indicado, e poderemos marcar um encontro para discutir as suas dúvidas ou se tiver necessidade faremos os encaminhamentos solicitados.

Colocamo-nos à disposição para maiores esclarecimentos. Grata,

Ribeirão Preto, novembro de 2014.

Ana Karina Braguim Martineli

Psicóloga

Telefone: 99972.4383

\author{
Prof. ${ }^{\text {a }}$ Dr. ${ }^{\text {a }}$ Sonia Regina Loureiro \\ Psicóloga e Orientadora \\ Telefone: 3315.2416
}

AUTORIZAÇÃO:

Tendo recebido informações sobre o projeto de pesquisa "Depressão materna e famílias expostas a múltiplos estressores: comportamento de escolares", eu $\mathrm{RG}$ , me disponho a participar da pesquisa.

São Joaquim da Barra, _______ 


\title{
APÊNDICE C - Termo de Consentimento Livre e Esclarecido (Crianças)
}

\author{
AUTORIZAÇÃO DE PAIS E MÃES PARA PARTICIPAÇÃo DE FILHO (A)
}

Nome da Pesquisa: Depressão materna e famílias expostas a múltiplos estressores: comportamento de escolares. Pesquisador Responsável: Ana Karina Braguim Martineli - CRP: 06/56396-8

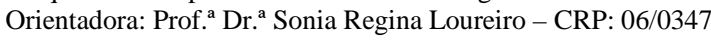

Seu(ua) filho(a) está sendo convidado(a) a participar da pesquisa intitulada "Depressão materna e famílias expostas a múltiplos estressores: comportamento de escolares", que é parte do mestrado da psicóloga Ana Karina Braguim Martineli, sob a orientação da psicóloga Prof. ${ }^{a}$ Dr. ${ }^{a}$ Sonia Regina Loureiro, junto ao Programa de Pós-Graduação em Psicologia, da Faculdade de Filosofia, Ciências e Letras de Ribeirão Preto - USP. A apresentação da pesquisa, a obtenção do consentimento e a coleta das informações será realizada pela psicóloga Ana Karina Braguim Martineli.

O estudo para o qual seu(ua) filho(a) está sendo convidado(a) a participar tem como interesse conhecer o modo como condições do ambiente familiar, dentre essas, a experiência de convivência com a depressão materna, podem influenciar o comportamento do seu(ua) filho(a). Para isso, pretendemos estudar famílias em que as mães já tiveram a experiência de depressão e famílias sem esta experiência. Esse conhecimento poderá ser útil para o planejamento de orientação a pais e para a prevenção de dificuldades das crianças. Os resultados deste estudo podem contribuir para a prática e intervenção em saúde mental infantil.

A autorização para a participação de seu(ua) filho(a) será muito importantes para conhecermos mais sobre como as situações familiares do dia a dia podem influenciar o comportamento da criança em casa e na escola.

Estamos consultando as mães com filhos com idade entre 7 a 10 anos, que estudam na Escola Estadual Adolfo Alfeu Ferrero, na cidade de São Joaquim da Barra- SP e que se disponham a participar deste estudo. A sua participação e a autorização para a participação de seu(ua) filho(a) são muito importantes para conhecermos mais sobre o tema proposto por este estudo. Sendo assim, pedimos a sua colaboração no sentido de participar e autorizar a participação de seu(ua) filho(a). Caso você autorize, convidarei o seu(ua) filho(a) a também participar do estudo. Também pedirei ao(à) professor(a) dele(a) que responda um questionário sobre o comportamento de seu (ua) filho(a) em sala de aula. A participação do professor não terá nenhuma implicação na vida escolar de seu (ua) filho(a) ou de sua avaliação pela escola. Vou precisar de um encontro com você de cerca de 70 minutos e também um encontro com seu(ua) filho(a) de 15 a 20 minutos e com o professor(a) dele(a) de 10 minutos.

Com seu(ua) filho(a), vamos realizar uma atividade parecida com as que as crianças realizam na escola, para conhecer o jeito dele(a) raciocinar. Seu(ua) filho(a) não será identificado, e tomaremos todos os cuidados para garantir o sigilo das informações. Os resultados individuais não serão divulgados, a não ser para vocês mesmos, se assim desejarem. Os resultados da pesquisa vão ser publicados, mas sem identificar as crianças, mães ou professores que participarem.

Não haverá qualquer tipo de despesas com as atividades ou material e vocês não receberão dinheiro para participar do estudo. As atividades com seu filho(a), serão realizadas na escola. A qualquer momento você ou seu(ua) filho(a) poderão desistir da participação neste estudo, sem nenhum prejuízo.

Esta é uma atividade de pesquisa, não é um atendimento psicológico. Contudo, caso você tenha interesse, poderemos conversar sobre os seus dados, para isso entre em contato com a pesquisadora Ana Karina Braguim Martineli, pelo telefone abaixo indicado, e poderemos marcar um encontro para discutir as suas dúvidas ou se tiver necessidade faremos os encaminhamentos solicitados.

Colocamo-nos à disposição para maiores esclarecimentos. Grata,

São Joaquim da Barra, novembro de 2014.
Ana Karina Braguim Martineli
Psicóloga
Prof. ${ }^{a}$ Dr. ${ }^{a}$ Sonia Regina Loureiro
Psicóloga e Orientadora
Telefone: 99972.4383
Telefone: 3315.2416

Tendo recebido informações sobre o projeto de pesquisa:

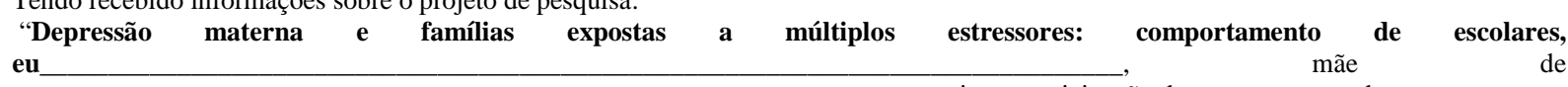

AUTORIZAÇÃO: , autorizo a participação do mesmo no estudo.

São Joaquim da Barra, ___ _ _ _ _

Assinatura do responsável 


\title{
APÊNDICE D - Termo de Consentimento Livre e Esclarecido (Professores)
}

\author{
Termo de Consentimento Livre e Esclarecido - Professores
}

Nome da Pesquisa: Depressão materna e famílias expostas a múltiplos estressores: comportamento de escolares.

Pesquisador Responsável: Ana Karina Braguim Martineli - CRP: 06/56396-8

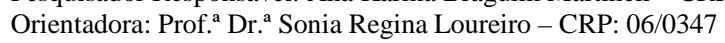

Você está sendo convidada(o) a participar da pesquisa, "Depressão materna e famílias expostas a múltiplos estressores: comportamento de escolares", que é parte do mestrado da psicóloga Ana Karina Braguim Martineli, sob a orientação da psicóloga Prof. ${ }^{a}$ Dr. ${ }^{a}$ Sonia Regina Loureiro, junto ao Programa de Pós-Graduação em Psicologia, da Faculdade de Filosofia, Ciências e Letras de Ribeirão Preto - USP. A apresentação da pesquisa, a obtenção do consentimento e a coleta das informações, será realizada pela psicóloga Ana Karina Braguim Martineli.

O estudo para o qual você está sendo convidada(o) a participar, tem como interesse conhecer o modo como condições do ambiente familiar, dentre essas, a experiência de convivência com a depressão materna, podem influenciar o comportamento das crianças. Para isso, pretendemos estudar famílias em que as mães já tiveram a experiência de depressão e famílias sem esta experiência. Esse conhecimento poderá ser útil para o planejamento de orientação a pais e para a prevenção de dificuldades das crianças.

Estamos consultando as mães com filhos entre 7 a 10 anos, e professores da Escola Estadual Adolfo Alfeu Ferrero, da cidade de São Joaquim da Barra- SP que se disponham a participar deste estudo.

O questionário que lhe será entregue é referente ao comportamento das crianças em sala de aula, mas só serão avaliadas aquelas crianças cujas mães já tenham consentido a sua participação. Vou precisar que você disponha de cerca de 10 minutos para responder a cada questionário. Cada professor responderá no máximo a 10 questionários, sobre 10 alunos, assim, no máximo, você disponibilizará uma hora e quarenta minutos de seu tempo para responder a todos os questionários.

Você não será identificado(a). Tomaremos todos os cuidados para garantir o sigilo das informações. Os resultados individuais não serão divulgados. Os resultados da pesquisa vão ser publicados, mas sem identificar as crianças, mães ou professores que participaram.

Não haverá qualquer tipo de despesas com as atividades ou material, e você não receberá dinheiro para participar do estudo. As atividades serão realizadas na própria escola em que você dá aula, em horários que não prejudiquem a rotina escolar, ou em local que você preferir. A qualquer momento você poderá desistir da participação neste estudo, sem nenhum prejuízo.

Esta é uma atividade de pesquisa, não é um atendimento psicológico. Mas, se for necessário e do seu interesse, estamos a disposição para maiores esclarecimentos. Caso tenha esse interesse, entre em contato com a pesquisadora Ana Karina Braguim Martineli, pelo telefone abaixo indicado, e poderemos marcar um encontro para discutir suas dúvidas.

Ribeirão Preto, novembro de 2014.

Ana Karina Braguim Martineli Psicóloga

Telefone: 99972. 4383
Prof. ${ }^{a}$ Dr. ${ }^{a}$ Sonia Regina Loureiro

Psicóloga e Orientadora

Telefone: 3315.2416

AUTORIZAÇÃO:

Tendo recebido informações sobre o projeto de pesquisa "Depressão materna e famílias expostas a múltiplos estressores: comportamento de escolares", $e \mathrm{u}$ RG me disponho a participar da pesquisa.

São Joaquim da Barra

Assinatura 


\section{APÊNDICE E - QUESTIONÁRIO GERAL (MÃES)}

1) Nome:

2) Estado civil:

3) Data de Nascimento/Idade:

4) Cor (família): o branco o negro o amarelo o mulato o outros

5) Chefe Família (quem contribui com a maior renda):

6) Grau de instrução:

Mãe:

Pai

7) Profissão/Ocupação:

Mãe:

Pai

8) Naturalidade (mãe/criança):

9) Endereço residencial:

Telefone(s):

Res: Cel: Recado: Trab:

10) Composição familiar

- Número de pessoas na casa:

- presença de pai ou padrasto: ( ) sim （）não

- número de filhos:

- idade e sexo dos filhos:

- Presença de: doenças crônicas deficiências adoção

11) Número de cômodos na casa

12) Renda aproximada da família:

Recebe bolsa ou auxílio governamental? ( ) sim （） não Qual?

13) Classificação econômica

o classe $\mathrm{A} 1$ (42 a 46 pontos)

o classe $\mathrm{A} 2$ (35 a 41 pontos)

o classe B1 (29 a 34 pontos)

o classe B2 (23 a 28 pontos)

o classe $\mathrm{C} 1$ (18 a 22 pontos)

o classe C2 (14 a 17 pontos)

o classe $\mathrm{D}$ (08 a 13 pontos) O classe E ( 0 a 07 pontos) 


\begin{tabular}{|c|c|c|c|c|c|}
\hline Posse de Itens & & & lade & & \\
\hline & & 1 & 2 & 3 & \\
\hline Quantidade de automóveis de passeio exc usivamente para uso partic & & & & & \\
\hline $\begin{array}{l}\text { Quantidade de empregados mensalistas, considerando apenas os que } \\
\text { trabalham pelo menos cinco dias por semana }\end{array}$ & & & & & \\
\hline Quantidade de máquinas de lavar roupa, excluindo tanquinho & & & & & \\
\hline Quantidade de banheiros & & & & & \\
\hline $\begin{array}{l}\text { DVD, incluindo qualquer dispositivo que leia DVD e desconsiderando } \\
\text { DVD de automóvel }\end{array}$ & & & & & \\
\hline Quantidade de geladeiras & & & & & \\
\hline Quantidade de freezers independentes ou parte da geladeira duplex & & & & & \\
\hline $\begin{array}{l}\text { Quantidade de microcomputadores, considerando computadores de mes } \\
\text { laptops, notebooks e netbooks e desconsiderando tablets, palms ou } \\
\text { smartphones }\end{array}$ & & & & & \\
\hline Quantidade de lavadora de louças & & & & & \\
\hline Quantidade de fornos de micro-ondas & & & & & \\
\hline $\begin{array}{l}\text { Quantidade de motocicletas, desconsiderando as usadas exclusivamente } \\
\text { para uso profissional }\end{array}$ & & & & & \\
\hline Quantidade de máquinas secadoras de roupas, considerando lava e seca & & & & & \\
\hline
\end{tabular}

\begin{tabular}{|l|l|}
\hline \multicolumn{2}{|c|}{ A água utilizada neste domicílio é proveniente de? } \\
\hline 1 Rede geral de distribuição & Pontuação \\
\hline 2 Poço ou nascente & \\
\hline 3 Outro meio & \\
\hline Grau de instrução do chefe de família & \\
\hline Analfabeto/ Fundamental I incompleto & \\
\hline Fundamental I completo / Fundamental II incompleto & \\
\hline Fundamental completo / Médio incompleto & \\
\hline Médio completo / Superior incompleto & \\
\hline Superior completo & \\
\hline
\end{tabular}

14) Você está fazendo algum tratamento psicológico/psiquiátrico e/ou neurológico?

( ) $\operatorname{sim}$ ( ) não

Qual?
15) Tem apresentado algum problema de saúde crônico?
( ) $\operatorname{sim}$
( ) não

Qual? 
16) Usa algum medicamento de uso contínuo? ( ) sim ( ) não

Qual?
17) Já usou algum tipo de drogas/álcool ao longo da vida?
( ) $\operatorname{sim}$
( ) não

Qual? Em que período?

18) Teve alguma doença e/ou trauma durante a gravidez? ( ) sim não

Qual?

19) Usou algum medicamento durante a gravidez? ( ) $\operatorname{sim} \quad$ ( ) não

Qual?

20) Na sua família, há casos atuais e/ou pessoas com histórico de depressão, que precisou de tratamento, internação ou uso de medicamento? (familiares $1^{\circ}$ grau)
( ) $\operatorname{sim}$
( ) não

Com relação à criança (nome):

Data de Nascimento: Idade:

21) Escolaridade atual:

Turno:

Escola:

22) Seu filho(a) já fez tratamentos psicológicos/psiquiátricos/neurológicos? $\quad$ ( ) sim $\quad$ ( ) não

Qual? Quando? Qual o motivo?

23) Seu (ua) filho (a) está em uso de algum medicamento de uso contínuo? ( ) sim $\quad$ ( ) não Qual? Quando?
24) Já usou em algum momento da vida?
( ) $\operatorname{sim}$
( ) não

Qual?

25) Como se saiu na escola nos últimos 12 meses? Como foi o se desempenho nos últimos meses?

26) Você observou alguma dificuldade no seu filho nos últimos 12 meses? ( ) sim

Em que áreas? Elas foram superadas? Como? Com a ajuda de quem? 
ANEXOS 



\title{
ANEXO A - Carta de Aprovação do Comitê de Ética em Pesquisa da FFCLRP-USP
}

\author{
Universidade de São Paulo \\ Faculdade de Filosofia, Ciências e Letras de Ribeiráo Preto \\ Comitê de Ética em Pesquisa
}

Campus de Ribeirso Preto

Of.CETP/FFCLRP-USP/109/-vjmc

Ribeirão Preto, 27 de novembro de 2014

Prezada Pesquisadora,

Comunicamos a V. Sa. que o projeto de pesquisa intitulado "DEPREssão materna e famillas expostas a múltiplos estressores: COMPORTAMENTO de Escolares" foi reanalisado pelo Comité de Ética em Pesquisa da FFCLRP-USP, em sua 138* Reuniảo Ordinária, realizada em 27.11.2014, e enquadrado na categoria: APROVADO (CAAE n. ${ }^{0} 36415514.5 .0000 .5407$ ).

Solicitamos que eventuais modificaçōes ou emendas ao projeto de pesquisa sejam apresentadas ao CEP, de forma sucinta, identificando a parte do projeto a ser modificada e suas justificativas, e que, ao tèrmino do estudo, um relatório final seja entregue, via Plataforma Brasil.

Atenciosamente,

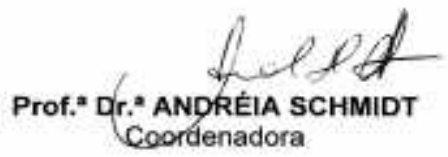

A Senhora

Ana Karina Braguim Martineli

Programa de Pós-graduação em Psicologia da FFCLRP-USP

c/c::

Profa. Dra. Sónia Regina Loureiro

Departamento de Psicologia da FFCLRP-USP

CEP - Comite de Etica em Pesquisa da IFCLRP USP

Fone $\langle 18\} 3602-4811$

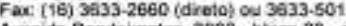

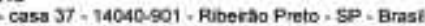

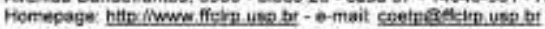




\section{ANEXO B - Questionário sobre a Saúde do Paciente-9}

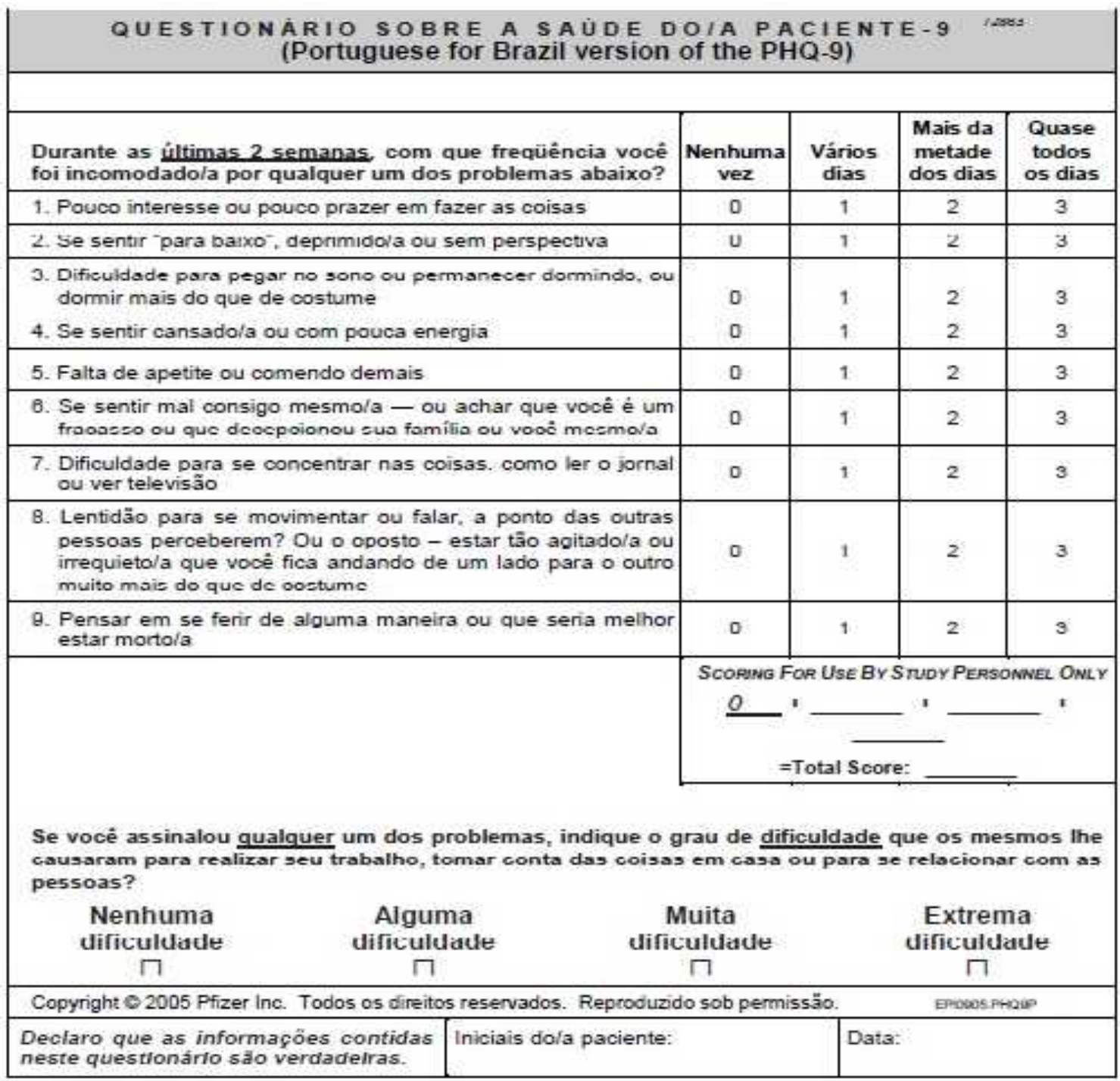




\section{ANEXO C - Inventário de Recursos do Ambiente Familiar}

\section{Inventário de Recursos do Ambiente Familiar (RAF)}

Aplica-se o roteiro sob forma de entrevista semi-estruturada, em que cada tópico é apresentado à mãe/informante oralmente, tendo o examinador liberdade para parafrasear o conteúdo da questão caso haja dificuldade de compreensão por parte da pessoa entrevistada. Em cada tópico, o entrevistador inicia fazendo a pergunta aberta que o introduz. Após registrar a resposta a essa pergunta, apresenta uma a uma, as demais alternativas de resposta.

\section{O QUE A CRIANÇA FAZ QUANDO NÃO ESTÁ NA ESCOLA?}

( ) Assiste à TV

( ) Ouve rádio

( ) Joga video-game

( ) Lê livros, revistas, gibis

( ) Brinca na rua

( ) Brinca dentro de casa

( ) Outro - especificar

2. QUAIS PASSEIOS QUE A CRIANÇA REALIZOU NOS ÚLTIMOS 12 MESES? Especificar quem acompanhou a criança - P (pai) / M (mãe) / Is (irmãos) / F (familiares) / E (educadores) / O (outro)

( ) Bosque Municipal

( ) Evento anual da cidade (feira, rodeio, ...)

( ) Cinema ou teatro

( ) Lanchonete

( ) Praia

( ) Viagem de trem

( ) Sítio, chácara ou fazenda

( ) Centro da cidade

( ) Museu

( ) Aeroporto

( ) Circo

( ) Shopping Center

( ) Parque de diversões

( ) Clube

( ) Visitas a parentes/ amigos da famílias

( ) Divertilândia

( ) Viagem para outra cidade

( ) Exposição (de pintura, de ciências, etc)

\section{HÁ ATIVIDADES PROGRAMAS QUE A CRIANÇA REALIZA REGURLAMENTE?}

( ) Faz catecismo, estudos bíblicos ou evangelização

( ) Frequenta núcleo municipal do bairro

( ) Pratica esporte em clubes, academias, ginásios

( ) Frequenta aulas para aprender atividade artesanato ( por exemplo, tapeçaria, pintura,...)

( ) Tem aulas de piano, violão ou outro instrumento musical

( ) Frequenta algum programa de atividades para crianças, como o Kurumim

( ) Tem aulas de inglês ou de outro idioma

( ) Faz computação

( ) Outro - especificar

4. Quais atividades que os pais desenvolvem com a criança em casa? Especificar quem acompanhou a criança $\mathrm{P}$ (pai) / M (mãe) / Is (irmãos) / F (familiares) / E (educadores) / O (outro)

( ) Brincar

( ) Jogar video-game ou outros jogos

( ) Assistir a filmes 
( ) Assistir a programas de infantis na TV

( ) Contar estórias e casos

( ) Ler livros, revistas

( ) Conversar sobre como foi o dia na escola

( ) Conversar sobre notícias, filmes e outros programas de TV

( ) Ouvir estórias da criança; conversar sobre assuntos que ela traz

( ) Realizar juntos atividades domésticas, como lavar o carro, fazer almoço ou outras

( ) Outras - especificar

\section{QUAIS OS BRINQUEDOS QUE ELE (ELA) TEM OU JÁ TEVE? SEU FILHO TEM OU JÁ TEVE:}

( ) Uma cama só para ele

( ) Brinquedos de andar (triciclo, bicicleta, patinete...)

( ) Brinquedos para movimentos do corpo (corda de pular, balanço,...)

( ) Instrumento musical de brinquedo ou de verdade (tambor, pianinho,...)

( ) Brinquedo que lida com números (dados, dominó,...)

( ) Brinquedos de letras (abecedários, quebra-cabeças com letras,...)

( ) Brinquedo de aprender cores, tamanhos, formas (quebra-cabeça, encaixes,...)

( ) Brinquedos para conhecer nomes de animais (livros, miniaturas,...)

( ) Objetos como giz, lousa, cola, tinta, tesoura, lápis de cor e papel

( ) Aparelho de som com discos

( ) Um animal de estimação

( ) Livrinhos de estórias infantis

( ) Jogos de regras (dama, loto, senha, memória,...)

( ) Brinquedos de faz de conta (panelinhas, bonecas, martelo, serrote,...)

( ) Brinquedos de construção (blocos, lego, pinos mágicos,...)

( ) Brinquedos de rodas (carrinhos, trens, carrinhos de boneca,...)

( ) Video-game

( ) Bola, pipa, bola de gude, carrinho de rolemã

( ) Outros - especifique

\section{HÁ JORNAIS E REVISTA NA SUA CASA?}

( ) Não

( ) Sim - tipo:

( ) Jornal

( ) Revista - ( ) de notícias ( ) de TV ( ) feminina ( ) de fotonovela （ ) de esporte ( ) religiosa ( ) outra-especifique

7. HÁ LIVROS NA SUA CASA?

( ) Não

( ) Sim - tipo:

( ) escolares

( ) romances, contos, literatura

( ) livrinhos infantis

( ) religiosos (bíblia, evangelhos, catecismo)

( ) enciclopédias

( ) dicionário

( ) outros - especifique

\section{ALGUÉM EM CASA ACOMPANHA A CRIANÇA NOS AFAZERES DA ESCOLA}

\begin{tabular}{|c|c|c|c|c|c|}
\hline Alguém em casa & ninguém & a mãe & o pai & Outra pessoa & (quem?) \\
\hline $\begin{array}{l}\text { Verifica se o material escolar } \\
\text { está em ordem }\end{array}$ & $($ ) & $($ ) & $($ ) & $(\quad)$ & \\
\hline $\begin{array}{l}\text { Avisa quando é hora de ir } \\
\text { para a escola }\end{array}$ & $($ ) & $($ ) & $($ ) & $(\quad)$ & \\
\hline $\begin{array}{l}\text { Supervisiona a } \\
\text { lição de casa }\end{array}$ & $($ ) & ( ) & ( ) & ( ) & \\
\hline
\end{tabular}


Supervisiona o estudo para

as provas

( )

( )

( )

( )

Comparece às

reuniões da escola

( )

( )

( )

( )

Acompanha as notas e

frequiência às aulas

( )

( )

( )

( )

Pontuação de cada item: mãe e pai $=3$; só a mãe $=2$; só o pai $=2$; outra pessoa $=1$; mãe, pai e outras pessoa $=1$; ninguém $=0$

9. SEU FILHO TEM HORA CERTA PARA:

\begin{tabular}{|c|c|c|c|}
\hline & Sempre & $\overline{\text { Às vezes }}$ & Nunca \\
\hline Almoçar & $(\quad)$ & () & $(\quad)$ \\
\hline Tomar banho & $($ ) & $($ ) & () \\
\hline Brincar & $($ ) & $($ ) & () \\
\hline Ir dormir & $($ ) & $(\quad)$ & () \\
\hline Levantar-se de manhã & $($ ) & $($ ) & $(\quad)$ \\
\hline Jantar & $($ ) & ( ) & () \\
\hline Fazer a lição de casa & $($ ) & $($ ) & () \\
\hline Assistir à TV & ( ) & ( ) & () \\
\hline
\end{tabular}

Pontuação: sempre $=2$; às vezes $=1$; nunca $=0$

10. SUA FAMÍLIA COSTUMA ESTAR REUNIDA:

\begin{tabular}{|c|c|c|c|}
\hline & Sempre & Às vezes & Nunca \\
\hline No café da manhã & $(\quad)$ & $(\quad)$ & $(\quad)$ \\
\hline No almoço & $($ ) & () & $(\quad)$ \\
\hline No jantar & $($ ) & $(\quad)$ & $(\quad)$ \\
\hline À noite, para assistir à TV & $($ ) & $(\quad)$ & $(\quad)$ \\
\hline
\end{tabular}

E nos fins de semana Em casa

Em casa

Em passeios

( )

( )

( )

( )

Pontuação: sempre $=2$; às vezes $=1$; nunca $=0$ 


\section{ANEXO D - Escala de Eventos Adversos \\ Escala de Eventos Adversos}

Nome:

Data:

1

Procedimento: $\mathrm{O}$ entrevistador diz à mãe que vai ler uma lista de situações que podem acontecer na vida das crianças, para que ela informe se alguma delas ocorreu com seu filho / sua filha. Em seguida, lê cada item do formulário e pede à mãe que diga se o evento ocorreu nos últimos 12 meses ou anteriormente na vida da criança. Preencher cada item com X na coluna apropriada. Se o evento ocorreu tanto nos últimos 12 meses como anteriormente, marcar $\mathrm{X}$ nas duas colunas.

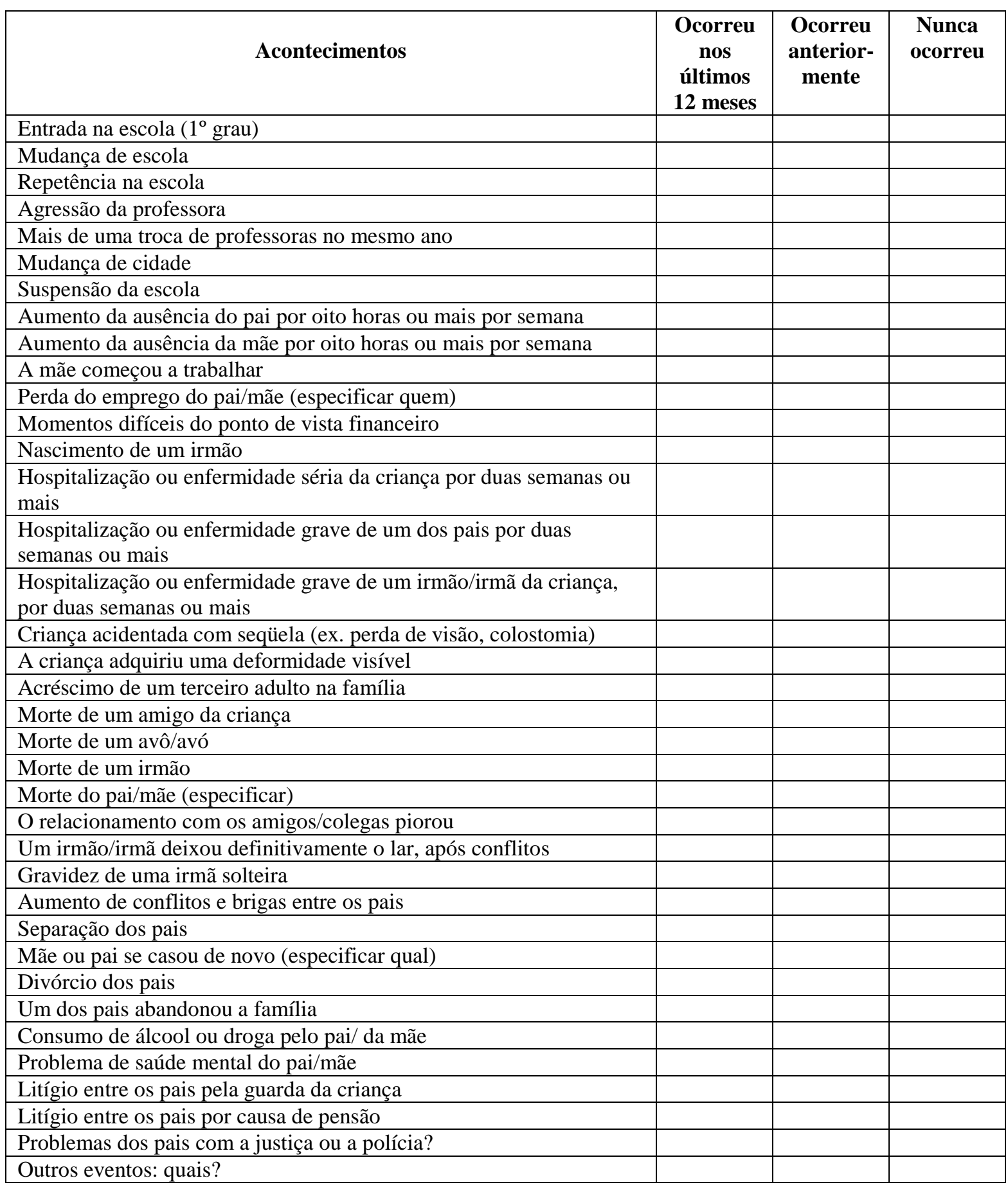




\section{ANEXO E - Escala de Adversidade Crônica \\ Escala de Adversidade Crônica}

Nome:

Data: I

CONDIÇÕES ADVERSAS PROLONGADAS OU RECORRENTES: DURAÇÃO DE UM ANO OU MAIS OU OCORRÊNCIA PREPETIDA DURANTE UM ANO OU MAIS.

\begin{tabular}{|l|l|l|}
\hline \multicolumn{1}{|c|}{ Condição } & Duração em anos & $\begin{array}{c}\text { Período da vida da } \\
\text { criança }\end{array}$ \\
\hline Doença crônica da criança: qual? & & \\
\hline Procedimento médico invasivo: qual? & & \\
\hline Uso de prótese: qual? & & \\
\hline Uso de óculos & & \\
\hline Criança com visão subnormal & & \\
\hline Criança com audição subnormal & & \\
\hline Sinal de nascença visível: qual? & & \\
\hline Hospitalização recorrente da criança & & \\
\hline Temperamento ("gênio") difícil do pai & & \\
\hline Temperamento ("gênio") difícil da mãe & & \\
\hline Conflitos familiares recorrentes ou crônicos & & \\
\hline Conflitos conjugais recorrentes ou crônicos & & \\
\hline Distúrbio mental crônico do pai ou substituto & & \\
\hline Distúrbio mental crônico da mãe ou substituta & & \\
\hline Dependência de droga pelo pai ou substituto & & \\
\hline Dependência de droga pela mãe ou substituta & & \\
\hline Alcoolismo severo do pai ou substituto & & \\
\hline Alcoolismo severo da mãe ou substituta & & \\
\hline Outra - especificar & & \\
\hline
\end{tabular}




\section{ANEXO F - Questionário de Capacidades e Dificuldades (versão mães) Questionário de Capacidades e Dificuldades (SDQ-Por) $\quad \mathbf{P a}^{4-10}$}

Instrucles: Por favor, em cada item marque com uma cruz o quadredo que melhor descreva a crianca. Responda a todas as perguntas da melhor maneira possivel, mesmo que voct nito tenha certeza absoluta ou so a pergunta the parocer estraniha. De suas respostas com base no comportamento da criança nos ûltimos seis meses.

Norne da Criança

Masculino/Feminiso

Data de Nascimento

Mais ou menos
verdadeiro Verdadeiro

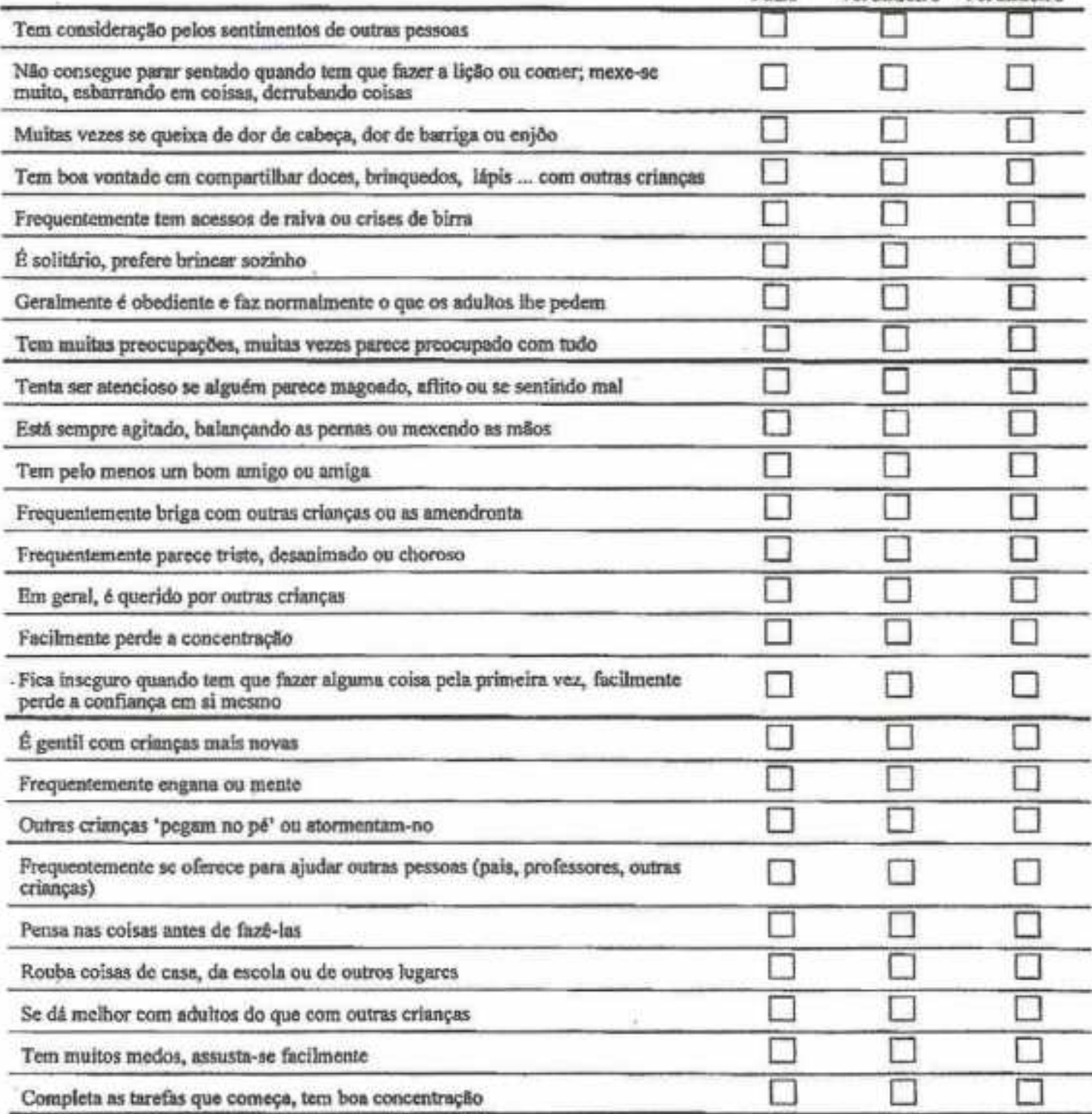

Voce tem algum outro comentírio on preocupaçēes? Descreva-os abaixo. 


\section{ANEXO G - Questionário de Capacidades e Dificuldades (versão professores)}

Professor (a):

Há quanto tempo é professor (a) deste aluno?

Rendimento Acadêmico do aluno: $\quad \mathrm{O}$

\section{Questionário de Capacidades e Dificuldades (SDQ-Por)}

Instruçôes: Por favor, em cada item marque com uma cruz a quadrado que melhor descreva a criança. Responda a todas as perguntas da melhor maneina possivel, mesmo que vocè nâo tenha eerteza absoluta ou se a pergunta the parecer estranha. Dé suas respostas com base no comportamento da criança nos últimos seis meses ou durante o ano escolar em curso.

Nome da Criança

Masculino/Feminino

Data de Nascimento

Mais ou menos

\begin{tabular}{|c|c|c|c|}
\hline \multirow{3}{*}{ Tem consideração pelos sentimentos de outras pessoas } & \multicolumn{3}{|c|}{ Mais ou menos } \\
\hline & \multirow[t]{2}{*}{ Falso } & verdadeiro & Verdadeir \\
\hline & & & \\
\hline \multicolumn{4}{|c|}{$\begin{array}{l}\text { Não consegue parar sentado quando tem que fazer a lição ou comer, mexe-se muito, } \\
\text { esburrando em coisas, derrubando coisas }\end{array}$} \\
\hline \multicolumn{4}{|c|}{ Muitas vezes se queixa de dor de cabeça, dor de barriga ou enjôo } \\
\hline \multicolumn{4}{|c|}{ Tem boa vontade em compartilhar doces, brinquedos, lápis ... com outras crianças } \\
\hline \multicolumn{4}{|l|}{ Frequentemente tem acessos de raiva ou crises de birra } \\
\hline \multicolumn{4}{|l|}{ É solitärio, prefere brincar sozinho } \\
\hline \multicolumn{4}{|c|}{ Geralmente é obediente e faz normalmente o que os adultos the pedem } \\
\hline \multicolumn{4}{|c|}{ Tem muitas preocupaçōes, muitas vezes parece preocupado com tudo } \\
\hline \multicolumn{4}{|c|}{ Tenta ser atencioso se alguém parece mugoado, aflito ou se sentindo mal } \\
\hline \multicolumn{4}{|c|}{ Está sempre agitado, balançando as pernas ou mexendo as mảos } \\
\hline \multicolumn{4}{|l|}{ Tem pelo menos um bom amigo ou amiga } \\
\hline \multicolumn{4}{|l|}{ Frequentemente briga com outras crianças ou as amendronta } \\
\hline \multicolumn{4}{|l|}{ Frequentemente parece triste, desanimado ou choroso } \\
\hline \multicolumn{4}{|l|}{ Em geral, é querido por outras crianças } \\
\hline \multicolumn{4}{|l|}{ Facilmente perde a concentração } \\
\hline \multicolumn{4}{|c|}{$\begin{array}{l}\text { Fica inseguro quando tem que fazer alguma coisa pela primeira vez, facilmente perde a } \\
\text { confianca } \mathrm{cm} \text { si mesmo }\end{array}$} \\
\hline \multicolumn{4}{|c|}{ É gentil com crianças mais novas } \\
\hline \multicolumn{4}{|l|}{ Frequentemente engana ou mente } \\
\hline \multicolumn{4}{|l|}{ Outras criancats 'pegam no pé ou atormentam-no } \\
\hline \multicolumn{4}{|c|}{ Frequentemente se oferece para ajudar outras pessoas (pais, professores, outras crianças) } \\
\hline \multicolumn{4}{|l|}{ Pensa nas coisas antes de fazê-las } \\
\hline \multicolumn{4}{|l|}{ Rouba coisas de casa, da escola ou de outros lugares } \\
\hline \multicolumn{4}{|l|}{ Se dá melhor com adultos do que com outras crianças } \\
\hline \multicolumn{4}{|l|}{ Tem muitos medos, assusta-se facilmente } \\
\hline Completa as tarefas que começa, tem boa concentração & & & \\
\hline
\end{tabular}

Vocế tem algum outro comentário ou preocupaçốes? Descreva-os abaixo. 
ANEXO H - Itens do Critério de Classificação Econômica Brasil desenvolvido pela Associação Brasileira de Empresas de Pesquisas - ABEP
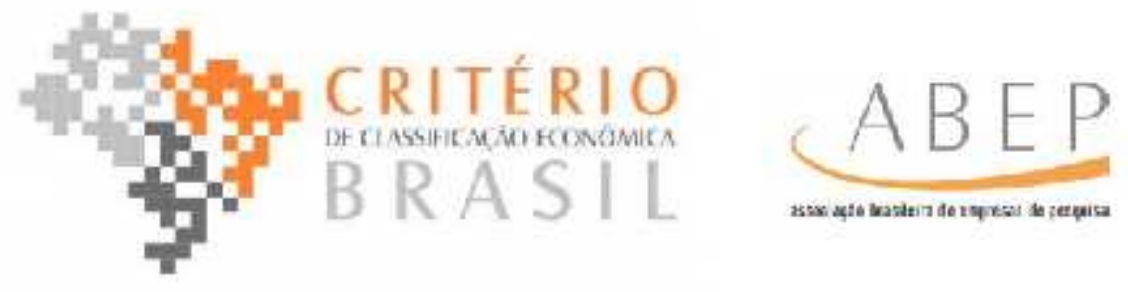

\section{SISTEMA DE PONTOS}

Variaivejs

\begin{tabular}{|c|c|c|c|c|c|}
\hline & \multicolumn{5}{|c|}{ Quantidade } \\
\hline & 0 & 1 & 2 & 3 & Aout \\
\hline Bustatios & 0 & 3 & 7 & 10 & 14 \\
\hline Emoregados domestizos & 0 & 3 & 7 & 10 & 13 \\
\hline Autemoves & 0 & 3 & 5 & 8 & 11 \\
\hline Microcomputador & 0 & 3 & 5 & 8 & 11 \\
\hline Lava louca & 0 & 3 & 6 & 6 & 6 \\
\hline Geladeira & 0 & 2 & 3 & 5 & 5 \\
\hline FI ㅂeᅳ<비 & 0 & 2 & 4 & E & 6 \\
\hline Lava roupa & 0 & 2 & 4 & 6 & 6 \\
\hline DVO & 0 & 1 & 3 & 4 & 6 \\
\hline Mirra-nndas & 0 & 2 & 4 & 4 & 4 \\
\hline Motucicletd & 0 & 1 & 3 & 3 & 3 \\
\hline Secadora roupa & 0 & 2 & 2 & 2 & 2 \\
\hline
\end{tabular}

\section{Grau de instrucäo de chefe de familiae acesso a servicos vúblicos}

\begin{tabular}{|c|c|}
\hline \multicolumn{2}{|l|}{ Escoluridade da pessua du referência } \\
\hline Analliabeto / Fundumentalt intornplete & 0. \\
\hline rundamental I completo / fundamentallI Incompleto & 1 \\
\hline Fur datmental If completo / Medio incompletu & 2 \\
\hline Medio completo / Superior incomplete & 4 \\
\hline Superine mmpletn & 7 \\
\hline \multicolumn{2}{|l|}{ Servicus publicos } \\
\hline NEOO & $\operatorname{sim}$ \\
\hline Asuэ encarada & 4 \\
\hline Ri:a pavimentada & 3 \\
\hline
\end{tabular}

\section{Cortes do Critério Brasil}

\begin{tabular}{|c|c|}
\hline Classe & Pentos \\
\hline A & $45 \quad 100$ \\
\hline 31 & $38-44$ \\
\hline 3) & 79.37 \\
\hline $\mathrm{Cl}$ & 23.78 \\
\hline $\mathrm{C} 2$ & $17 \cdot 22$ \\
\hline$D-F$ & 0.16 \\
\hline
\end{tabular}

